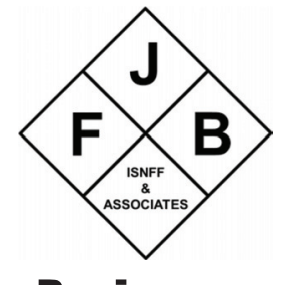

Journal of Food Bioactives

\title{
Spices and herbs as immune enhancers and anti-inflammatory agents: a review
}

\author{
Andrew Garnier and Fereidoon Shahidi*
}

\begin{abstract}
Department of Biochemistry, Memorial University, St. John's, NL, Canada A1B 3X9
*Corresponding author: Fereidoon Shahidi, Department of Biochemistry, Memorial University of Newfoundland, St. John's, NL, Canada A1B3X9. Tel: +1 (709) 864-8552; Fax: +1 (709) 864-2422; E-mail: fshahidi@mun.ca

DOI: $10.31665 / J F B .2021 .14266$

Received: June 18, 2021; Revised received \& accepted: June 30, 2021

Abbreviations: AIDS, acquired immunodeficiency syndrome; BSS, beta-sitosterol; BSSG, beta-sitosterol glucoside; COX, cyclooxygenase; CRP, C-reactive protein; HIV, human immunodeficiency virus; IFN, interferon; Ig, immunoglobulin; IL, interleukin; iNOS, inducible nitric oxide synthase; LPS, lipopolysaccharide; MAPK, mitogen-activated protein kinase; NF- $\mathrm{BB}$, nuclear factor kappa-B; NSAID, non-steroidal anti-inflammatory drugs; NO, nitric oxide; ROS, reactive oxygen species; TGF- $\beta$, transforming growth factor-beta; Th1, T helper type 1; Th17, T helper type 17; Th2, T helper type 2; TNF, tumor necrosis factor; Treg, Regulatory T; TRPV1, transient receptor potential vanilloid 1 Citation: Garnier, A., and Shahidi, F. (2021). Spices and herbs as immune enhancers and anti-inflammatory agents: a review. J. Food Bioact. 14: $20-52$.
\end{abstract}

\begin{abstract}
Spices and herbs have been used in traditional medicine for centuries, with research starting to accumulate on their beneficial properties. Of these properties, the immune-enhancing and anti-inflammatory capabilities of many spices and herbs have led to promising results. The current review article aims to explore the current research of several spices and herbs as immune-enhancers and anti-inflammatory agents. The spices and herbs examined are African potato (Hypoxis hemerocallidea), allspice (Pimenta dioica), basil (Ocimum basilicum), black pepper (Piper nigrum), chili powders (Capsicum species), clove (Syzygium aromaticum), Devil's claw (Harpagophytem procumbens), fenugreek (Trigonella foenum-graecum), ginger (Zingiber officinale), lavender (Lavandula angustifolia), oregano (Origanum vulgare), rooibos (Aspalathus linearis), rosemary/sage (Salvia rosmarinus/officinalis), saffron (Crocus sativus), South African geranium (Pelargonium sidoides), and turmeric (Curcuma longa). All the spices and herbs exhibited immune-enhancing or immunomodulatory and anti-inflammatory capabilities through various processes. Rooibos and oregano had the most contradictory results, with some studies finding pro-inflammatory properties, especially at high doses regarding oregano. Turmeric had the most extensive research with positive results.
\end{abstract}

Keywords: Anti-inflammatory; Immunity; Spice; Herb; Traditional medicine.

\section{Introduction}

Spices and herbs are hidden gems in the culinary world that may have a great impact outside of the kitchen, doing more than just pleasing tastebuds but also the body as a whole. Before we talk about spices and herbs, we must consider how we got here.

\subsection{History}

Spice and herb usage has a long history. Archaeological evidence dates their usage back to the Paleolithic period, about 60,000 years ago. For the following tens of thousands of years, humans continued to use herbs medicinally. Moving into ancient history, we gain further knowledge of herb usage with different cultures cultivating different spices and herbs. Written records indicate that the Sumerians in Mesopotamia wrote lists of hundreds of medicinal plants some 5,000 years ago (Sumner, 2000). Similarly, Ancient Egyptians, Indians, Chinese, Greeks, and Romans curated lists of medicinal plants. The choice of spice and herb was limited by location and availability as it was hard to obtain spices and herbs that were not native to the lands inhibited. Although spices were 
considered a luxury in some countries, people would travel far and wide to obtain them

Trading has been a part of civilization since prehistoric times, and there is no exception for spices. Spice trade had a surge with the introduction of the Silk Road beginning around 210 BC. The Silk Road connected Asia with Persia, the Arabian Peninsula, East Africa, and Southern Europe, making trade more feasible. Spice trade continued for the following centuries and continues until today but in a much different form. In the 17th century, spices began to lose much of their value as India and the Americas began to export ample spices due to colonization. Today, spices are seen less as a luxury due to their relatively newfound abundance and accessibility.

\subsection{Traditional functions in society}

Spices and herbs have long had a profound impact on many social factors, one of which being status. Before the 1600s in Europe, the scarcity of spices led to their possession being a status symbol. Once spices became more abundant due to colonization, they lost their privilege as a status symbol, and the roles reversed. The wealthy stopped spicing their foods as the middle class could now afford to.

There are claims that spices were used traditionally as a food preservative, but these claims are unsound for several reasons. First, spices are ineffective at preservation as compared to salting, smoking, pickling, or drying food (Freedman, 2008). Second, spices were typically expensive and, therefore, it would be impractical to use them as a food preservative. Finally, old cookbooks do not mention using spices as preservatives and suggest they could increase spoilage (Krondl, 2008). Although, it has been found that some spices have antimicrobial properties (Shelef, 1984). Nevertheless, these reasons refute the idea of the traditional use of spices as preservatives. However, the use of spices in hot climates may contradict this view as lack of refrigeration in earlier times led to their inclusion in food for shelf-life extension.

Aside from their cooking usage, spices and herbs also have a rich history with medicinal uses, known as traditional medicine. One of the earliest forms of traditional medicine, Ayurveda, came from India around 3,000 BC. Ayurveda revolves around balancing diet, herbal treatment, disease prevention, and health promotion. Some examples of spices and herbs used in Ayurveda are turmeric as a treatment for jaundice, basil to protect the heart, mace to treat stomach infections, cinnamon to promote blood circulation, and ginger for a wide variety of treatments (Tapsell et al., 2006). Another early form of traditional medicine comes from China in the mid to late 2,000 BC. Spices and herbs served a dual purpose for flavouring food and promoting health. Examples of traditional Chinese use of spices and herbs as medicine are ginseng for improving stamina and ginkgo biloba for cognitive performance (Tapsell et al., 2006). There are plenty of other examples of traditional medicinal use across cultures, such as ancient Egypt, ancient Greece, and Africa from 5,000 BC to the current day. The use of spices and herbs as medicine is becoming acknowledged in modern science.

\subsection{Biological relevance}

Spices and herbs differ based on the part of the plant they originate. A spice is a dried part of a plant, such as a seed, fruit, root, or bark, while an herb is a fresh part of a non-woody plant, such as the leaves, flowers, or stems.
For the plant, bioactive compounds present in spices can act as both an attractant and a deterrent to aid their proliferation. The desire for spices is not exclusive to humans. Bugs are commonly found in household spices, such as paprika and cayenne, and fish are attracted to allspice (Harada, 1990). Having organisms attracted to the plant can help in seed distribution to continue the plant's life cycle. Contrarily, spices also act to deter organisms through unpleasant flavors. An example of a deterring spice is capsaicin, found in chili peppers, which gives a burning sensation when eaten. The painful sensation from capsicum consumption is almost ubiquitously avoided by mammals, with the only known mammals seeking them out being humans and tree shrews (Han et al., 2018). While having fewer mammals aiding in seed distribution seems like an evolutionary mistake, there is a purpose. The reason is that mammals are worse seed distributors than birds, which unaffected by spices such as capsaicin (Norman et al., 1992). Having only birds consuming the spice, and consequently the seed, aids in the distribution and plant proliferation. Also, various spices have antimicrobial properties that slow microorganism growth and reduce toxin production (Sherman and Flaxman, 2001). Microorganism reduction can help the plant to survive and grow, as well as being beneficial to the consumer of the plant.

The bioactive properties of spices and herbs are frequently associated with their most abundant bioactive compound(s) (Table $1)$.

\subsection{Immune system and enhancers}

To talk about immune enhancers, we must first ask what the immune system is. The immune system is a network of cells, tissues, and organs that work together to stop bodily infections and diseases. There are two divisions of the immune system: innate immunity and adaptive immunity. Innate immunity includes aspects of the immune system that are indiscriminate in their foreign targets, such as physical barriers and macrophages. Adaptive immunity is parts of the immune system with specific targets, such as B and T lymphocytes. Together, the innate and adaptive immunities are complementary, interacting to neutralize potential threats.

Since the immune system has an instrumental role in health, being able to boost it could be useful in improving health. Some lifestyle factors for enhancing the immune system include avoiding smoking, getting sufficient sleep, minimizing stress, and practicing hygiene. Aside from lifestyle changes, some supplements and remedies boast the ability to enhance the immune system. While some supplements alter components related to immune system function, there is debate on if they are effective in protecting the consumer from infection and disease. Nevertheless, the immune system may benefit from supplement consumption that affects components of the immune system. Spices and herbs have grown in popularity as immune enhancers. A summary of immune-enhancing properties of select spices and herbs is seen in Table 2 .

\subsection{Inflammation}

Inflammation is a natural response in reaction to injury and disease caused by the immune system. There is a healthy level of inflammation necessary to combat and heal from injury or disease. Issues arise when inflammation runs rampant, causing the immune system to hurt the body more than it heals. Inflammation occurs in the event of an injury where the damaged cells produce signaling chemicals, including histamine, bradykinin, and prostaglandins, 
Table 1. Main bioactive compound of select spices and herbs

\begin{tabular}{|c|c|c|}
\hline Spice/herb & Main bioactive compound & Reference \\
\hline African potato (Hypoxis hemerocallidea) & Hypoxoside and rooperol & Zimudzi, 2014 \\
\hline Allspice (Pimenta dioica) & Eugenol & Zhang and Lokeshwar, 2012 \\
\hline Basil (Ocimum basilicum) & Linalool & Radulović et al., 2013 \\
\hline Black pepper (Piper nigrum) & Piperine & Lee et al., 2020 \\
\hline Chili powders (Capsicum species) & Capsaicin & Barceloux, 2009 \\
\hline Clove (Syzygium aromaticum) & Eugenol & Neveu et al., 2010 \\
\hline Devil's claw (Harpagophytem procumbens) & Harpagoside and harpagide & Williams, 2013 \\
\hline Fenugreek (Trigonella foenum-graecum) & Trigonelline and 4-hydroxyisoleucine & Singh et al., 2020 \\
\hline Ginger (Zingiber officinale) & Gingerols, shogaols, and paradols & Mao et al., 2019 \\
\hline Lavender (Lavandula angustifolia) & Linalyl acetate and linalool & Chen et al.,, 2020 \\
\hline Oregano (Origanum vulgare) & Thymol and carvacrol & Singletary, 2010 \\
\hline Rooibos (Aspalathus linearis) & Aspalathin & Hoosen, 2019 \\
\hline Rosemary/sage (Salvia rosmarinus/officinalis) & Carnosic acid, carnosol, and rosmarinic acid & Kontogianni et al., 2013; Ali et al., 2019 \\
\hline Saffron (Crocus sativus) & Crocin, picrocrocin, and safranal & Khorasany and Hosseinzadeh, 2016 \\
\hline South African geranium (Pelargonium sidoides) & Gallic acid & Kayser et al., 2001 \\
\hline Turmeric (Curcuma longa) & Curcumin & Sahne et al., 2017 \\
\hline
\end{tabular}

that serve three purposes. The first is vasodilation: where there are a few seconds of vasoconstriction followed by vasodilation, resulting in increased blood flow to the affected area. The increased blood flow causes the slowing and inactivation of red blood cells involved in blood clotting. Another is increased vascular permeability, which allows large proteins, such as serum albumins, to go through the blood vessels into the tissues. The last is that they attract immune cells, named neutrophils. These neutrophils loosely bind and then squeeze through endothelial gaps to migrate to the site of injury for phagocytosis, or destruction of, the damaged cell, effectively removing the threat. Macrophages then enter the tissue to dispose of the dead neutrophils and cellular debris (Aderem and Underhill, 1999).

The five classic signs of inflammation are redness, swelling, heat, pain, and loss of function. There are two kinds of inflammation, acute and chronic. Acute and chronic inflammation differ by severity and prolongation. Acute inflammation is typically shortterm in response to injury or illness and is usually more severe than chronic inflammation. Contrarily, chronic inflammation is a more prolonged and typically less severe form of inflammation that can occur without the stimulation of injury or illness and does not necessarily end once healed. Prolonged inflammation can lead to many health conditions, such as atherosclerosis, cancer, and heart disease (Libby et al., 2002, Coussens and Werb, 2002, Haught et al., 1996).

To combat these diseases, anti-inflammatory agents may prove useful. Anti-inflammatory agents inhibit the inflammatory response. Examples of anti-inflammatory drugs are non-steroidal anti-inflammatory drugs (NSAIDs). NSAIDs lessen the inflammatory response by blocking the production of prostaglandins by cyclooxygenase (COX) enzymes in the pathway (Weissmann, 1987). Similarly, aspirin is a drug that also blocks prostaglandin production. Corticosteroid drugs, on the other hand, suppress genes associated with inflammation (Barnes, 2006). While drugs effectively reduce inflammation, spices and herbs may be a natural alternative with similar effects. A summary of the anti-inflammatory activity of select spices and herbs is seen in Table 3 .

\subsection{Other considerations}

The effects of spices and herbs can be diverse. It is important to consider negative properties, such as cytotoxicity and drug interference, so that spices and herbs can be properly administered. Contrarily, spices and herbs may have utility aside from promoting health themselves, such as bioenhancing. Some additional properties of select spices and herbs are seen in Table 4.

\subsection{Scope of selection}

The spice and herbs selected in this review have either culinary popularity or have significance in traditional African medicine (i.e., African potato, rooibos, Devil's claw, and South African geranium).

\subsection{Goals}

Since the antioxidative properties of spices and herbs have already been established well, we aim to determine if spices and herbs also have a role as immune enhancers and as anti-inflammatory agents.

\section{African potato (Hypoxis hemerocallidea)}

\subsection{Introduction and source}

Hypoxis hemerocallidea is commonly known as African potato but has other names such as African star grass, star lily, magic muthi, and yellow stars. African potato is native to southern Africa, with its habitat ranging from South Africa to Mozambique and Zim- 
Table 2. Immune-enhance properties of select spices and herbs

\begin{tabular}{|c|c|c|c|}
\hline Spice/herb & Summary of research & Model & Reference \\
\hline $\begin{array}{l}\text { African potato } \\
\text { (Hypoxis } \\
\text { hemerocallidea) }\end{array}$ & $\begin{array}{l}\text { No distinction between immune- } \\
\text { enhancing capabilities and anti- } \\
\text { inflammatory properties }\end{array}$ & $N / A$ & $\mathrm{~N} / \mathrm{A}$ \\
\hline \multirow[t]{3}{*}{$\begin{array}{l}\text { Allspice (Pimenta } \\
\text { dioica) }\end{array}$} & $\begin{array}{l}\text { Increased serum albumin, globulin, } \\
\text { and myeloperoxidase levels }\end{array}$ & Mozambique tilapia & $\begin{array}{l}\text { Güllü et al., 2016; Yilmaz } \\
\text { and Ergün, } 2014\end{array}$ \\
\hline & Decreased mortality & & \\
\hline & Increased leukocutes and hemoglobin & Mouse & Nayak and Abhilash, 2008 \\
\hline \multirow[t]{3}{*}{$\begin{array}{l}\text { Basil (Ocimum } \\
\text { basilicum) }\end{array}$} & $\begin{array}{l}\text { Increased number of antibodies } \\
\text { created against a bird disease } \\
\text { and infectious bronchitis }\end{array}$ & Broiler chicken & $\begin{array}{l}\text { Jahejo et al., 2019; } \\
\text { Mohammed et al., } 2017\end{array}$ \\
\hline & Decreased IL-4 and IgE concentrations & Rat & Eftekhar et al., 2019; Kaur et al., \\
\hline & Stabilized mast cells & & 2018; El-Ashram et al., 2017 \\
\hline \multirow[t]{2}{*}{$\begin{array}{l}\text { Black pepper } \\
\text { (Piper nigrum) }\end{array}$} & $\begin{array}{l}\text { Black pepper oil (no piperine) } \\
\text { increased IgM and IgG levels }\end{array}$ & Rabbit & Abdelnour et al., 2018 \\
\hline & $\begin{array}{l}\text { Piperine inhibited IgM secretion and } \\
\text { antigen presentation B lymphocytes }\end{array}$ & Mouse & $\begin{array}{l}\text { Bernardo et al., 2015; } \\
\text { Soutar et al., } 2017\end{array}$ \\
\hline \multirow[t]{3}{*}{$\begin{array}{l}\text { Chili powders } \\
\text { (Capsicum species) }\end{array}$} & $\begin{array}{l}\text { Increased the immune response } \\
\text { and increased response to induced } \\
\text { delayed-type hypersensitivity }\end{array}$ & Mouse & Viveros-Paredes et al., 2021 \\
\hline & $\begin{array}{l}\text { Increased IFN- } \gamma \text { production and } \\
\text { release from lymphocytes }\end{array}$ & $\begin{array}{l}\text { Human cell } \\
\text { line MG-63 }\end{array}$ & Jin et al., 2016 \\
\hline & $\begin{array}{l}\text { Pre-treatment protective against } \\
\text { experimental autoimmune neuritis }\end{array}$ & Rat & Motte et al., 2018; Grüter et al., 2020 \\
\hline \multirow[t]{2}{*}{$\begin{array}{l}\text { Clove (Syzygium } \\
\text { aromaticum) }\end{array}$} & $\begin{array}{l}\text { Reduced immune cell counts in response } \\
\text { to immunostimulatory agents }\end{array}$ & Mouse & $\begin{array}{l}\text { Dibazar et al., 2014; Bereswill et } \\
\text { al., 2021; Chniguir et al., } 2019\end{array}$ \\
\hline & $\begin{array}{l}\text { Increased immune cells and Ig } \\
\text { with bacterial or no challenge }\end{array}$ & $\begin{array}{l}\text { Mouse and } \\
\text { broiler chicken }\end{array}$ & $\begin{array}{l}\text { Wael et al., 2018; Mahrous et al., } \\
\text { 2017; Al-Mufarrej et al., } 2019\end{array}$ \\
\hline \multirow{2}{*}{$\begin{array}{l}\text { Devil's claw } \\
\text { (Harpagophytem } \\
\text { procumbens) }\end{array}$} & $\begin{array}{l}\text { Immunostimulant with decrease } \\
\text { IL-21 and IL-23 secretion }\end{array}$ & Human cell line THP-1 & Cholet et al., 2019 \\
\hline & $\begin{array}{l}\text { Increased leukocyte transmigration protein } \\
\text { mRNA expression in inactivated cells }\end{array}$ & & Schopohl et al., 2016 \\
\hline \multirow{3}{*}{$\begin{array}{l}\text { Fenugreek (Trigonella } \\
\text { foenum-graecum) }\end{array}$} & Increased IgM levels & Fish & Moustafa et al., 2020; Yu et al., 2019 \\
\hline & $\begin{array}{l}\text { Improved lysozyme activity, increased } \\
\text { protease activity, and increased } \\
\text { complement component } 3 \text { levels }\end{array}$ & & $\begin{array}{l}\text { Moustafa et al., 2020; Yu et al., } \\
\text { 2019; Guardiola et al., } 2018\end{array}$ \\
\hline & No effect on antibody titer & $\begin{array}{l}\text { Hen and broiler } \\
\text { chicken }\end{array}$ & $\begin{array}{l}\text { Samani et al., 2020; } \\
\text { Laudadio et al., } 2020\end{array}$ \\
\hline \multirow[t]{3}{*}{$\begin{array}{l}\text { Ginger (Zingiber } \\
\text { officinale) }\end{array}$} & $\begin{array}{l}\text { Increased globulin, lysozyme, and Ig levels as } \\
\text { well as erythrocyte and leukocyte numbers }\end{array}$ & Fish & $\begin{array}{l}\text { Talpur et al., 2013; Mohammadi } \\
\text { et al., 2020; Kanani et al., 2014; } \\
\text { Sukumaran et al., } 2016\end{array}$ \\
\hline & $\begin{array}{l}\text { Increased bactericidal, phagocytic, and } \\
\text { lysozyme activities but nonsignificant } \\
\text { change in Ig and globulin }\end{array}$ & $\begin{array}{l}\text { Hen and broiler } \\
\text { chicken }\end{array}$ & $\begin{array}{l}\text { Qorbanpour et al., 2018; Elmowalid } \\
\text { et al., 2019; An et al., } 2019\end{array}$ \\
\hline & $\begin{array}{l}\text { Decreased T-bet gene, increased } \\
\text { erythrocytes, and IgM, and unaffected NF-кB }\end{array}$ & Clinical trial & $\begin{array}{l}\text { Aryaeian et al., 2019; Mahassni and } \\
\text { Bukhari, 2019; Honarvar et al., } 2019\end{array}$ \\
\hline
\end{tabular}

(continued) 
Table 2. (continued)

\begin{tabular}{|c|c|c|c|}
\hline Spice/herb & Summary of research & Model & Reference \\
\hline \multirow[t]{4}{*}{$\begin{array}{l}\text { Lavender (Lavandula } \\
\text { angustifolia) }\end{array}$} & $\begin{array}{l}\text { Activated both the innate and adaptive } \\
\text { response through the complement } \\
\text { system, whole blood phagocytes, } \\
\text { neutrophils, macrophages, and Peyer's } \\
\text { patches immunocompetent cells }\end{array}$ & $\begin{array}{l}\text { Human cell lines } \\
\text { and mouse }\end{array}$ & Georgiev et al., 2017a \\
\hline & $\begin{array}{l}\text { Stimulated phagocytes, cytotoxic } \\
\text { T-cells, and regulatory T-cells }\end{array}$ & & Georgiev et al., 2017b \\
\hline & Increased TGF- $\beta$ expression & Rat & Mori et al., 2016 \\
\hline & $\begin{array}{l}\text { Anticancer and antiproliferative activity } \\
\text { through increased cancer cell death }\end{array}$ & Human cell lines & Gezici, 2018 \\
\hline \multirow[t]{2}{*}{$\begin{array}{l}\text { Oregano (Origanum } \\
\text { vulgare) }\end{array}$} & $\begin{array}{l}\text { Increased lysozyme, protease, } \\
\text { and bactericidal activity }\end{array}$ & Fish & $\begin{array}{l}\text { Zhang et al., 2020; Beltrán et al., 2020; } \\
\text { Espirito Espirito Santo et al., 2018; } \\
\text { Mabrok and Wahdan, 2018; Shourbela } \\
\text { et al., 2021; Rashidian et al., } 2021\end{array}$ \\
\hline & Increased specific Ig & Broiler chicken & $\begin{array}{l}\text { Galal et al., 2016; } \\
\text { Franciosini et al., } 2016\end{array}$ \\
\hline $\begin{array}{l}\text { Rooibos (Aspalathus } \\
\text { linearis) }\end{array}$ & $\begin{array}{l}\text { May increase pro-inflammatory } \\
\text { cytokine IL- } 6 \text { to stimulate hepatocytes, } \\
\text { however no conclusion can be made }\end{array}$ & $\begin{array}{l}\text { Mouse cell line RAW } \\
264.7 \text { and human } \\
\text { white blood cells }\end{array}$ & $\begin{array}{l}\text { Hendricks and Pool, 2010; } \\
\text { Hoosen and Pool, } 2019\end{array}$ \\
\hline \multirow[t]{2}{*}{$\begin{array}{l}\text { Rosemary/sage (Salvia } \\
\text { rosmarinus/officinalis) }\end{array}$} & $\begin{array}{l}\text { Conflicting results on if rosemary/ } \\
\text { sage increases specific Ig }\end{array}$ & $\begin{array}{l}\text { Mouse and } \\
\text { broiler chicken }\end{array}$ & $\begin{array}{l}\text { Rasouli et al., 2020; Rostami et } \\
\text { al., 2018; Al Sheyab et al., } 2012\end{array}$ \\
\hline & Augmented innate immunity & Goat & $\begin{array}{l}\text { Shokrollahi et al., 2015; Naiel et } \\
\text { al., 2020; Yousef et al., } 2020\end{array}$ \\
\hline $\begin{array}{l}\text { Saffron (Crocus } \\
\text { sativus) }\end{array}$ & $\begin{array}{l}\text { Wide range of immunomodulatory } \\
\text { effects including inhibited leukocyte } \\
\text { infiltration, decreased serum IgM } \\
\text { concentration, decreased microglia, } \\
\text { and modulating Th1/Th2 balance }\end{array}$ & $\begin{array}{l}\text { Mouse and human } \\
\text { peripheral blood } \\
\text { mononuclear cells }\end{array}$ & $\begin{array}{l}\text { Feyzi et al., 2016; Fernández-Albarral } \\
\text { et al., 2019; Boskabady et al., } 2020\end{array}$ \\
\hline \multirow{4}{*}{$\begin{array}{l}\text { South African } \\
\text { geranium } \\
\text { (Pelargonium sidoides) }\end{array}$} & Activated macrophages & Mouse cell line L929 & Kayser et al., 2001 \\
\hline & Increased IgG and IFN- $\nu$ & Cow & Seckin et al., 2018 \\
\hline & $\begin{array}{l}\text { Protective against acute bronchitis, } \\
\text { as well as reducing symptom } \\
\text { severity and disease duration }\end{array}$ & $\begin{array}{l}\text { Mouse, rat, } \\
\text { and human }\end{array}$ & Bao et al., 2015; Kamin et al., 2010 \\
\hline & $\begin{array}{l}\text { Increased neutrophil, Th17, and Th22 } \\
\text { cells through the MAPK pathway }\end{array}$ & Human monocytes & Witte et al., 2015 \\
\hline $\begin{array}{l}\text { Turmeric (Curcuma } \\
\text { longa) }\end{array}$ & $\begin{array}{l}\text { Immunomodulatory properties } \\
\text { for a variety of diseases }\end{array}$ & Clinical trail & Abdollahi et al., 2018; Bose et al., 2015 \\
\hline
\end{tabular}

IFN, interferon; Ig, immunoglobulin; IL, interleukin; MAPK, mitogen-activated protein kinase; NF-kB, nuclear factor kappa-B; TGF- $\beta$, transforming growth factor-beta; Th1, T helper type 1; Th17, T helper type 17; Th2, T helper type 2

babwe. While known as African potato, the plant is not related to the staple food root vegetable and is part of the lily family. The corms, an underground storage organ of the plant, are used for the African potato's activities. Usage of the corms may lead to overharvesting. Crucially, the leaves are not a viable alternative as they lack phytochemicals and bioactive similarities, leading to the importance of corm preservation (Katerere and Eloff, 2008). Nevertheless, the African potato has been used in traditional African medicine for centuries to treat many ailments.

\subsection{Current uses}

Some of the medical conditions African potato is used to treat are urinary tract disorders, prostate problems, cancers, lung diseases, human immunodeficiency virus (HIV), and acquired immunodeficiency syndrome (AIDS). Of these, African potato is most used to treat HIV and AIDS, although there is little evidence supporting its effectiveness. The bioactive compounds in African potato affect cytochrome P450 activity, which is the same target as antiretroviral drugs, resulting in possible drug effectiveness interference (Mills et al., 2005).

\subsection{Bioactive compounds}

The bioactive compounds present in African potato are terpenoids, saponins, tannin, reducing sugars, phytoglycosides, and sterols 
Table 3. Anti-inflammatory activity of select spices and herbs

\begin{tabular}{|c|c|c|c|}
\hline Spice/herb & Summary of research & Model & Reference \\
\hline \multirow{3}{*}{$\begin{array}{l}\text { African potato (Hypoxis } \\
\text { hemerocallidea) }\end{array}$} & Improvement in allergic rhinitis & Human & Matyanga et al., 2020 \\
\hline & Inhibited IL-6 and TNF secretion & & \\
\hline & $\begin{array}{l}\text { Inhibited NO synthase } \\
\text { and NF-KB activity }\end{array}$ & $\begin{array}{l}\text { Human and mouse } \\
\text { cell line RAW } 264.7\end{array}$ & Zulfiqar et al., 2020 \\
\hline \multirow[t]{3}{*}{$\begin{array}{l}\text { Allspice (Pimenta } \\
\text { dioica) }\end{array}$} & $\begin{array}{l}\text { Inhibited COX-2 production } \\
\text { and the NF-KB pathway }\end{array}$ & $\begin{array}{l}\text { Mouse cell line RAW } \\
264.7 \text { and human } \\
\text { cell line HeLa }\end{array}$ & Zhang and Lokeshwar, 2012 \\
\hline & Inhibited blood vessel proliferation & Rat and mouse & Al-Rehaily et al., 2002 \\
\hline & $\begin{array}{l}\text { Antitumor activity against } \\
\text { breast cancer }\end{array}$ & Mouse & Zhang et al., 2015 \\
\hline \multirow[t]{4}{*}{$\begin{array}{l}\text { Basil (Ocimum } \\
\text { basilicum) }\end{array}$} & $\begin{array}{l}\text { Dose-dependent anti- } \\
\text { inflammatory IL-10 production }\end{array}$ & Human leukocytes & Güez et al., 2017 \\
\hline & $\begin{array}{l}\text { Decreased phospholipase } \mathrm{A} 2 \\
\text { and serum total protein levels }\end{array}$ & Rat & Eftekhar et al., 2019 \\
\hline & $\begin{array}{l}\text { Higher anti-inflammatory } \\
\text { activity than aspirin }\end{array}$ & $\begin{array}{l}\text { Egg albumen } \\
\text { denaturation }\end{array}$ & Osei Akoto et al., 2020 \\
\hline & Significantly reduced edema & Mouse & Rodrigues et al., 2016 \\
\hline \multirow[t]{3}{*}{$\begin{array}{l}\text { Black pepper } \\
\text { (Piper nigrum) }\end{array}$} & $\begin{array}{l}\text { Reduced pro-inflammatory } \\
\text { cytokines IL-1 } \beta \text {, TNF- } \alpha, \text { IL- } \\
6 \text {, and prostaglandin } E_{2}\end{array}$ & $\begin{array}{l}\text { Mouse, BV2 microglia } \\
\text { cells, mouse cell line } \\
\text { ATDC5, and rat }\end{array}$ & $\begin{array}{l}\text { Reynoso-Moreno et al., 2017; Wang-sheng et } \\
\text { al., 2017; Ren and Liang, 2018; Pei et al., 2020; } \\
\text { Mao et al., 2017; Viswanadha et al., } 2020\end{array}$ \\
\hline & $\begin{array}{l}\text { Inhibited macrophage } \\
\text { inflammation in pancreatic islets }\end{array}$ & Mouse & Yuan et al., 2021 \\
\hline & $\begin{array}{l}\text { Treated allergic inflammatory } \\
\text { through major T helper cell groups }\end{array}$ & Mouse & Bui et al., 2017; Bui et al., 2019 \\
\hline \multirow[t]{4}{*}{$\begin{array}{l}\text { Chili powders } \\
\text { (Capsicum species) }\end{array}$} & $\begin{array}{l}\text { High doses lowered the } \\
\text { pro-inflammatory cytokines } \\
\text { TNF } \alpha \text {, IFN- } \gamma \text {, IL-1 } \beta \text {, and IL-6 }\end{array}$ & $\begin{array}{l}\text { Rat, human colon } \\
\text { carcinoma cell } \\
\text { lines, and mouse }\end{array}$ & $\begin{array}{l}\text { Motte et al., 2018; Bessler and } \\
\text { Djaldetti, 2017; Xu et al., 2017; Kang } \\
\text { et al., 2017; Zhang et al., 2019 }\end{array}$ \\
\hline & $\begin{array}{l}\text { Contradicting effects on anti- } \\
\text { inflammatory cytokine IL-10 }\end{array}$ & $\begin{array}{l}\text { Human cell lines } \\
\text { and mouse }\end{array}$ & Bessler and Djaldetti, 2017; Kang et al., 2017 \\
\hline & $\begin{array}{l}\text { Increased anti-inflammatory } \\
\text { cytokine IL-4 }\end{array}$ & Rat & Motte et al., 2018 \\
\hline & $\begin{array}{l}\text { Unclear if TRPV1 is the pathway } \\
\text { used for anti-inflammatory } \\
\text { properties, p38MAPK and colonic } \\
\text { cannabinoid receptor type } 1 \\
\text { pathways were proposed }\end{array}$ & Rat and mouse & Xu et al., 2017; Kang et al., 2017 \\
\hline \multirow[t]{3}{*}{$\begin{array}{l}\text { Clove (Syzygium } \\
\text { aromaticum) }\end{array}$} & Reduced paw edema & Rat & $\begin{array}{l}\text { Marmouzi et al., 2019; Saeed et } \\
\text { al., 2017; Humbal et al., } 2019\end{array}$ \\
\hline & $\begin{array}{l}\text { Reduced pro-inflammatory } \\
\text { markers CRP, COX- } 2 \text {, IL- } \\
6 \text {, TNF- } \alpha \text {, TGF- } \beta \text {, and } \\
\text { epidermal growth factor }\end{array}$ & & Jose et al., 2017; Abdelrahman et al., 2018 \\
\hline & $\begin{array}{l}\text { Eugenol reduced ear edema and } \\
\text { proinflammatory cytokines }\end{array}$ & $\begin{array}{l}\text { Mouse, rat, } \\
\text { IPEC-J2 cell line }\end{array}$ & $\begin{array}{l}\text { Tsai et al., 2017; de Araújo Lopes } \\
\text { et al., 2018; Kumar et al., 2021; Ma } \\
\text { et al., 2018; Hui et al., } 2020\end{array}$ \\
\hline $\begin{array}{l}\text { Devil's claw } \\
\text { (Harpagophytem } \\
\text { procumbens) }\end{array}$ & Strong inhibition of COX-2 & $\begin{array}{l}\text { Human serum } \\
\text { and mouse cell } \\
\text { line RAW } 264.7\end{array}$ & $\begin{array}{l}\text { Gyurkovska et al., 2011; Rahimi et } \\
\text { al., 2016; Fiebich et al., } 2012\end{array}$ \\
\hline
\end{tabular}

(continued) 
Table 3. (continued)

\begin{tabular}{|c|c|c|c|}
\hline Spice/herb & Summary of research & Model & Reference \\
\hline & $\begin{array}{l}\text { Reduced pro-inflammatory } \\
\text { cytokines IL-1 } \beta \text {, IL- } 6 \text {, and TNF- } \alpha\end{array}$ & $\begin{array}{l}\text { Mouse cell line } \\
\text { RAW } 264.7\end{array}$ & Inaba et al., 2010 \\
\hline & Inhibited IL-6 production & $\begin{array}{l}\text { Human serum and } \\
\text { chondrocytes }\end{array}$ & Gyurkovska et al., 2011; Haseeb et al., 2017 \\
\hline \multirow[t]{3}{*}{$\begin{array}{l}\text { Fenugreek (Trigonella } \\
\text { foenum-graecum) }\end{array}$} & $\begin{array}{l}\text { Reduced pro-inflammatory } \\
\text { cytokines TNF- } \alpha, \text { IL-1 } 1 \beta \text {, and IL- } 6\end{array}$ & Mouse and rat & $\begin{array}{l}\text { Zhou et al., 2020Liu, 2019; Khound et al., } \\
\text { 2018; Piao et al., 2017; Sindhu et al., 2018; } \\
\text { Nagamma et al., 2021; Yu et al., } 2019\end{array}$ \\
\hline & Reduced paw edema & & $\begin{array}{l}\text { Cheurfa et al., 2021; Sindhu et al., 2018; } \\
\text { Pournamdari et al., 2018; El-Taib et al., } 2020\end{array}$ \\
\hline & $\begin{array}{l}\text { Increased anti-inflammatory } \\
\text { cytokines IL-10, IFN- } \gamma \text {, and TGF- } \beta\end{array}$ & Mouse & Liu, 2019; Piao et al., 2017 \\
\hline \multirow[t]{2}{*}{$\begin{array}{l}\text { Ginger (Zingiber } \\
\text { officinale) }\end{array}$} & $\begin{array}{l}\text { Decreased pro-inflammatory } \\
\text { cytokines TNF- } \alpha, \text { IL-1 } 1 \beta, \text { IL- } 6\end{array}$ & $\begin{array}{l}\text { Clinical trial, rat, } \\
\text { and mouse }\end{array}$ & $\begin{array}{l}\text { Al Hroob et al., 2018; Çifci et al., 2018; } \\
\text { Kim et al., 2018; Kim and Kim, 2018; } \\
\text { He et al., 2019; Mozaffari-Khosravi } \\
\text { et al., 2016; Askari et al., } 2020\end{array}$ \\
\hline & $\begin{array}{l}\text { Broad anti-inflammatory response } \\
\text { exhibited through reduced } \\
\text { monocyte chemoattractant } \\
\text { protein-1, CRP, NF-KB subunit } \\
\text { p65, COX-2, and iNOS }\end{array}$ & & $\begin{array}{l}\text { Kim et al., 2018; He et al., 2019; Askari et al., } \\
\text { 2020; Hsiang et al., 2015; Hamza et al., } 2021\end{array}$ \\
\hline \multirow[t]{4}{*}{$\begin{array}{l}\text { Lavender (Lavandula } \\
\text { angustifolia) }\end{array}$} & $\begin{array}{l}\text { Decreased the expression of } \\
\text { pro-inflammatory cytokines } \\
\text { TNF- } \alpha \text { and IL-1 } \beta\end{array}$ & $\begin{array}{l}\text { Common carp, } \\
\text { rat, and mouse }\end{array}$ & $\begin{array}{l}\text { Yousefi et al., 2020; Aboutaleb et al., 2019; } \\
\text { Souri et al., 2019; Chen et al., } 2020\end{array}$ \\
\hline & $\begin{array}{l}\text { Significantly increased the } \\
\text { expression of the anti- } \\
\text { inflammatory cytokine IL-10 }\end{array}$ & & \\
\hline & $\begin{array}{l}\text { Reduced the pro-inflammatory } \\
\text { expression of NF-KB and COX-2 }\end{array}$ & Mouse & Chen et al., 2020; Cardia et al., 2018 \\
\hline & $\begin{array}{l}\text { Increased anti-inflammatory } \\
\text { cytokine TGF- } \beta\end{array}$ & Common carp & Yousefi et al., 2020 \\
\hline $\begin{array}{l}\text { Oregano (Origanum } \\
\text { vulgare) }\end{array}$ & $\begin{array}{l}\text { High doses have pro-inflammatory } \\
\text { properties while lower doses have } \\
\text { anti-inflammatory properties }\end{array}$ & Pig and rat & $\begin{array}{l}\text { Cappelli et al., 2021; Rivera-Gomis et } \\
\text { al., 2020; Sharifi-Rigi et al., } 2019\end{array}$ \\
\hline $\begin{array}{l}\text { Rooibos (Aspalathus } \\
\text { linearis) }\end{array}$ & $\begin{array}{l}\text { Mixed results on whether } \\
\text { rooibos is anti-inflammatory } \\
\text { or pro-inflammatory }\end{array}$ & N/A & N/A \\
\hline \multirow[t]{2}{*}{$\begin{array}{l}\text { Rosemary/sage (Salvia } \\
\text { rosmarinus/officinalis) }\end{array}$} & $\begin{array}{l}\text { Decreased pro-inflammatory } \\
\text { cytokine production }\end{array}$ & Mouse & Yousef et al., 2020; Farahpour et al., 2020 \\
\hline & Limited recent research (<5 years) & N/A & N/A \\
\hline Saffron (Crocus sativus) & $\begin{array}{l}\text { Clinical trials often show no } \\
\text { anti-inflammatory effects }\end{array}$ & N/A & N/A \\
\hline \multirow[t]{2}{*}{$\begin{array}{l}\text { South African geranium } \\
\text { (Pelargonium sidoides) }\end{array}$} & $\begin{array}{l}\text { Decreased pro-inflammatory } \\
\text { molecules from fibroblasts, } \\
\text { leukocytes, and macrophages }\end{array}$ & Human cell lines & Jekabsone et al., 2019 \\
\hline & Modulated chemokines & Human & Perić et al., 2020 \\
\hline $\begin{array}{l}\text { Turmeric (Curcuma } \\
\text { longa) }\end{array}$ & $\begin{array}{l}\text { Extensive anti-inflammatory or } \\
\text { neutral properties supported } \\
\text { by many clinical trials }\end{array}$ & Clinical trail & N/A \\
\hline
\end{tabular}

COX, cyclooxygenase; CRP, C-reactive protein; IFN, interferon; IL, interleukin; iNOS, inducible nitric oxide synthase; NF-KB, nuclear factor kappa-B; NO, nitric oxide; TGF- $\beta$, transforming growth factor-beta; TNF, tumor necrosis factor; TRPV1, transient receptor potential vanilloid 1 
Table 4. Other important considerations for the listed spices and herbs

\begin{tabular}{|c|c|c|}
\hline Spice/herb & Property & Reference \\
\hline African potato (Hypoxis hemerocallidea) & Possible HIV/AIDS drug interference & Mills et al., 2005 \\
\hline Allspice (Pimenta dioica) & N/A & $\mathrm{N} / \mathrm{A}$ \\
\hline Basil (Ocimum basilicum) & $\begin{array}{l}\text { Dose-dependent cytotoxic effects } \\
\text { against Hep-2 and HeLa cell lines }\end{array}$ & Kathirvel and Ravi, 2012 \\
\hline Black pepper (Piper nigrum) & $\begin{array}{l}\text { Application as a bioenhancer, increasing the } \\
\text { bioavailability of other therapeutic agents }\end{array}$ & Tiwari et al., 2020 \\
\hline Chili powders (Capsicum species) & $\begin{array}{l}\text { Low doses of capsaicin may be responsible } \\
\text { for cancer-promoting effects, whereas high } \\
\text { doses are observed with cancer-inhibition }\end{array}$ & $\begin{array}{l}\text { Lin et al., 2018; Chen et al., 2021; } \\
\text { Xu et al., 2017; Guo et al., } 2019\end{array}$ \\
\hline Clove (Syzygium aromaticum) & N/A & N/A \\
\hline Devil's claw (Harpagophytem procumbens) & $\begin{array}{l}\text { Harpagide observed to have a toxic } \\
\text { effect at a concentration of } 1 \mathrm{mg} / \mathrm{mL}\end{array}$ & Gyurkovska et al., 2011 \\
\hline Fenugreek (Trigonella foenum-graecum) & $\mathrm{N} / \mathrm{A}$ & $\mathrm{N} / \mathrm{A}$ \\
\hline Ginger (Zingiber officinale) & Safe and effective for treating nausea & Nikkhah Bodagh et al., 2018 \\
\hline Lavender (Lavandula angustifolia) & $\begin{array}{l}\text { Some irritative properties at } 10 \% \text { in topical } \\
\text { treatments and cytotoxic at } 30 \text { and } 90 \mathrm{ug} / \mathrm{mL}\end{array}$ & Rai et al., 2020; Cardia et al., 2018 \\
\hline Oregano (Origanum vulgare) & Pro-inflammatory at high doses & $\begin{array}{l}\text { Rivera-Gomis et al., 2020; } \\
\text { Sharifi-Rigi et al., } 2019\end{array}$ \\
\hline Rooibos (Aspalathus linearis) & $\begin{array}{l}\text { Contradictory results on immunomodulation } \\
\text { abilities and inflammatory properties }\end{array}$ & N/A \\
\hline $\begin{array}{l}\text { Rosemary/sage (Salvia } \\
\text { rosmarinus/officinalis) }\end{array}$ & $\mathrm{N} / \mathrm{A}$ & N/A \\
\hline Saffron (Crocus sativus) & Cytotoxic at very high doses & Mehri et al., 2020 \\
\hline $\begin{array}{l}\text { South African geranium } \\
\text { (Pelargonium sidoides) }\end{array}$ & Risk of bias in some studies & N/A \\
\hline Turmeric (Curcuma longa) & Low bioavailability of curcumin & Kunnumakkara et al., 2019 \\
\hline
\end{tabular}

(Zimudzi, 2014). One of the bioactive compounds attributed to African potato's medicinal activity is hypoxoside, a glycoside product. Hypoxoside is a prodrug that is oxidized by $\beta$-glucosidase to form rooperol, an aglycone. The enzyme $\beta$-glucosidase is found in the gastrointestinal tract, released by cancer cells in tumor tissues, and released by the activation of macrophages in inflammatory sites (Albrecht, 1996). The phytosterols within African potato include $\beta$-sitosterol (BSS), $\beta$-sitosterol glucoside (BSSG), campesterol, and stigmasterol, with BSS and BSSG being most studied (Bouic, 2001).

\subsection{Immune-enhancing properties}

The immune-enhancing capability of African potato is attributed to its anti-inflammatory activity, in which there is little distinction in the literature. Ling and Jones (1995) reported an improvement in allergic rhinitis and sinusitis after 12 weeks of BSS/BSSG administration, believed to be a result of cytokine profile changes. The cytokine changes caused by BSS and BSSG are inhibition of interleukin (IL)-6 and tumor necrosis factor (TNF) secretion, leading to anti-inflammatory effects (Matyanga et al., 2020). BSS and BSSG have also been used in HIV treatment resulting in a favourable $\mathrm{T}$ helper type 1 (Th1) cell response (Bouic, 2001). Phytosterols as a class of molecules have been shown to have immune-modulating properties in vitro (Saeidnia et al., 2014).

\subsection{Anti-inflammatory properties}

Rooperol, one of the main bioactive compounds in African potato, has been shown to have potent anti-inflammatory abilities through reactive oxygen species (ROS) and nitric oxide (NO) production (Boukes and van de Venter, 2012). Contrarily, three hypoxhemerolosides and one obtuside from African potato were shown to inhibit nitric oxide production in lipopolysaccharide (LPS)-stimulated macrophages (Zulfiqar et al., 2020). Nevertheless, these same glucosides in the ethyl acetate extract inhibited nitric oxide synthase and nuclear factor kappa-B (NF-kB) activity (Zulfiqar et al., 2020). The exact mechanisms behind the medicinal effects of African potato compounds remain unknown.

\subsection{Recent advancements}

Gold nanoparticles are used as a catalyst for biological reactions and have gained much attention as a means as an anticancer and antibacterial material. The effects of gold nanoparticles have been combined with African potato extract and hypoxoside to enhance the protective effects. The four gold nanoparticle treatments syn- 
thesized showed the ability to lower macrophage pro-inflammatory cytokine levels with the one synthesized with hypoxoside reducing cytokines in natural killer cells (Elbagory et al., 2019). These results highlight the potential of African potato and its bioactive compounds in advancing emerging technologies.

\section{Allspice (Pimenta dioica)}

\subsection{Introduction and source}

Allspice, also known as Jamaica pepper, myrtle pepper, pimenta, and pimento, is the dried unripe berry of Pimenta diocia. Pimenta diocia is a mid-canopy tree native to the Greater Antilles, southern Mexico, and Central America. Allspice was introduced to Europe in the 16th century after Christopher Columbus discovered allspice while searching for other common spices. The name allspice comes from the spice having the combined aromatic flavours of cloves, pepper, cinnamon, and nutmeg. Today, allspice is cultivated in many warm climates.

\subsection{Current uses}

Allspice is used in a variety of dishes across many cultures. In Caribbean cuisine, allspice is an important ingredient in the popular jerk seasoning. In the Middle East, allspice is used to flavour stews, meat dishes, and tomato sauces. In northern Europe and North America, allspice is an ingredient in curry powders.

\subsection{Bioactive compounds}

Allspice extract has been shown to have many flavonoids, alkaloids, tannins, triterpenoids, and phytosterols (Nayak and Abhilash, 2008). Additionally, allspice is particularly high in polyphenols. Eugenol is the main bioactive compound, with other potent compounds being quercetin, gallic acid, and ericifolin (Zhang and Lokeshwar, 2012). Clove (Syzygium aromaticum) shares eugenol as the main bioactive compound and thus they may share physiological properties as pertains to eugenol (see clove).

\subsection{Immune-enhancing properties}

To assess the immunological capabilities of allspice, Güllü et al. (2016) have looked at blood parameters in Mozambique tilapia (Oreochromis mossambicus) after oral administration. They found that serum albumin and globulin levels were increased in groups supplemented with $15 \mathrm{~g}$ of allspice per $\mathrm{kg}$ of fish feed, compared to the group with no supplementation and the $5 \mathrm{~g} \mathrm{~kg}^{-1}$ group (Güllü et al., 2016). Increases in the serum albumin and globulin in fish are thought to be related to a better innate immune response (Wiegertjes et al., 1996). Additionally, the activity of lysozyme (an enzyme that is a factor in immune defence) was found to increase in the allspice supplemented groups compared to the control group (Güllü et al., 2016). Another enzyme, myeloperoxidase, was increased in the supplemented groups compared to the control (Güllü et al., 2016). Myeloperoxidase is important for enhancing neutrophils and macrophages in fish (Güllü et al., 2016). Nayak and Abhilash (2008) have looked at the effects of giving mice allspice orally. They found increased leukocytes and hemoglobin which may be attributed to the allspice leaves. Fur- thermore, Yilmaz and Ergün (2014) have found decreased mortality in Mozambique tilapia after allspice supplementation in which immune system augmentation by allspice may be an important factor. These findings support the idea that allspice may prove an effective immune enhancer, although more research needs to be done, particularly in preclinical and clinical trials, as most benefits are in fish models.

\subsection{Anti-inflammatory properties}

Eugenol, the major bioactive compound in allspice, is known for its anti-inflammatory activity (Kim et al., 2003). Eugenol has an inhibitory effect on COX-2 production and the NF- $\mathrm{KB}$ pathway in LPS-induced activated macrophages, both of which are characteristic of inflammation (Zhang and Lokeshwar, 2012). Quercetin, another bioactive compound in allspice, is also anti-inflammatory with inhibition of the NF-kB pathway, of inflammatory cytokine expression, and by influencing inflammatory gene expression (Zhang and Lokeshwar, 2012). Allspice has also been shown to reduce inflammation in rats by inhibiting blood vessel proliferation, characteristic of inflammation (Al-Rehaily et al., 2002). Furthermore, allspice has been shown to have antitumor activity against breast cancer, with a major cause of cancer being inflammation through inhibiting mechanistic target of rapamycin (Zhang et al., 2015). Nevertheless, the main bioactive compound of allspice is eugenol which likely inhibits inflammation through COX-2 inhibition, similar to some NSAIDs.

\section{Basil (Ocimum basilicum)}

\subsection{Introduction and source}

Ocimum basilicum, commonly known as basil or sweet basil, is an herb of the mint family Lamiaceae. It is native to tropical regions ranging from central Africa to Southeast Asia and is now cultivated worldwide (Simon, 1998). Today, basil is considered one of the most popular herbs in the world and is sometimes referred to as the "King of Herbs". The name basil is shared with other varieties in the Ocimum genus as well as hybrids, including Thai basil $(O$. basilicum var. thysiflora), lemon basil (O. citriodorum), and holy basil (O. tenuiflorum). However, here basil will refer exclusively to $O$. basilicum.

\subsection{Current uses}

The main use of basil is as a fresh ingredient, adding a sweet flavour to meals. Typically, basil is added at the end of recipes as cooking can destroy flavour. In addition, drying the herb can result in loss of flavour. Basil is a main ingredient in the Italian sauce pesto, added to salads and soups, and used as a garnish for many other dishes. Apart from cuisine, basil is used in the creation of some perfumes and it has a history as a therapeutic in Ayurveda (traditional Indian medicine) and traditional Chinese medicine.

\subsection{Bioactive compounds}

There are many compounds in basil which include linalool, estragole, methyl eugenol 1,8-cineole, camphor, limonene, thymol, citral, $\alpha$-linalool, $\beta$-linalool, chichoric acid, myrecene, borneol, 
neral, and anthocyanins (Purushothaman et al., 2018). The major bioactive compounds of these are linalool, methyl eugenol, and 1,8-cineol (Radulović et al., 2013). The anthocyanins are responsible for the purple flower pigment, with 11 being cyanidin-based and 3 being peonidin-based (Phippen and Simon, 1998)

\subsection{Immune-enhancing properties}

The immune-enhancing effects of basil have been examined in various animal models. Jahejo et al. (2019) assessed the immunomodulatory effects of basil supplementation in broiler chickens. They found that basil seed supplementation at $5 \mathrm{~g} / \mathrm{kg}$ of feed resulted in an increased number of antibodies created against a highly contagious bird disease (Newcastle disease) 12 days after vaccination of the chickens, as compared to a group without supplementation (Jahejo et al., 2019). Additionally, they noted a lower rate of mortality in the basil-fed group which may be caused by increased immunity. These results are in agreement with a similar study by Mohammed et al. (2017) which fed broiler chickens basil seeds at 3 and $6 \mathrm{~g} / \mathrm{kg}$ of feed. In this study, it was found that after 42 days the two supplemented groups had an increased number of antibodies against Newcastle disease and infectious bronchitis (Mohammed et al., 2017).

In an in vivo rat model studying asthma, Eftekhar et al. (2019) found that treatment with basil extract at $0.75,1.50$, and $3.00 \mathrm{mg} /$ $\mathrm{mL}$ in drinking water resulted in decreased IL-4 and immunoglobulin (Ig) type E concentrations as compared to no treatment. IL-4 is produced by Th2 cells which stimulates IgE production, both of which contribute to asthma, with higher levels consistent with disease progression (Murdoch and Lloyd, 2010; Sandeep et al., 2010). Additionally, with an in vitro rat model it has been found that basil can stabilize mast cells, a cell type vital for immune surveillance, in a dose-dependent manner (Kaur, Singh, and Shri, 2018). Finally, El-Ashram et al. (2017) showed enhanced non-specific immune response in Nile-tilapia after basil oil supplementation at $0.25,0.5$, and $1 \%$ basil oil per $\mathrm{kg}$ diet for 42 days. Additionally, supplemented fish had a lower bacterial count in their muscle at the end of the 42 days and they had a decrease in mortality rates after infection (El-Ashram et al., 2017). Poultry and fish account for much of the benefits of basil, thus clinical trials are needed to confirm effects.

\subsection{Anti-inflammatory properties}

The anti-inflammatory properties of basil have also been evaluated using several models. First, Güez et al. (2017) showed an increased production of the anti-inflammatory cytokine IL-10 in human leukocyte cell cultures treated with basil extract. They found the correlation to be dose-dependent, with a higher extract concentration leading to a higher production of IL-10 (Güez et al., 2017). In the in vivo rat model seen earlier, Eftekhar et al. (2019) found a decrease in phospholipase A2 and serum total protein levels. Phospholipase A2 induces inflammation in the airway and serum proteins are known to be a sign of inflammation in asthma, therefore a reduction in these suggests anti-inflammatory action (Eftekhar et al., 2019). Using the egg albumen denaturation method, where anti-inflammatory activity is approximated with reduced thermal denaturation of protein, Osei Akoto et al., (2020) found that ethanol and hexane extracts of basil had significantly higher anti-inflammatory activity than aspirin. An in vivo mouse model study has shown that supplementation of basil essential oil significantly reduced edema (swelling caused by inflammation) in the first hour and up to five hours after inducing edema (Rodrigues et al., 2016).

The anti-inflammatory effects of basil may be able to be extended using cyclodextrins, a class of molecules used to extend molecule bioavailability, safety, and stability. Rodrigues et al. (2017) found that orally administering mice with basil essential oil complexed with $\beta$-cyclodextrin resulted in significant inhibition of arachidonic acid, a molecule associated with edema.

\subsection{Cytotoxicity}

Further clinical trials are needed to properly assess the efficacy of basil supplementation for immune-enhancing and anti-inflammatory activities in humans. However, caution should be practiced as basil oil has been found to have a dose-dependent cytotoxic effect against HEp-2 and HeLa human cell lines (Kathirvel and Ravi, 2012). It is possible that the cytotoxic activity of basil oil is only against these cell lines and, therefore, more studies should be done to make a conclusion. Nevertheless, basil has promising potential in immune-enhancing and anti-inflammatory activity.

\section{Black pepper (Piper nigrum)}

\subsection{Introduction and source}

Black pepper is the name for the spice derived from grinding the cooked and dried unripe fruit, known as a peppercorn, of the Piper nigrum flowering vine and the name for the plant itself. Herein, black pepper will refer to the spice rather than the plant. Similar to the black pepper, the uncooked dried unripe fruit of peppercorn is used to produce green pepper while the ripe fruit seeds are used to produce white pepper. As a spice, black pepper is the most common of the three and is one of the most commonly used spices in the world. Additionally, black pepper is the most traded spice globally, owing to its title as the "King of Spices". Black pepper, commonly referred to as simply pepper, is native to India and is today extensively cultivated in many tropical regions. Black peppers usage dating back to prehistoric times as one of the earliest known spices.

\subsection{Current uses}

Black pepper finds extensive usage in many cuisines around the world. It is added as a seasoning to many dishes, commonly paired with salt. The spicy flavour observed from consuming black pepper is from the compound piperine. Black pepper is also used in many traditional medicines for its proposed health benefits, ranging from treating indigestion, heart disorders, toothaches, and more.

\subsection{Bioactive compounds}

Black pepper contains phenols, flavonoids, alkaloids, and terpenes (Lee et al., 2020). The bioactive properties of black pepper are attributed to the phenols, flavonoids, and alkaloids, with a consensus that piperine (an alkaloid) is the major bioactive compound in black pepper (Lee et al., 2020; Gorgani et al., 2017; Banerjee et al., 2021). It is important to note that black pepper oil does not contain piperine as it is a highly volatile compound (Bober et al., 2018). The terpenes are responsible for the flavour of black pep- 
per and are primarily $\delta$-3-carene $(27.8 \%)$, DL-linonene $(18.1 \%)$, 2 - $\beta$-pinene $(16.9 \%), \alpha$-pinene $(15.0 \%), 1$-phellandrene $(6.4 \%)$, and $\beta$-myrcene (5.4\%) (Lee et al., 2020).

\subsection{Immune-enhancing properties}

Black pepper has been found to have some immunomodulatory effects. Abdelnour et al. (2018) found that supplementing rabbits with black pepper oil at $0.5,1.0$, and $1.5 \mathrm{~g} / \mathrm{kg}$ of diet increased IgM and $\operatorname{IgG}$ levels as compared to the control group. This contrasts with a study by Bernardo et al. (2015) which found that piperine inhibited IgM secretion in mouse B lymphocytes. Similarly, Soutar et al. (2017) found that piperine exhibited immunosuppressive qualities in mouse B lymphocytes through impairment of antigen presentation. Recalling that black pepper oil is absent of piperine, it can be inferred that another or a combination of bioactive compounds in black pepper causes immunostimulation while piperine causes immunosuppression. More studies are needed to make conclusions about the immunomodulatory effects of black pepper and piperine as current research is limited. The immune-enhancing capabilities of black pepper are typically associated with the antiinflammatory properties, which have been examined.

\subsection{Anti-inflammatory properties}

Various alkaloids within black pepper have been shown to ameliorate LPS-induced inflammation in mouse models. Levels of LPSinduced pro-inflammatory cytokines IL- $1 \beta$, TNF- $\alpha$, and IL- 6 were reduced by guineensine (Reynoso-Moreno et al., 2017), piperine (Wang-sheng et al., 2017; Ren and Liang, 2018), and three alkaloids of unknown identity (Pei et al., 2020). Additionally, piperine and the three unknown alkaloids were shown to inhibited LPSstimulated pro-inflammatory Prostaglandin $\mathrm{E}_{2}$ release (Wangsheng et al., 2017; Pei et al., 2020). Piperine was further found to inhibit macrophage inflammation in pancreatic islets. Yuan et al. (2021) found that mice fed a high-fat diet had shrunk, poorly stained islets with fibrosis (scarring), whereas the mice fed a highfat diet treated with piperine had regular islets with no fibrosis. They found that piperine inhibited the production of cytokines consistent with macrophages inside the islets (CD11c, Gal-3, and IL-1ß), relieving inflammation (Yuan et al., 2021). Also, piperine was found to down-regulate miRNA-127 expression, which normally up-regulates myD88 expression, and expression of these together result in further inflammatory damage from LPS (Ren and Liang, 2018). These results highlight the anti-inflammatory role of several alkaloids in black pepper, particularly piperine, and more research should be conducted on these alkaloids.

Black pepper extract has been shown to treat allergic inflammation. T helper type 2 (Th2) immune response plays an important role in the progression of allergic responses, particularly when there are excess Th2 cells, creating an imbalance with Th1 cells (Berger, 2000). Bui et al. (2017) found that allergic inflammation induced mice treated with black pepper extract had decreased Th2 cytokine production (i.e., IL-6, GATA3, and IL-4) and increased Th1 cytokine production (i.e., interferon (IFN)- $\gamma$ in their bronchoalveolar lavage fluid and lung tissues. They later confirmed and added to these findings with a study that showed that an identical treatment of mice led to (a) the same results in regard to Th2 and Th1 cytokines and (b) a decrease in T helper type 17 (Th17) cytokine production (i.e., RORc and IL-17A) and an increase in regulatory $\mathrm{T}$ (Treg) cell cytokine production (IL-10) (Bui et al., 2019). Th17 cells are responsible for pro-inflammatory cytokine production while Treg cells control the immune response. Therefore, black pepper extract was effective in treating allergic inflammatory through major Th cell groups.

Black pepper may also find use in regulating inflammation disrupted iron homeostasis, inflammation related to epilepsy, and myocardial inflammation. Hepcidin is a protein that regulates iron homeostasis and is up regulated under inflammatory conditions, resulting in iron deficiency. Banerjee et al. (2021) found that black pepper extract, as well as piperine alone, were able to downregulate hepcidin expression caused by turpentine-induced inflammation in mice. In an epileptic rat model, piperine treatment was shown to decrease neuronal levels of pro-inflammatory cytokines TNF- $\alpha$ and IL-1 $\beta$, which at high levels may cause or worsen convulsions (Mao et al., 2017). In myocardial tissue of rats faced with isoproterenol-induced inflammation, piperine pre-treatment resulted in no changes in TNF- $\alpha$, IL- 6 , and inducible nitric oxide synthase (iNOS), as compared to increased expression in the group without pre-treatment (Viswanadha et al., 2020). Thus, piperine pretreatment was effective in reducing isoproterenol-induced inflammation of the myocardial tissue. Taken together, black pepper has been shown to have a profound impact on reducing different forms of inflammation. It would be useful to perform clinical trials to further validate results.

\subsection{Bioenhancing properties}

It is worth mentioning that piperine has profound application as a bioenhancer, increasing the bioavailability of other therapeutic agents. It has successfully been used in conjunction with resveratrol (variety of pharmacological functions) (El-Ghazaly et al., 2020), ginsenoside Rh2 (a bioactive compound in Panax ginseng) (Jin et al., 2016), Tagetes patula extract (antioxidant and antihyperlipidemic) (Nawale et al., 2018), raloxifene (a drug for osteoporosis and breast cancer) (Izgelov et al., 2018), and many more (Tiwari et al., 2020). Additionally, the oral bioavailability of piperine has been shown to be able to be enhanced by 3.65 -fold using nanosuspension (Zafar et al., 2019). Therefore, the bio-enhancing abilities of piperine may also be enhanced using emerging technology, however, more studies are needed to make conclusions.

\section{Chili Powders (Capsicum species)}

\subsection{Introduction and source}

Chili powder (also spelt chile and chilli) is primarily made from the dried and pulverized fruit of chili peppers from the genus Capsicum. In the genus, there are five main species each with many cultivars: C. annuum which includes bell peppers, banana pepper, cayenne pepper, jalapeños, Thai peppers, chiltepin, and New Mexico chile; C. frutescens which includes malgueta, tabasco, piri piri, and Malawian kambuzi; $C$. chinense which includes ghost pepper, habanero, datil, and scotch bonnet; $C$. pubescens which includes Rocoto and Manzano peppers; and C. baccatum which inclused South American aji peppers. Chili peppers are believed to originate from Mexico (Kraft et al., 2014) and subsequently spread globally in the $15^{\text {th }}$ and $16^{\text {th }}$ century with the Columbian Exchange, a widespread transfer of products between the New World, Old World, and West Africa. Aside from the chilis, chili powder often includes other ingredients, such as cumin, onion, and garlic powder. One quality that all chili powders have in common is the presence of capsaicin, a compound unique to chili peppers. 


\subsection{Current uses}

Chili peppers and powders are used to add heat to dishes across many cultures, such as Mexican chiles rellenos, Indian curries, Bhutanese ema datshi, Thai som tam, and Italian arrabbiata sauce. Capsaicin is the compound responsible for the hot, burning sensation obtained from eating chili peppers and chili powder. A psychological interpretation for humans' preference for consuming capsaicin is that it represents a controlled risk, where the body's warning system is alerted but there is no real threat (Rozin and Schiller, 1980). This can result in a euphoric feeling for the consumer. Alternatively, capsaicin is used as a deterrent because of the same pain-inducing properties. Capsaicin is used as a chemical irritant in pepper sprays and some tear gases. Additionally, chili peppers are planted around crops in African and Asian countries to defend against elephants, which avoid the burning sensation like all other mammals except humans and tree shrews (Han et al., 2018). However, capsaicin is also used in treatments due to its activity. Capsaicin has been used in traditional medicines in many countries such as Mexico, Brazil, India, China, and Africa. Across these cultures, capsaicin is used to relieve fevers, combat indigestion, stop flatulence, skin infections, and more (Dewitt, 2021). In addition, capsaicin is used as a topical analgesic to relieve pain of muscles and joints (Fattori et al., 2016).

\subsection{Capsaicin receptor}

Capsaicin acts through the transient receptor potential vanilloid 1 (TRPV1), also known as the capsaicin receptor (Caterina et al., 1997). TRPV1 functions to detect and regulate body temperature and give a heat and pain sensation. TRPV1 is found mostly in nociceptive (pain) neurons of the peripheral nervous system, such as taste buds and the skin, but is also found in the central nervous system and on non-neuronal cells (Bujak et al., 2019). Capsaicin is also believed to act through pathways other than TRPV1 (Omari et al., 2016).

\subsection{Bioactive compounds}

Chili peppers have a variety of bioactive compounds, including vitamin C, carotenoids, capsaicinoids, and capsinoids (MontoyaBallesteros et al., 2014; Georgescu et al., 2017). The most abundant capsaicinoid in chili peppers is capsaicin $(69 \%)$, however, dihydrocapsaicin (22\%), nordihydrocapsaicin (7\%), homocapsaicin $(1 \%)$, and homodihydrocapsaicin $(1 \%)$ are also present (Barceloux, 2009). The capsaicinoids, in particular capsaicin, and capsinoids are considered the main bioactive compounds of chili peppers. As capsaicin is found in chili peppers, capsaicin is found in any spice made from chili peppers including not only chili powders but also paprika and cayenne pepper.

\subsection{Immune-enhancing properties}

Capsaicin has gained a lot of interest for its therapeutic properties. Of note, are capsaicin's immune-enhancing capabilities. ViverosParedes et al. (2021) looked at the effect of capsaicin in modulating the immune system of mice under chronic stress. They found that capsaicin treatment increased the immune response, evidenced by increased spleen lymphocyte proliferation and increased response to induced delayed-type hypersensitivity (Viveros-Paredes et al., 2021). Additionally, they found that spleen lymphocytes did not succumb to stress-induced apoptosis after capsaicin treatment
(Viveros-Paredes et al., 2021). Furthermore, they found significantly reduced corticosterone (stress hormone) production in capsaicin-treated groups (Viveros-Paredes et al., 2021).

An in vitro study by Jin et al. (2016) found that treatment of osteosarcoma (bone cancer) cells with $200 \mu \mathrm{M}$ of capsaicin for 24 hours induced surface translocation of calreticulin, a molecule that promotes immunogenic tumor cell death. Compared to treatment with cisplatin, a chemotherapy medication, capsaicin treatment resulted in increased IFN- $\gamma$ production and release from lymphocytes (Jin et al., 2016). However, capsaicin may be more effective in prevention than in treatment. Motte et al. (2018) found that pre-treatment of rats with capsaicin was protective against experimental autoimmune neuritis, with the strongest effects at 50 $\mu \mathrm{g} / \mathrm{d}$, whereas treatment started at the neuritis onset needed unphysiologically high dosages of capsaicin to have a therapeutic effect. Grüter et al. (2020) similarly found capsaicin to have an immunomodulatory effect in rats with experimental autoimmune neuritis.

\subsection{Anti-inflammatory properties}

Capsaicin has popularity as an anti-inflammatory agent. Studies have found that capsaicin supplementation effectively lowers the pro-inflammatory cytokines TNF- $\alpha$, IFN- $\gamma$, IL- $1 \beta$, and IL-6 (Motte et al., 2018; Bessler and Djaldetti, 2017; Xu et al., 2017; Kang et al., 2017; Zhang et al., 2019). Of these, IL-6 was found to be decreased with $200 \mu \mathrm{M}$ of capsaicin, whereas lower concentrations of capsaicin led to increased production of pro-inflammatory cytokine IL-6 (Bessler and Djaldetti, 2017). Additionally, Bessler and Djaldetti (2017) found that capsaicin treatment of colon carcinoma cell cultures between 10 and $200 \mu \mathrm{M}$ resulted in decreased anti-inflammatory cytokine IL-10 production. Contrarily, Kang et al. (2017) found that capsaicin supplementation of mice at 0.01 $\mathrm{g} / 100 \mathrm{~g}$ of diet resulted in increased IL-10 production. The difference in IL-10 production could be due to the method of administration between the studies. In the colon carcinoma cell culture study capsaicin was used as a treatment on carcinogenic cells, whereas in the mouse study capsaicin was used as a preventative measure with chronic low-grade inflammation following. Alternatively, the difference could be between the type of study (in vitro and in vivo) or the models used (human cell line and mice). Further research is needed to determine if IL-10 production is increased or decreased by capsaicin or which factors could lead to increased production in one situation and decreased in another. Nevertheless, the antiinflammatory cytokine IL-4 was found to be increased with capsaicin supplementation of rats (Motte et al., 2018). Taken together with the previous results, capsaicin may help alleviate inflammation by reducing pro-inflammatory cytokines production and maybe partially by increasing anti-inflammatory cytokine production, particularly IL-4.

Capsaicin pre-treatment has been shown effective against various forms of inflammation, including experimental autoimmune neuritis (Motte et al., 2018), pulmonary arterial hypertension (Xu et al., 2017), systemic chronic low-grade inflammation (Kang et al., 2017), concanavalin A-induced hepatitis (Zhang et al., 2019), and LPS-induced inflammation of myoblasts (Shang et al., 2017). It is unclear if TRPV1 had a major role in the first three studies listed, while the latter two have little mentioned of a proposed mechanism. Motte et al. (2018) found that specific macrophage expression was inconsistent with increased TRPV1 expression and points to the p36 mitogen-activated protein kinase (MAPK) pathway as a potential means. Consistent with this idea, Xu et al. (2017) found that capsaicin pre-treatment inhibited the p38MAPK pathway. This 
inhibition was believed to be responsible for the anti-inflammatory effects of capsaicin pre-treatment. Kang et al. (2017) found that capsaicin elevated butyrogenic bacterium and butyrate levels which inhibited colonic cannabinoid receptor type 1 and reduced LPS biosynthesis. It is likely that capsaicin functions through a variety of pathways and more research is needed to confirm this idea.

The anti-inflammatory effects of capsaicin may be enhanced when used in combination with other spices. One study showed that pre-treatment of mice with a combination of capsaicin and curcumin (the main active ingredient in turmeric) resulted in better protection against LPS-induced inflammation than capsaicin alone (Vasanthkumar et al., 2018). This result highlights the potential beneficial impact of combining spices. Chili powder often includes ingredients other than chili pepper and it would be interesting to see if the combination of spices in chili powder results in better effects than the dried, pulverized chili pepper alone.

\subsection{Cancer progression}

The effect of capsaicin on cancer progression is unclear. Capsaicin has been observed to have cancer-promoting effects on prostate cancer cells (Díaz-Laviada, 2010), colon cancer cells (Liu et al., 2012), and skin cancer cells (Hwang et al., 2010). Additionally, a meta-analysis found a correlation between higher spicy food consumption (including chili pepper) and increased cancer incidence (Chen et al., 2017). Low doses of capsaicin may be responsible for cancer-promoting effects, whereas high doses are observed with cancer-inhibition (Lin et al., 2018; Chen et al., 2021; Xu et al., 2017; Guo et al., 2019). The effect of capsaicin on cancer should be further examined.

\section{Clove (Syzygium aromaticum)}

\subsection{Introduction and source}

The flowering buds of the clove tree (Syzygium aromaticum) are used to make the spice clove. The clove tree is native to the Maluku islands in eastern Indonesia, but it is grown in many different countries including India, Jamacia, West Indies, Brazil, Sumatra, and other tropical climates. Clove is available year-round from those grown in different locations.

\subsection{Current uses}

Clove is used in a variety of foods. It is used to flavour curries, marinades, fruit, hot beverages, and baked goods. Clove is described to have an intense, pungent warm flavour and aroma, lending to its use to bring warmth to baked goods such as gingerbread cookies. Additionally, its intense flavours lead to its frequent use in spice blends, such as pumpkin pie spice and speculoos spice. Aside from cuisine, clove finds use in an Indonesian cigarette, as an ant repellent, as an anaesthetic, and in traditional medicine. In traditional medicine, clove is used to treat vomiting, flatulence, nausea, liver problems, bowel and stomach disorders, and as a stimulant (Batiha et al., 2020).

\subsection{Bioactive compounds}

Eugenol is the main bioactive compound in clove as well as allspice (previously covered) (Neveu et al., 2010). Eugenol is believed to be responsible for much of clove's physiological properties. Other compounds in clove include flavonoids, hydroxybenzoic acids, hydroxycinamic acids, and hydroxyphenylpropens (gallic, caffeic, ferulic, elagic, and salicylic acids), essential oils (eugenol acetate, $\beta$-cariofilenol, and $\alpha$-humulen), and volatile compounds ( $\beta$-pinene, limonene, farnesol, benzaldehyde, 2-heptanone, and ethyl hexanoate) (Cortés-Rojas et al., 2014).

\subsection{Immune-enhancing properties}

Clove has varying immunomodulatory properties. On mouse phytohemagglutinin-activated splenocytes, clove essential oil at 100 and $1,000 \mu \mathrm{g} / \mathrm{mL}$ was found to reduce the induced splenocyte proliferation and suppress IFN- $\gamma$ release from the immune cells (Dibazar et al., 2014). Similarly, mice supplemented daily with clove essential oil at $100 \mathrm{mg} / \mathrm{kg}$ of body weight were found to reduce increases in macrophages, monocytes, and $\mathrm{T}$ cells caused by acute campylobacteriosis (Bereswill et al., 2021). Furthermore, clove extract was found to decrease the number of mouse neutrophils challenged with LPS (Chniguir et al., 2019). These three studies showed clove as an immunosuppressive, reducing cellular damage when exposed to immunostimulatory agents. However, clove has also immunostimulatory properties. Salmonella typthimurium-infected mice supplemented with clove extract at $150 \mathrm{mg} / \mathrm{kg}$ of body weight had increased numbers of lymphocytes and lymphoblasts (Wael et al., 2018). Additionally, broiler chickens supplemented with up to $1.5 \mathrm{~g}$ of ground clove per $\mathrm{kg}$ of diet for five weeks had increased globulin, IgG, IgM, and IFN- $\gamma$ (Mahrous et al., 2017). Another study with broiler chickens found clove supplementation at $4-6 \%$ of diet increased antibodies in unvaccinated birds, while antibodies in vaccinated birds were unaffected (Al-Mufarrej et al., 2019). These studies indicate that clove can augment the resting and infection-challenged immune system, although not as effective as vaccination.

Eugenol-focused studies have shown similar results to those of clove supplementation. On mouse LPS- and pokeweed mitogenactivated splenocytes, eugenol at 100 and $1,000 \mu \mathrm{g} / \mathrm{mL}$ was found to suppress IFN- $\gamma$ activity and B cell proliferation through T celldependent and independent pathways (Saraphanchoiwitthayaet et al., 2019). Contrarily, eugenol was found to inhibit myeloid-derived suppressor cells (immune inhibitors) in spleen cells from tumor-bearing mice, resulting in increased immune response (Ding et al., 2018). Additionally in mice with experimental visceral leishmaniasis, eugenol oleate was found to activate the immune system to clear the parasite (Raja et al., 2020). Thus, clove and eugenol may be beneficial in modulating the immune system. More studies are needed to support these results.

\subsection{Anti-inflammatory properties}

Clove has been shown to have anti-inflammatory properties. An in vitro study using chronically inflamed human dermal fibroblasts found that clove essential oil significantly inhibited increases in the pro-inflammatory biomarkers vascular cell adhesion molecule-1, interferon $\gamma$-induced protein 10, interferon-inducible T-cell $\alpha$ chemoattractant, and monokine induced by $\gamma$ interferon (Han and Parker, 2017). Multiple studies have demonstrated clove essential oil supplementation to be effective in reducing carrageen-induced rat paw edema (swelling caused by inflammation) at 250 and 500 $\mathrm{mg} / \mathrm{kg}$ of body weight (Marmouzi et al., 2019; Saeed et al., 2017; Humbal et al., 2019). Additionally, in rats, clove extracts were 
found to decrease pro-inflammatory markers (C-reactive protein (CRP), COX-2, IL-6, TNF- $\alpha$, transforming growth factor (TGF)- $\beta$, and epidermal growth factor) (Jose et al., 2017; Adberlrahman et al., 2018). Supporting this, a clinical trial using Clovinol ${ }^{\circledR}$, a clove extract supplement, significantly decreased CRP and IL-6 in the treated group as compared to the placebo (Mammen et al., 2018). It is important to note that four of the authors are affiliated with the company that produced Clovinol ${ }^{\circledR}$, resulting in a possibility of bias. Similarly, the study by Jose et al. (2017) used Clovinol® in their experiments and disclosed a conflict of interest. Further, unbiased, studies should be conducted to determine the anti-inflammatory properties of clove.

The anti-inflammatory properties of eugenol have also been examined. In mice, eugenol treatment decreased induced ear edema (Tsai et al., 2017; de Araújo Lopes et al., 2018). Furthermore, eugenol supplementation was found to reduce pro-inflammatory cytokines in mice (TNF- $\alpha$, IL-1 $\beta$, IL-6, and IL-8) (Tsai et al., 2017; de Araújo Lopes et al., 2018), in rats (TNF- $\alpha$, IL-1 $\beta$, and IL-6) (Kumar et al., 2021; Ma et al., 2018), and IPEC-J2 cell line (TNF- $\alpha$ and IL-8) (Hui et al., 2020). Like clove, further studies should be conducted using eugenol to confirm results.

\section{Devil's claw (Harpagophytum procumbens)}

\subsection{Introduction and source}

Harpagophytum procumbens is an herb native to Southern Africa, including Namibia, Botswana, and South Africa. The plant has several names, including grapple plant and wood spider, but it is most known as Devil's claw. The popular name comes from its appearance, having its fruit covered in tiny hooks. The name Devil's claw is not exclusive to $H$. procumbens and is used for the other species in the genus, $H$. zeyheri, some species of the Proboscidea genus, which are native to the southern United States and Mexico, and some species of the Pisonia genus. The Southern Africa H. procumbens has been long used to relieve pain and to reduce inflammation.

\subsection{Bioactive compounds}

The bioactive compounds in $H$. procumbens include iridoid glycosides, acetylated phenolic glycosides, and terpenoids (Williams, 2013). The main bioactive compound in H. procumbens is harpagoside and, to a lesser extent, harpagide. There is disagreement on what constitutes Devil's claw. Some believe that only $H$. procumbens extracts should be regarded as Devil's claw, while others believe that either H.procumbens or H. zeyheri extracts could be labelled Devil's claw, depending on the concentration of harpagoside. In favour of the latter, it has been found that harpagoside is a main component in each species (Kondamudi et al., 2016). Additionally, harpagoside content can fluctuate in either species depending on many environmental and harvesting conditions, meaning that labelling $H$. procumbens extracts as Devil's claw does not necessarily mean that harpagoside is present.

\subsection{Immune-enhancing properties}

The immune-enhancing effects of Devil's claw have been examined minimally in the literature. H. procumbens extracts have been found to decrease IL-21 and IL-23 secretion, associated with T helper type 17 (Th17) cells, and increase Th1 cell cytokines in mitogen-activated human leukemic monocytic cells (Cholet et al., 2019). These results suggest that $H$. procumbens has an immunostimulant effect. Harpagoside and harpagide have been found to decrease the TNF- $\alpha$ cytokine secretion in mitogen-activated human leukemic monocytic cells while inactivated cells are poorly affected (Schopohl et al., 2016). Interestingly, harpagoside and harpagide increased leukocyte transmigration protein mRNA expression in inactivated cells, potentially leading to increased cell migration (Schopohl et al., 2016).

\subsection{Anti-inflammatory properties}

Devil's claw is used commonly for its anti-inflammatory properties. H. procumbens extracts have been shown to decrease nitric oxide accumulation and suppress IL-6 expression in LPS-stimulated macrophages (Gyurkovska et al., 2011). Additionally, there has been strong inhibition of COX-1 and COX-2 by $H$. procumbens extracts (Gyurkovska et al., 2011). Inhibition of COX-2 is associated with the molecular docking of harpagoside and harpaside, with binding energies of -9.13 and $-5.53 \mathrm{kcal} / \mathrm{mol}$, respectively (Rahimi et al., 2016). H. procumbens extracts have also been found to inhibit COX-2 expression by reducing the activator protein 1 transcription factor pathway at concentrations between 100 and $200 \mu \mathrm{g} / \mathrm{mL}$ (Fiebich et al., 2012). Inhibition of COX-2 is a common pathway utilized by NSAIDs, indicating a potential use of Devil's claw as an alternative for NSAIDs. Furthermore, it was found that harpagoside is not solely responsible for Devil's claw anti-inflammatory properties, but there is a beneficial effect from other bioactive compounds (Hostanska et al., 2014). Importantly, harpagide has been observed to have a toxic effect at a concentration of $1 \mathrm{mg} / \mathrm{mL}$ (Gyurkovska et al., 2011). Therefore, caution should be exercised when using Devil's claw products as harpagide is a common component.

Devil's claw has been examined in studies determining its effect on inflammatory-related diseases. Regarding rheumatoid arthritis, an in vitro study using LPS-induced mouse macrophages showed a reduction in pro-inflammatory cytokines, IL- $1 \beta$, IL- 6 , and TNF- $\alpha$ (Inaba et al., 2010). In a study looking at osteoarthritis, harpagoside inhibited IL-6 production in human osteoarthritis chondrocytes (Haseeb et al., 2017). For inflammatory bowel disease, $H$. procumbens extracts were shown to reduce inflammatory and oxidative stress markers in LPS-induced rat colon specimens (Locatelli et al., 2017). These results suggest a potential use for Devil's claw in the treatment of various inflammatory-related diseases.

\section{Fenugreek (Trigonella foenum-graecum)}

\subsection{Introduction and source}

Fenugreek (Trigonella foenum-graecum) is a plant whose leaves are used as an herb and seeds as a spice. However, fenugreek is mainly used as a spice. Fenugreek is native to southern Europe and the Mediterranean region. Today, fenugreek is cultivated in Europe, western Asia, India, and northern Africa.

\subsection{Currents uses}

The seeds of fenugreek are described to have a strong, sweet, and bitter taste and aroma, much like maple syrup. Fenugreek is used in cooking, especially in the Indian subcontinent where it is used 
in vegetable dishes, dal, pastes, and spice mixes. Fenugreek seed is composed of $45.4 \%$ dietary fiber, resulting in a hypoglycemic effect and its use as a food stabilizer (Wani and Kumar, 2018). Other products fenugreek is added to are artificial maple syrup, beverages, ice cream, candies, tobacco, soaps, and cosmetics. In traditional medicine, fenugreek is used to aid digestion, treat gastrointestinal inflammation, and promote milk production in lactating women (Petruzzello, 2016). Fenugreek has been used for thousands of years in cooking and traditional medicine, with evidence dating back to $4000 \mathrm{BC}$.

\subsection{Bioactive compounds}

Sapogenins, flavonoids, alkaloids, and steroids are the major classes of compounds in fenugreek (Singh et al., 2020). Two major bioactive compounds in fenugreek are trigonelline $(91.20 \mathrm{mg} / \mathrm{g})$ and 4-hydroxyisoleucine $(90.10 \mathrm{mg} / \mathrm{g}$ ) (Singh et al., 2020). Other bioactive compounds include pinitol $(45.80 \mathrm{mg} / \mathrm{g})$, isovitexin $(3.18$ $\mathrm{mg} / \mathrm{g})$, sarsasapogenin $(1.35 \mathrm{mg} / \mathrm{g})$, and isoorientin $(1.12 \mathrm{mg} / \mathrm{g})$ (Singh et al., 2020).

\subsection{Immune-enhancing properties}

Fenugreek supplementation has varying effects on the immune system; however, results are inconsistent and less impressive than other plants. IgM levels were increased in Nile tilapia (Oreochromis niloticus) (Moustafa et al., 2020) and juvenile blunt snout bream (Megalobrama amblycephala) (Yu et al., 2019) supplemented fenugreek at 0.3 and $0.16 \%$ of diets, respectively. Contrarily, fenugreek supplemented gilthead seabream (Sparus aurata L.) at 1,5 , and $10 \%$ of diet had no change in IgM levels (Guardiola et al., 2018). Nevertheless, these studies found improved lysozyme activity (Moustafa et al., 2020), increased protease activity (Yu et al., 2019), and increased complement component 3 levels (Guardiola et al., 2018). Complement component 3 is a key protein in the complement system (Sahu and Lambris, 2001). Furthermore, Nile tilapia supplemented a diet with $2.5 \%$ crude fenugreeks seeds had increased total leukocytes after cadmium toxicity (Abbas et al., 2019). These results in fish show promising properties of fenugreek supplementation, however clinical trials are needed to confirm results.

Other animal models have had fewer promising results. Hens and broiler chickens supplemented with fenugreek had no change in antibody titer against sheep erythrocytes compared to the control groups (Samani et al., 2020; Laudadio et al., 2020). However, fenugreek was effective at augmenting the antibody titer of black cumin (Nigella sativa L.) (Laudadio et al., 2020). Additionally, fenugreek supplemented broiler chickens had little change in immune response towards phytohemagglutinin-P-induced swelling (Al-Homidan et al., 2020). Compared to mung bean (Vigna radiata) and garden cress (Lepidium sativum), fenugreek gave the weakest response (Al-Homidan et al., 2020). Thus, fenugreek may be effective at enhancing innate immunity but not adaptive immunity, particularly in fish, although it may be less effective than other plants. Furthermore, fish and poultry are not optimal models for determining the applicability of fenugreek on human health, thus preclinical and clinical trials are needed to gain a better understanding.

\subsection{Anti-inflammatory properties}

The anti-inflammatory properties have been demonstrated us- ing fenugreek. Multiple studies have shown fenugreek to lower pro-inflammatory cytokines, including TNF- $\alpha$, IL- $1 \beta$, and IL-6, released in response to induced inflammation (Zhou et al., 2020; Liu, 2019; Khound et al., 2018; Piao et al., 2017; Sindhu et al., 2018; Nagamma et al., 2021; Yu et al., 2019). Moreover, a clinical trial found that $15 \mathrm{~g}$ /day supplementations of fenugreek seed powder decreased CRP (a general measure of inflammation) levels in type 2 diabetes patients, however, there was no effect on IL-6 and TNF- $\alpha$ (Tavakoly et al., 2018). Anti-inflammatory cytokines were found to be increased with fenugreek supplementation, specifically IL-10, IFN- $\gamma$, and TGF- $\beta$ (Liu, 2019; Piao et al., 2017). Fenugreek has been found to inhibit c-Jun N-terminal kinases and NF- $\kappa$ B activation (Zhou et al., 2020) as well as COX-1 and COX2 (El-Taib et al., 2020). Furthermore, fenugreek has been found effective at reducing carrageenan- and Mycobacterium tuberculosis-induced paw edema (Cheurfa et al., 2021; Sindhu et al., 2018; Pournamdari et al., 2018; El-Taib et al., 2020). Thus, fenugreek has shown promising results in ameliorating inflammation. It is important to note that the clinical trial found no change in two major pro-inflammatory cytokines, inconsistent with many animal studies. More research should be conducted to confirm the effects of fenugreek on pro-inflammatory cytokines.

\section{Ginger (Zingiber officinale)}

\subsection{Introduction and source}

Ginger is a flowering plant with the taxonomic classification of Zingiber officinale. The rhizome (subterranean plant stem) of ginger is used as a spice with the same name. Ginger originated in Maritime Southeast Asia and was first traded with the spice trade where it was used by ancient Greeks and Romans. Today, ginger is grown in many places across the world, although most ginger is grown in Asia.

\subsection{Current uses}

Ginger has many uses in cooking. In South Asian cuisine, ginger is a common ingredient in preparing seafood, meat, and vegetarian dishes. Examples include Indian lentil curries, Burmese gyin-thot, and Vietnamese shrimp-and-yam soup. Additionally, ginger is used for cooking in the Caribbean and Western cultures. In Western cultures, dry powdered ginger is commonly used to produce products such as gingerbread, cookies, ginger ale, and ginger beer. Perhaps the most common use for ginger is to combat nausea and vomiting. In traditional medicine, ginger has also found use across several cultures. In traditional Chinese medicine, ginger is used to treat illnesses caused by cold weather (Moghaddasi and Kashani, 2012). In Ayurveda, ginger is used extensively for purposes including fighting heart disease, reducing cholesterol, and combating arthritis (Moghaddasi and Kashani, 2012). In Iranian traditional medicine, ginger has been used for improving kidney health, memory, and digestive system health (Khodaie and Sadeghpoor, 2015).

\subsection{Bioactive compounds}

The main groups of bioactive compounds in ginger are the phenolic compounds gingerols, shogaols, and paradols (Mao et al., 2019). In particular, 6-gingerol and 6-shogaol are most often reported as the most common bioactive compounds (Sarip et al., 2014; Ma- 
nasa et al., 2013; da Silverira Vasconcelos et al., 2019). However, other gingerol, shogaol, and paradol isomers are commonly found within ginger (Manasa et al., 2013; da Silverira Vasconcelos et al., 2019). These three phenolic compounds contribute to the pungent and pleasant aroma of ginger (McGee, 2007).

\subsection{Immune-enhancing properties}

The immune-enhancing properties of ginger have been studied across several models, including fish, birds, and humans. In fish, positive results have been found with ginger supplementation in different species. Ginger supplementation of up to $13 \mathrm{~g} / \mathrm{kg}$ of feed has been found to increase the number of erythrocytes and leucocytes in Asian sea bass (Lates calcarifer) and common carp (Cyprinus carpio) compared to controls (Talpur et al., 2013; Mohammadi et al., 2020). Both cell types contribute to immunity, as leucocytes are immune cells and erythrocytes are recently emerging as important modulators of the innate immune system (Anderson et al., 2018). Furthermore, the Asian sea bass study found an increased serum bactericidal activity, consistent with an increased immune response (Talpur et al., 2013). In addition, the common carp study found increased serum globulin, lysozyme, and Ig (Mohammadi et al., 2020). Consistent with these findings, an increase in globulin has been found with ginger-supplemented beluga sturgeon (Huso huso) (Kanani et al., 2014), whereas increases in lysozyme and Ig have been found with ginger-supplemented Rohu (Labeo rohita) (Sukumaran et al., 2016). Globulin, lysozyme, and Ig are important factors for the immune response.

The immune-enhancing properties of ginger supplementation have been less promising in birds. Qorbanpour et al. (2018) fed broiler chickens ginger powder at up to $0.25 \%$ of the diet for 42 days and found increased $\operatorname{IgM}$ and $\operatorname{IgG}$, produced against sheep erythrocytes, compared to the control. However, the increases were not significant. Elmowalid et al. (2019) fed broiler chickens $15 \mathrm{~g}$ of ginger extract per $\mathrm{kg}$ of diet for 21 days and found significantly increased bactericidal and phagocytic activity, consistent with an increased immune capability. Hens given diets with $0.1 \%$ ginger extract for 42 days had significantly increased serum lysozyme activity, while serum globulin was not affected (An et al., 2019). Perhaps ginger supplementation has a lesser effect on globulin and Ig in birds while maintaining other immunological activities.

Ginger supplementation has shown promising results in clinical trials. Aryaeian et al. (2019) supplemented rheumatoid arthritis patients with $1,500 \mathrm{mg}$ of ginger powder for 12 weeks and found a significantly decreased expression of the T-bet gene. T-bet is a transcription factor that inhibits Th2 differentiation and induces the proliferation of Th1 (Aryaeian et al., 2019). Thus, reduced Tbet expression would result in a relatively increased Th2 concentration. Additionally, they found an increased expression of FoxP3 with ginger supplementation (Aryaeian et al., 2019). FoxP3 is a transcription factor that increases the function of Treg cells, a modulator of the immune system (Wing and Sakaguchi, 2010). Another study supplemented smokers and non-smokers with ginger extract for 21 days and found different results for each group. The smokers had an increased number of erythrocytes while non-smokers had increased IgM levels, both consistent with better immunity albeit in different ways (Mahassni and Bukhari, 2019). Contrarily, diabetic patients supplemented with $2 \mathrm{~g}$ of ginger powder for 10 weeks exhibited no significant difference in NF- $\mathrm{kB}$ subunit $\mathrm{p} 65$ concentrations in lymphocytes and monocytes as compared to the control group (Honarvar et al., 2019). However, other immunological factors were not considered in this study, and ginger extract may have had other effects as several anthropometric measure- ments were improved with ginger supplementation (Honarvar et al., 2019).

The immune-enhancing properties are promising for ginger, particularly regarding results from clinical trials, with many studies demonstrating positive results and fewer with no changes.

\subsection{Anti-inflammatory properties}

The anti-inflammatory properties of ginger have been extensively examined. In inflammation-induced models, ginger supplementation has been found to significantly decrease levels of pro-inflammatory cytokines TNF- $\alpha$, IL-1 $\beta$, IL-6 in rats (Al Hroob et al., 2018; Cifci et al., 2018; Kim et al., 2018) and mice (Kim and Kim, 2018; He et al., 2019). Similarly, a clinical trial using $500 \mathrm{mg}$ daily ginger supplementation for osteoarthritis patients found decreased serum levels of TNF- $\alpha$ and IL-1 $\beta$ compared to the control group after 3 months (Mozaffari-Khosravi et al., 2016). Additionally, a meta-analysis of 14 clinical trials found ginger supplementation to significantly reduce TNF- $\alpha$ and IL-6 (Askari et al., 2020).

Additional inflammatory mediators have also been found to be modulated by ginger. Monocyte chemoattractant protein-1 were reduced in ginger-supplemented rats (Kim et al., 2018) and mice (He et al., 2019). Monocyte chemoattractant protein-1 is a chemokine that regulates monocyte and macrophage infiltration (Deshmane et al., 2009). Less immune cell infiltration would result in less inflammation. The aforementioned meta-analysis found a decrease in CRP (a general measure of inflammation) with ginger supplementation (Askari et al., 2020). Furthermore, increased NF$\kappa \mathrm{B}$ subunit p65 activities from induced inflammation have been found to be suppressed by ginger supplementation in mice (Hsiang et al., 2015) and rats (Hamza et al., 2021). These results contrast that of Honarvar et al. (2019) which found no difference in NF$\kappa \mathrm{B}$ subunit $\mathrm{p} 65$. However, this study was limited to the concentration found within the lymphocytes and monocytes, while the other two studies considered all cells. Furthermore, COX-2 and iNOS (inflammatory mediators) levels have been found to be reduced in liver cancer-induced rats given ginger supplementation as compared to those without supplementation (Hamza et al., 2021). Gene expression of angiotensin II, TGF- $\beta 1$, and TGF- $\beta 3$ has been found to be decreased in streptozotocin-induced diabetic rats with ginger supplementation (Abdi et al., 2021). These proteins have important roles in heart inflammation caused by diabetes (Abdi et al., 2021). Thus, preclinical and clinical trials have shown ginger to reduce inflammation.

\subsection{Side effects and nausea treatment}

There have been suggestions that ginger may negatively interact with anticoagulant medications, such as warfarin. However, studies have found ginger to have no interaction with warfarin (Jiang et al., 2005; Ali et al., 2008). Furthermore, the safety of ginger use in pregnancy has been well established as it is not associated with any increased risk of congenital malformations and it does not pose a risk for spontaneous abortions (Heitmann et al., 2013; Viljoen et al., 2014). Some side effects are possible, but rare, with ginger consumption, including heartburn, belching, bruising, rash, and gastrointestinal discomfort (Nikkhah Bodagh et al., 2019). Nevertheless, ginger consumption is considered safe (Menon et al., 2021).

Ginger has been found effective in combating pregnancy-, chemotherapy-, drug-, and sport-induced nausea and vomiting as detailed in a systematic review of clinical trials (Nikkhah Bodagh et al., 2018). 
11. Lavender (Lavandula angustifolia)

\subsection{Introduction and source}

Lavender is the common name for the genus Lavandula as well as the species Lavandula angustifolia (formerly L. officinalis). Other names for $L$. angustifolia include true lavender, English lavender, garden lavender, common lavender, and narrow-leaved lavender. $L$. angustifolia is the most commonly cultivated species of the genus and is native to the Mediterranean. Popularity of L. angustifolia comes from its pleasant fragrance and colourful flowers.

\subsection{Current uses}

L. angustifolia is commonly used for its fragrance, it is said to have the sweetest fragrance of the genus. Essential oil is made from the plant that is used to scent perfumes, balms, cosmetics, soaps, candles, and more. Additionally, the essential oil is used in aromatherapy where the fragrance is believed to promote calmness and wellness. In cooking, L. angustifolia is the most common lavender species used, adding a sweet floral flavour to dishes. Alternatively, L. angustifolia is used to deter clothing moths and in the production of monofloral honey (honey made from the nectar of only one flower). L. angustifolia has also found use in traditional medicine dating back to the ancient Greeks and Romans.

\subsection{Bioactive compounds}

The main bioactive compounds in L. angustifolia are the terpenoids linalyl acetate $(28.89 \%)$, linalool $(24.30 \%)$, caryophyllene (7.89\%), (E)-3,7-dimethylocta-1,3,6-triene (4.64\%), 4-terpineol $(4.04 \%)$, acetic acid lavandulyl ester $(3.49 \%)$, borneol $(2.60 \%)$ and eucalyptol $(2.05 \%)$ as determined by gas chromatography with quadrupole time-of-flight mass spectrometry (Chen et al., 2020). However, these values can differ between flowers (Woronuk et al., 2011; Prashar et al., 2004). Additionally, the primary phenolics of $L$. angustifolia were determined to be chlorogenic acid, gallic acid, umbelliferone, luteolin 7-O-glucoside, vitexin, and isoquercitroside by ultraviolet-visible spectrophotometry (Radulescu et al., 2017). Furthermore, L. angustifolia contains pectins, a soluble fiber found in most plants.

\subsection{Immune-enhancing properties}

L. angustifolia has shown promising immunomodulatory activities. Pectins from L. angustifolia were found to activate both the innate and adaptive response through the complement system, whole blood phagocytes, neutrophils, macrophages, and Peyer's patches immunocompetent cells by measuring chemiluminescence in response to ROS (Georgiev et al., 2017a). L. angustifolia polysaccharide complexes, which are rich in pectins, were similarly shown to have immunomodulatory activity by stimulating $\mathrm{CD} 8^{+} \mathrm{T}$ cells (cytotoxic), CD25 ${ }^{+} \mathrm{T}$ cells (regulatory), and phagocytes using a concentration of $100 \mu \mathrm{g} / \mathrm{ml}$ on human leukocytes (Georgiev et al., 2017b). These studies contrast most studies which focus on the terpenoids as the bioactive compounds in L. angustifolia, highlighting the roles of under-considered compounds.

As a dietary supplement, Yousefi et al. (2020) found that feeding common carp diets consisting of $1.0-1.5 \%$ L. angustifolia extract for 70 days significantly increased blood leukocytes, plasma globulin, alternative complement, and total Ig of the fish. As a topical treatment, Mori et al. (2016) found that applying L. angustifolia oil to a wound on rats for 14 days significantly increased TGF- $\beta$ expression. TGF- $\beta$ is important in wound healing through influencing fibroblast collagen synthesis and proliferation as well as production of granulation tissue (Clark et al., 1995). Accordingly, Mori et al. (2016) found an increased number of fibroblasts with L. angustifolia oil treatment. Using cancer cell lines, Gezici (2018) found that $L$. angustifolia essential oil had anticancer and antiproliferative activity through increased cancer cell death even at the lowest concentrations $(5 \mu \mathrm{g} / \mathrm{ml})$ tested. These studies highlight the potential variety in applications of $L$. angustifolia and the variety of methods it can be used, however, clinical trials are needed to confirm results.

\subsection{Anti-inflammatory properties}

Anti-inflammatory properties of $L$. angustifolia have been examined. Studies have found that $L$. angustifolia oil significantly decreased the expression of pro-inflammatory cytokines TNF- $\alpha$ and IL-1 $\beta$ in fish (Yousefi et al., 2020), rats (Aboutaleb et al., 2019; Souri et al., 2019), and mice (Chen et al., 2020). Additionally, Chen et al. (2020) found that $L$. angustifolia oil significantly reduced the pro-inflammatory expression of NF- $\mathrm{KB}$ and $\mathrm{COX}-2$. Inhibition of COX-2 is the target of many NSAIDs which may suggest that $L$. angustifolia oil exerts anti-inflammatory as a COX antagonist. Supporting this idea, Cardia et al. (2018) found that $L$. angustifolia oil inhibited edema (inflammation) formation in mice in a similar manner to COX and COX-2 antagonists. Nevertheless, Chen et al. (2020) found that L. angustifolia oil had better antiinflammatory activity than ibuprofen (a common NSAID) at the same dosage. These results suggest that L. angustifolia's may have potential as a natural replacement for NSAIDs.

Anti-inflammatory cytokine expression has also been examined with $L$. angustifolia oil usage. Previously mentioned studies have found that $L$. angustifolia oil significantly increased the expression of the anti-inflammatory cytokine IL-10 (Yousefi et al., 2020; Aboutaleb et al., 2019; Souri et al., 2019). Additionally, Yousefi et al. (2020) found that the anti-inflammatory cytokine TGF- $\beta$ was similarly increased with dietary L. angustifolia oil supplementation of fish. Overall, L. angustifolia oil seems promising as an antiinflammatory agent with clinical trials needed to confirm results.

\subsection{Cytotoxicity and irritative properties}

Caution should be exercised when using L. angustifolia oil as some irritative properties have been found. Topical treatments of $L$. angustifolia oil have been shown to be irritative to the skin of mice at $10 \%$ in polyethylene glycol 200 (Rai et al., 2020) and at $2.5 \mathrm{mg} / \mathrm{ear}$ (Cardia et al., 2018). Furthermore, L. angustifolia oil concentrations of 30 and $90 \mathrm{ug} / \mathrm{mL}$ have been shown to be cytotoxic, while lower concentrations were not (Cardia et al., 2018). More studies should be conducted to further determine the beneficial properties of $L$. angustifolia, especially at low doses.

\section{Oregano (Origanum vulgare)}

\subsection{Introduction and source}

Oregano (Origanum vulgare), also known as wild marjoram, is 
an herb in the mint family Lamiaceae. Oregano is native to the Mediterranean area but can also be grown in all warm garden soils. There are several other plants which go by the name oregano, including Coleus amboinicus (Cuban oregano), Lippia graveolens (Mexican oregano), and Hedeoma patens (small oregano).

\subsection{Current uses}

The most prominent use of oregano is in Italian cuisine where it is used in flavouring meat and vegetables. Most notably, oregano is used in many tomato sauces and olive oil dishes. Oregano is also widely used in Latin American and Mediterranean cuisines. It is described to have a bold, earthy, subtly sweet, and slightly bitter taste. Aside from cuisine, oregano has been used in traditional medicine to treat ailments including cramps, flatulence, coughs, and menstrual problems (Oniga et al., 2018).

\subsection{Bioactive compounds}

Thymol and carvacrol are considered to be the main bioactive compounds in oregano (Singletary, 2010). Several classes of compounds have been isolated from oregano, including essential oil, polyphenols, triterpenoids, and sterols (Oniga et al., 2018). Identified by HPLC-MS, four phenolic acids in oregano are gentisic acid, chlorogenic acid, p-coumeric acid, and rosmarinic acid while six flavonoids are hyperoside, isoquercitrin, rutin, quercitrin, quercetin and luteolin (Oniga et al., 2018). Other phenolic compounds in oregano include 2,5-dihydroxybenzoic acid, 3,4-dihydroxybenzoic acid, origanoside, maltol 60-O-(5-Op-coumaroyl)-b-D-apiofuranosyl-b-D-glucopyranoside, E-caffeic acid, amburoside A, oresbiusin A, (+)-(R)-butyl rosmarinate, apigenin, apigenin 7-O-b-D-glucoside, luteolin, 6,7,40-trihydroxyflavone, 5,7,30,40-tetrahydroxy-8-C- $p$-hydroxybenzylflavone, and didymin (Alagawany et al., 2020).

\subsection{Immune-enhancing properties}

The immune-enhancing properties of oregano have been examined by mostly using fish models. Dry oregano leaf powder supplementation at 0.5 and $1 \%$ of diets resulted in increased IgM, skin mucus bactericidal activity, serum protease activity, and kidney leucocyte phagocytic activity in koi carp (Cyprinus carpio) (Zhang et al., 2020) and gilthead seabream (Sparus aurata L.) (Beltrán et al., 2020), thus providing evidence of improved humoral and cellular immunity. In Nile Tilapia (Oreochromis niloticus), dry oregano leaf powder supplementation at $0.075 \%$ of diet resulted in increased lysozyme and bactericidal activity (Espirito Santo et al., 2018). Similarly, fish supplemented with oregano essential oil showed immune-enhancing properties. Redbelly tilapia (Tilapia zillii) supplemented with oregano essential oil at $1 \mathrm{~g} / \mathrm{kg}$ of diet had increased plasma proteases, lysozyme activity, and plasma bactericidal capacity (Mabrok and Wahdan, 2018). Moreover, Nile tilapia supplemented with oregano essential oil at 1 or $2 \mathrm{~mL} / \mathrm{kg}$ of diet had increased lysosomal and phagocytic activities as well as rendering improvements in erythrocytes and leukocytes levels (Shourbela et al., 2021). Oregano extract supplementation of zebrafish (Danio rerio) resulted in increased lysozyme and protease activity (Rashidian et al., 2021). However, increases were most significant with fish supplemented $1 \%$ extract per $\mathrm{kg}$ of diet, with less significant increases with 0.5 and $2 \%$ supplementation (Rashidian et al., 2021).
Broiler chickens vaccinated against Newcastle disease and avian influenza supplemented with oregano essential oil at 1 and $2 \mathrm{~mL} / 20 \mathrm{~L}$ drinking water $(0.005$ and $0.01 \%)$ had increased antibodies and INF- $\alpha$ RNA levels (Galal et al., 2016). INF- $\alpha$ is a trigger for the immune system (Galal et al., 2016). Furthermore, broiler chickens supplemented with $2 \mathrm{~g}$ of oregano extract per $\mathrm{kg}$ of diet had increased IgG and lower Staphylococcus spp. populations compared to the control group (Franciosini et al., 2016). Bactericidal activity was also seen in vitro in human dendritic cells treated with oregano extract (De Santis et al., 2019). Thus, oregano in various forms shows potential as an immune enhancer. However, as most benefits are seen in fish and poultry, preclinical and clinical trials are needed to confirm the results.

\subsection{Anti-inflammatory properties}

Oregano has anti- and pro-inflammatory properties. Pigs fed a diet of $0.2 \%$ oregano essential oil had decreased expression of $\mathrm{NF}-\kappa \mathrm{B}$ and STAT3, transcription factors involved with inflammation (Cappelli et al., 2021). On the other hand, pigs fed a diet of over $0.4 \%$ oregano essential oil had increased CRP, a general measure of inflammation, while those fed below $0.4 \%$ had no change in CRP (Rivera-Gomis et al., 2020). Additionally, rats fed 200 and $400 \mathrm{mg}$ of oregano extract per kg body weight per day had reduced pro-inflammatory TNF- $\alpha$ and liver lymphocyte infiltration (Sharifi-Rigi et al., 2019). However, rats fed $800 \mathrm{mg}$ of oregano extract per kg body weight per day had increased TNF- $\alpha$ and liver lymphocyte infiltration (Sharifi-Rigi et al., 2019). As these studies suggest, high doses of oregano often lead to increased inflammation while lower doses more often lead to reduced inflammation.

Several other studies have demonstrated the anti-inflammatory properties of oregano. Mice with $P$. acnes-induced ear edema had reduced symptoms with oregano extract injections (Chuang et al., 2018). The same study found that the human THP-1 monocytes cell line treated with oregano extract had decreased pro-inflammatory cytokines IL-8, IL-1 $\beta$, and TNF- $\alpha$ as well as reduced inhibition of NF- $\kappa \mathrm{B}$ translocation (Chuang et al., 2018). Furthermore, the human keratinocyte cell line NCTC 2544 treated with oregano had reduced pro-inflammatory mediators inter-cellular adhesion molecule-1, iNOS, and COX-2 (Avola et al., 2020). Murine RAW264.7 cells treated with oregano essential oil displayed inhibition of proinflammatory cytokines IL- $1 \beta$, IL- 6 , and TNF- $\alpha$ as well as reduction of LPS-induced MAPK, protein kinase B, and NF- $\kappa B$ activation (Cheng et al., 2018). In short, oregano possesses promising anti-inflammatory properties, however, caution should be exercised in dosing as high levels lead to proinflammatory responses. Clinical trials are needed to confirm effects.

\section{Rooibos (Aspalathus linearis)}

\subsection{Introduction and source}

Rooibos is an herb native to the mountainous area in the Western Cape of South Africa. Rooibos is available unfermented as green rooibos or fermented as rooibos. The primary use of rooibos is making teas. These teas have the names rooibos, bush tea, red tea, and redbush tea. Plants, such as rooibos, have been used for centuries in Africa as herbal medicine, and the recent popularity of these products has grown internationally. Rooibos gained much attention as an herbal medicine for its proposed anti-inflammatory and 
immune-enhancing effects. The popularity of the plant has led to threats to other local species, and climate change threatens rooibos farming.

\subsection{Bioactive compounds}

The main bioactive compound of rooibos is aspalathin, a $\mathrm{C}-\mathrm{C}$ linked dihydrochalcone glucoside (Hoosen, 2019). Rooibos contains many other flavonoids, such as aspalalinin, nothofagin, isoorientin, isovitexin, hemiphlorin, quercetin, hyperoside, isoquercetrin, and rutinamougst (Hoosen, 2019). Additionally, rooibos contains nonflavonoids such as lignans and phenolic acids (Hoosen, 2019). On the other hand, rooibos contains no caffeine and has low tannin levels (Nel et al., 2007).

\subsection{Immune-enhancing properties}

There has been no reported toxicity of rooibos tea in humans (Hoosen and Pool, 2019). Some studies have shown that rooibos has immune-modulating properties (McKay and Blumberg, 2007) while others find that it does not (Hendricks and Pool, 2010; Hoosen and Pool, 2019). To determine the immune-enhancing effects of rooibos, Hendricks and Pool (2010) measured IL-10 secretion in rooibos extract treated LPS-stimulated and unstimulated leukocytes. IL-10 secretion was used as a biomarker for fluid immunity. They found that the unstimulated leukocytes had increased IL-10 synthesis (immune suppressing), while the stimulated leukocytes had decreased IL-10 synthesis (immune enhancing) (Hendricks and Pool, 2010). These results are contrary to the expectation of rooibos enhancing the immune system as a preventative measure. Another study by Hendricks and Pool (2010) similarly concluded that rooibos does not affect nitric oxide or IL-6 synthesis, which are inflammatory markers, in LPS-stimulated macrophages. Also, IL-6 was increased in unstimulated macrophages, which is a proinflammatory response (Hoosen and Pool 2019). They suggested that increased IL-6 may stimulate hepatocytes, thus enhancing immune response while increasing inflammation, but this remains unconfirmed. The difference in results from other studies could be because other studies used ethanolic extracts of rooibos. The research on rooibos is limited and more studies should be conducted to further determine the herb's effects.

\subsection{Anti-inflammatory properties}

Like the immune-enhancing function, there are some inconsistent results for the effect of rooibos in inflammation. Most studies report anti-inflammatory properties. One study by Baba et al. (2009) found increased serum superoxide dismutase and decreased 8-hydroxy-2'-deoxyguanosine concentration in urine, an antioxidant and a marker of DNA damage, respectively (Baba et al., 2009). They believe that the antioxidant activity is responsible for preventing inflammation in vivo (Baba et al., 2009). Another study by Mueller et al. (2010) found a reduction in IL-6 and IL-10 in rooibos incubated stimulated macrophages, both of which lead to less inflammation. Green rooibos extract supplementation for six weeks was similarly found to lower inflammation in preconditioned cardiovascular disease-compromised rat hearts (Smit et al., 2020). Additionally, rooibos extracts have been found to have anti-inflammatory effects on hepatic inflammation caused by diesel exhaust particles through intervention in the TNF- $\alpha / \mathrm{IkKB} / \mathrm{IkB} /$ NFkB signalling pathway (Lawal and Elekofehinti, 2019).

\subsection{Pro-inflammatory properties}

The pro-inflammatory properties of rooibos have been reported in some studies. A study measuring nitric oxide production in human endothelial cells found a dose-dependent nitric oxide concentration increase while, in healthy volunteers, there was no effect on nitric oxide concentration (Persson et al., 2006). These results indicate that there may be a difference in the effects or active components of rooibos in vitro and in vivo studies. In addition, as previously mentioned, IL-6 was increased in unstimulated macrophages (Hoosen and Pool, 2019). Another reason for the differences in the results may be the variation in dosages used to study rooibos (Hoosen, 2019). Finally, the amounts of phytochemicals in the plant can differ depending on many factors, such as ground nutrients and time of harvest.

Overall, to fully understand the effects of rooibos as an immune enhancer and as an anti-inflammatory agent, more studies need to be conducted. These studies should consider the concentration of rooibos in its most common form of consumption, tea. With this concentration, in vitro studies should be standardized to keep results consistent. Another aspect to consider is the difference in phytochemicals expressed in ethanol extracted rooibos, frequently used for in vitro studies. Additionally, since results differ between in vitro and in vivo studies, there should be caution in extrapolating results from in vitro studies.

\section{Rosemary/sage (Salvia rosmarinus/officinalis)}

\subsection{Introduction and source}

Rosemary is the common name of the Salvia rosmarinus herb, scientifically known as Rosmarinus officinalis until 2017. Rosemary is part of the mint family Lamiaceae and is closely related to common sage (Salvia officinalis), or more simply known as sage, both belonging to the sage family. Other plants which do not belong to the Salvia genus share the name sage, most of which belong to the Artemesia genus. Rosemary and sage are native to the Mediterranean region but are now grown worldwide.

\subsection{Current uses}

Rosemary is a versatile herb in cuisine, especially in traditional Mediterranean cuisine. Described to have a woodsy and peppery taste, rosemary is used to flavour soups, bread, meats, and stew, among other dishes. Additionally, rosemary finds use as an herbal tea. Aside from cuisine, rosemary is used for its fragrance in perfumes and cleaning products. Furthermore, since ancient times, rosemary has been believed to improve memory and today is used in commemorating wars and the deceased. Finally, rosemary has long been used in traditional medicine to improve memory, as an antidepressant, anti-inflammatory agent, and more (Ribeiro-Santos et al., 2015).

Sage also finds use in many cuisines, such as Italian, Balkan, middle eastern, British, and American. Additionally, sage has been used in traditional medicine to treat mild indigestion, excessive sweating, and inflammation (Ghorbani and Esmaeilizadeh, 2017).

\subsection{Bioactive compounds}

The main bioactive compounds of rosemary are carnosic acid, carnosol, and rosmarinic acid (Kontogianni et al., 2013; Ali et al., 
2019). Other bioactive compounds in rosemary include ursolic acid and betulinic acid, which are attributed to cytotoxic activity (Kontogianni et al., 2013), and 1,8-cineole, $\alpha$-pinene, and camphor, which are the major volatile compounds (Ali et al., 2019). Of these, carnosic acid is the most investigated compound, followed by carnosol, rosmarinic acid, and ursolic acid (Andrade et al., 2018). Rosemary and sage have been shown to have a similar profile of phenolic compounds (Shahidi and Ambigaipalan, 2015; Kontogianni et al., 2013).

\subsection{Immune-enhancing properties}

Rosemary has shown promising immune-enhancing and immunomodulatory capabilities in animal models. With mice, Yousef et al. (2020) found that rosemary extract treatment modulates allergen-mediated mast cell activation. They demonstrated that mast cells treatment with up to $25 \mu \mathrm{g} / \mathrm{mL}$ rosemary extract inhibited mast cell degranulation (release of mediators such as cytokines) by $15 \%$ compared to the control. Additionally, rosemary extract treatment significantly impaired MAPK and NF- $\kappa B$ pathways activation (Yousef et al., 2020), both of which are involved with inflammation (Moens et al., 2013; Liu et al., 2017). Al Sheyab et al. (2012) found that mice treated with 10,50 , and $100 \mathrm{mg}$ rosemary extract per kg of body weight for 15 days had increased levels of IgM and IgG against membrane proteins of sheep erythrocytes compared to a control group. Similarly, broiler chickens given sage extract had increased levels of IgM and IgG against sheep erythrocytes in a dose-dependent manner (Rasouli et al., 2020).

Recent studies have investigated the usage of rosemary supplementation in fish feed. Yousefi et al. (2019) have reported that common carp (Cyprinus carpio) fed diets containing 2 and 3\% rosemary leaf powder for 65 days had increased leukocytes and total plasma Ig levels as compared to a control group. Similarly, Nile Tilapia (Oreochromis niloticus) fed diets containing up to 10 $\mathrm{g}$ of rosemary leaf powder per $\mathrm{kg}$ of feed for 60 days results in improved immune function (Naiel et al., 2020). In particular, the fish had increased complement activity as measured with ACH50, decreased ROS production as measured with nitroblue tetrazolium, and increased lysozyme activity (Naiel et al., 2020).

In a study that examined the effects of rosemary extract supplementation in goat kid feed, Shokrollahi et al. (2015) found significant changes in globulin and leukocyte levels. Interestingly, the highest globulin levels were obtained with $400 \mathrm{mg}$ of rosemary extract per kg of body weight, while leukocyte levels were highest with $200 \mathrm{mg} / \mathrm{kg}$ supplementation (Shokrollahi et al., 2015). Additionally, they found no significant change in lymphocytes or neutrophils (Shokrollahi et al., 2015). This suggests that the increase in leukocytes is monocytes, basophils, or eosinophils, which pertain to the innate immune system. Consistent with this suggestion, Rostami et al. (2018) found no change in specific antibody titers in rosemary-supplemented broiler chickens vaccinated with avian influenza-, Newcastle disease-, and infectious bronchitis- inactivated virus. However, they did find modulation of humoral immunity (Rostami et al., 2018).

Further research should be conducted to determine the role of rosemary supplementation in immunity. There are conflicting reports of rosemary impacting adaptive immunity, however, this may be due to differences in models or supplementation details. It is important to note that poultry and fish models are not optimal for determining health effects in humans but can act as an initial point of research to be confirmed with preclinical and clinical trials. Nevertheless, rosemary appears to have a role in modulating the innate immune system and clinical studies would prove useful in determining practical applications of rosemary. Additionally, more research should be conducted using sage as it may have different physiological effects than rosemary despite sharing a similar phenolic profile.

\subsection{Anti-inflammatory properties}

The anti-inflammatory properties of rosemary have been examined with animal models. With the decrease in mast cell degranulation mentioned earlier, there was also a decrease in the production and release of pro-inflammatory mediators, such as IL-6, IL-13, TNF- $\alpha$, CCL1, and CCL3, in the mice (Yousef et al., 2020). Similarly, Rahbardar et al. (2017) found that rats supplemented with $400 \mathrm{mg}$ of rosemary extract per $\mathrm{kg}$ of body weight for 14 days after chronic injury of the sciatic nerve resulted in a significant decrease in spinal cord levels of pro-inflammatory markers COX-2, prostaglandin E2, and NO. Rosemary extract has also been found to be effective in reducing adjuvant-induced arthritis rat paw edema (swelling caused by inflammation) (de Almeida Gonçalves et al., 2018). The rosemary extract treatment was at $150 \mathrm{mg} / \mathrm{kg}$ body weight from 5 days before adjuvant treatment until 18 days after (de Almeida Gonçalves et al., 2018). Reduced rat paw edema has also been found using rosemary essential oil. A single dose of 300 $\mathrm{mg}$ of rosemary essential oil per $\mathrm{kg}$ of body weight was administered 30 minutes before carrageenan injection (to induce edema), resulting in a $50 \%$ reduction in the maximum peak of the edema (Borges et al., 2018). Finally, an in vitro study with RAW 264.7 murine macrophage cells found that 50 and $100 \mu \mathrm{g} / \mathrm{mL}$ concentrations of rosemary extract significantly increased anti-inflammatory activity, as measured by reduced nitrite and prostaglandin E2 levels (Karadağ et al., 2019).

There is limited recent research $(<5$ years $)$ regarding the antiinflammatory properties of rosemary despite the herb having consistent promising results (Huang et al., 1994; Chan et al., 1995; Peng et al., 2007). Future research should be conducted to further knowledge on the anti-inflammatory properties of rosemary for potential clinical use.

Sage treatment has recently been shown effective at modulating inflammatory cytokines. In diet-induced obese mice, Khedher et al. (2018) found that five-week sage extract treatment at 100 $\mathrm{mg} / \mathrm{kg}$ of body weight resulted in increased plasma levels of antiinflammatory cytokines IL-2, IL-4, and IL-10 while there was a decrease in pro-inflammatory cytokines IL-12, and TNF- $\alpha$. Topical treatment using sage essential oil of infected mice was also shown to decrease levels of pro-inflammatory cytokines IL-6, IL-1 $\beta$, and TNF- $\alpha$ (Farahpour et al., 2020). Additionally, these three pro-inflammatory cytokines were reduced in vitro, with sage extract-treated RAW 264.7 murine macrophages (Brindisi et al., 2021) and human subcutaneous mature adipocytes (Russo et al., 2021). These results highlight the potential usage of sage as an anti-inflammatory agent, with consistent results across different models, one of which is a human cell line. Nevertheless, clinical trials are needed to confirm results.

\section{Saffron (Crocus sativus)}

\subsection{Introduction and source}

Saffron is a spice that is derived from the Crocus sativus flower, commonly known as saffron crocus or autumn crocus. Saffron is produced from the crimson stigma and styles of the flower, known 
as threads. Each flower possesses just three threads which must be carefully hand-picked due to their fragility. Consequently, saffron is the most expensive spice by weight, sometimes costing over 10 thousand USD/kg (Business Insider, 2021). Its high price contributes to its colloquial title of "red gold". Iran is commonly believed to be a place of origin of saffron. Today, saffron is produced in a belt across Eurasia, from Spain on the west to Jammu and Kashmir on the East. However, saffron can grow in any temperate climate, with some production in North America. Nevertheless, Iran is the largest producer of saffron, producing over $90 \%$ of the global supply (Business Insider, 2021).

\subsection{Current uses}

Saffron's main use is in cuisine across many different cultures. For example, saffron is used in Iranian khoresh, Italian Milanese risotto, Spanish paella, and French bouillabaisse. Saffron is described to have a hay-like and sweet taste. Additionally, saffron adds vibrant yellow-orange colour to foods. This colour allows saffron to find use as a fabric dye, while saffron's bittersweet scent is harnessed in perfumes. Saffron is also used for Hindu, Buddhist, and Jewish religious purposes as well as for Islamic traditions. Finally, saffron has a long history in traditional medicine, used to treat ailments in inflammation, cardiovascular system, central nervous system, eye disease, gastrointestinal system, genitourinary system, infectious disease, respiratory system, skin disease, and more (Hosseinzadeh and Nassiri-Asl, 2013).

\subsection{Bioactive compounds}

The main bioactive compounds of saffron are crocin, picrocrocin, and safranal (Khorasany and Hosseinzadeh, 2016) which are responsible for colour, taste, and aroma, respectively (Garavand et al., 2019). Another compound of note is crocetin, which forms the central core of crocin. Additionally, saffron contains an estimated 150 compounds (Bathaie and Mousavi, 2010), including small amounts of other pigments like anthocyanin, $\alpha$-carotene, $\beta$-carotene, and zeaxanthin (Melnyk et al., 2010).

\subsection{Immune-enhancing properties}

The immune-enhancing properties of saffron and its compounds have been examined. In a study using a mouse model of glaucoma, Fernández-Albarral et al. (2019) treated laser-induced ocular hypertension mice with $60 \mathrm{mg} / \mathrm{kg}$ of bodyweight of saffron extract for 15 days before laser induction and up to 7 days afterward. They found that saffron treatment decreased microglia (nervous system macrophage) activation, resulting in a neuroprotective effect due to reduced production of neurotoxic molecules, such as NO, TNF- $\alpha$, IL-1 $\beta$, and ROS (Fernández-Albarral et al., 2019). Using human peripheral blood mononuclear cells, Feyzi et al. (2016) found that safranal modulated the Th1/Th2 balance after phytohemagglutinin stimulation at concentrations of $0.1,0.5$, and 1.0 $\mathrm{mM}$. Crocetin has been similarly shown to modulate the immune system. In ovalbumin-induced asthma mice, Ding et al. (2015) found that $100 \mu \mathrm{mol} / \mathrm{L}$ daily intranasal administration of crocetin increased immunoregulatory protein Foxp3 and protein 8-like 2 levels in Treg cells. Furthermore, crocin has also been found to be immune enhancing. In ovalbumin-challenged mice treated with $100 \mathrm{mg}$ of crocin per $\mathrm{kg}$ of bodyweight, Xiong et al. (2015) found the bronchoalveolar lavage fluid to have reduced mast-cell specific tryptase and eosinophil peroxidase. Additionally, they found reduced expression of p-JNP, p-ERK, and p-p38, which are involved in the MAPK pathway, reducing airway inflammation (Xiong et al., 2015). Another study found that osteoarthritis patients given a daily treatment of $15 \mathrm{mg}$ crocin for four months had a reduction of pro-inflammatory Th17 cells and an increase in regulator T cells as compared to the starting point (Poursamimi et al., 2020). These studies highlight various immunological effects of saffron and its compounds. However, many more discovered effects are not listed, such as inhibited leukocyte infiltration, decreased serum IgM concentration, improved thrombosis, and beyond (Boskabady et al., 2020).

The crocus sativus petal may also exhibit beneficial immunological effects. In a study where rats were given petal extract daily, it was found that using a concentration of $75 \mathrm{mg} / \mathrm{kg}$ of body weight increased IgG expression as compared to other concentrations (Hosseini et al., 2018). As saffron quantity is inherently limited and often expensive, using the petals for similar effects would greatly increase the applicability of the plant in treatments.

\subsection{Anti-inflammatory properties}

There are conflicting results regarding the anti-inflammatory properties of saffron. Many studies have found saffron to have antiinflammatory properties, while others have found no effect. Generally, anti-inflammatory properties of saffron have been found in animal or in vitro studies, while fewer effects have been observed in clinical trials.

One study that found anti-inflammatory properties of saffron used a model of rats after chronic injury of the sciatic nerve (Amin et al., 2014). Amin et al. (2014) found that daily administration of $200 \mathrm{mg} / \mathrm{kg}$ of bodyweight saffron extracts reduced the concentration of pro-inflammatory IL- $1 \beta$, IL-6, and TNF- $\alpha$ cytokines. A study by Faridi et al. (2019) found that streptozocin-induced diabetic mice treated daily with $500 \mathrm{mg} / \mathrm{kg}$ of body weight for 3 weeks had decreased production of pro-inflammatory IL-17 cytokines and NO as well as increased levels of anti-inflammatory IL-10 and TGF- $\beta$ cytokines in the pancreatic cells. An in vitro study using RAW 264.7 cells found that crocin has inhibitory activity on COX1 and COX-2, with inhibition of COX-2 being greater than the NSAID indomethacin (Xu et al., 2009).

While many clinical trials show no anti-inflammatory properties, some have shown anti-inflammatory properties. One such study found that asthma patients given $100 \mathrm{mg}$ daily supplementation of saffron for 8 weeks had reduced levels of anti-heat-shock protein 70 (risk factor and related to severity of asthma) and CRP (a general measure of inflammation) (Hosseini et al., 2018). Another study found that type 2 diabetes patients given an identical treatment had decreased serum TNF- $\alpha$ levels as well as downregulated TNF- $\alpha$ and IL-6 mRNA levels as compared to a placebo group (Mobasseri et al., 2020).

Contrarily, some studies have shown no changes in inflammatory markers. Ege et al. (2020) found that human osteosarcoma cells treated with saffron extracts at various concentrations had no significant alteration to the expression of IL-6 and IL-8. A metaanalysis of eight clinical trials similarly concluded that saffron supplementation did not affect inflammatory cytokines (Asbaghi et al., 2021). Hamidi et al. (2020) treated rheumatoid arthritis patients with $100 \mathrm{mg}$ of saffron daily for 12 weeks and found no significant difference in CRP, IFN- $\gamma$, TNF- $\alpha$, and malondialdehyde between the treated and non-treated groups. However, beneficial outcomes were observed, such as a lower number of tender and swollen joints, lower pain intensity, and a lower disease activity 
score (Hamidi et al., 2020).

While it is unclear if saffron positively affects inflammatory markers, this should not be reason to dismiss the use of saffron in treatments as it may exert positive effects through other mechanisms. Consequently, further research should be conducted to determine other mechanisms of saffron.

\subsection{Cytotoxicity}

Saffron has exhibited some cytotoxic properties. High doses of saffron can induce organ toxicity, embryonic toxicity, and may lead to an increased miscarriage rate in pregnant females (Mehri et al., 2020). However, doses used in clinical and experimental studies are not high enough to result in significant toxicity (Mehri et al., 2020). Therefore, caution should be exercised in the consumption of saffron, particularly at high doses.

\section{South African geranium (Pelargonium sidoides)}

\subsection{Introduction and source}

Pelargonium sidoides is a South African herb used in traditional medicine native to the Eastern Cape in South Africa. Its names include South African geranium, black geranium, and Cape pelargonium. EPs 7630 is an extract of $P$. sidoides and is marketed under many different names, including Kaloba, Umckaloabo, Umckalor, Umcka, Umquan, and Renikan, differing depending on the region. For example, in Canada, EPs 7630 is sold by Nature's Way under the brand name Umcka. Extracts of $P$. sidoides were sold exclusively by Dr. Willmar Schwabe GmbH and Co. KG (Schwabe Group) and its subsidiaries until a European Patent Office ruling resulted in withdrawal from their patents in 2010 (Herrmann and Thöle, 2010). Typically, the roots of the plant are used to produce the extracts, although, there is evidence supporting the use of the shoots and leaves as a substitute, with both having comparable properties to the roots (Lewu et al., 2006).

\subsection{Bioactive compounds}

Isolated active compounds of $P$. sidoides include scopoletin, umckalin, 5,6,7-trimethoxycoumarin, 6,8-dihydroxy-5,7-dimethoxycoumarin, $(+)$-catechin, gallic acid, and its methyl ester (Kayser and Kolodziej, 1997). The main bioactive components in P. sidoides are believed to be gallic acid and its methyl ester (Kayser et al., 2001).

\subsection{Immune-enhancing properties}

The immune-enhancing capabilities of $P$. sidoides have been studied extensively, although much of the research is affiliated with the Schwabe Group. The following research has no declaration of affiliation with the Schwabe group. All the previously mentioned active compounds have shown antimicrobial activities, except for (+)-catechin (Kayser and Kolodziej, 1997). Some fungi inhibited include Asperillus niger, Fusarium oxyporum, and Phizopus stolonifer (Mativandlela et al., 2006). The antibacterial activity has been associated with macrophage activation determined through TNF- $\alpha$ and inorganic nitric oxide in macrophage cultures (Kayser et al., 2001). Additionally, P. sidoides has been used in a tablet with Echinacea purpurae increasing IgG and IFN- $\gamma$, as well as certain cytokine gene expressions, modulating immune response (Seckin et al., 2018).

One study showed that EPs 7630 had antibacterial properties, increased TNF and interferon activities, and increased the synthesis of IFN- $\beta$, an interferon used to treat multiple sclerosis (Kolodziej et al., 2003). Another study showed that EPs 7630 was effective in combating various respiratory viruses, including seasonal influenza A virus strains, respiratory syncytial virus, human coronavirus, parainfluenza virus, and coxsackievirus (Michaelis et al., 2011). In addition, EPs 7630 has been shown to be protective against acute bronchitis, as well as reducing symptom severity and disease duration (Bao et al., 2015; Kamin et al., 2010). Pre-treatment with $P$. sidoides extracts has been shown to counteract LPScaused physiological issues and inhibit herpesviruses (Nöldner and Schötz, 2007; Schnitzler et al., 2008). Furthermore, EPs 7630 has been shown to increase neutrophil, Th17, and Th22 cells through the MAPK pathway (Witte et al., 2015).

\subsection{Anti-inflammatory properties}

The anti-inflammatory capabilities of $P$. sidoides have been studied without obvious affiliation with the Schwabe Group. A study found that $P$. sidoides extract and proanthocyanidin, from the extract, decreased various LPS-induced pro-inflammatory molecules from fibroblasts, leukocytes, and macrophages (Jekabsone et al., 2019). Another study found that $P$. sidoides extract could modulate chemokines, affecting inflammatory response and activating immune response to the site of inflammation (Perić et al., 2020). $P$. sidoides has also been used in conjunction with Coptis chinensis, a traditional Chinese medicine, to show anti-inflammatory, through the decrease of pro-inflammatory compounds, and antiallergic activities (Min et al., 2020; Park et al., 2018). Nevertheless, a systematic review found low quality of evidence relating Pelargonium sidoides extracts to acute bronchitis, acute sinusitis, and the common cold and no reliable data on other acute respiratory tract infections (Timmer et al., 2013).

Caution should be exercised in interpreting results from studies regarding $P$. sidoides extracts due to financial interests and doubts on the quality of evidence. P. sidoides may have beneficial properties, but more unbiased studies with high-quality evidence are needed to make conclusions.

\section{Turmeric (Curcuma longa)}

\subsection{Introduction and source}

Turmeric (Curcuma longa) is a plant whose rhizome (subterranean plant stem) is used as a spice. Turmeric is native to South and Southeast Asia where it continues to thrive today in warm climates and with ample rainfall.

\subsection{Current uses}

Described to have an earthy and bitter taste, turmeric is an ingredient in many Asian and Middle Eastern dishes. It is to flavour a variety of products such as curries, mustards, butters, and cheeses. Additionally, turmeric is used in beverages like milk and teas. Turmeric adds a bright yellow colour to foods. This dyeing property is also used to bring a warm gold colour to fabrics. Furthermore, turmeric can be used as a chemical indicator for solutions between $\mathrm{pH} 7.4$ and 
9.2, turning from yellow in acidic and neural solutions to brown in alkaline media. Turmeric has long been used in religious ceremonies and traditional medicine. In Ayurvedic, turmeric is used to treat respiratory conditions, liver disorders, anorexia, rheumatism, diabetic wounds, runny nose, cough, and sinusitis (Prasad and Aggarwal, 2011). In traditional Chinese medicine, turmeric is used to treat diseases associated with abdominal pain (Prasad and Aggarwal, 2011).

\subsection{Bioactive compounds}

Curcumin is the main bioactive compound in turmeric and is believed to be responsible for most of turmeric's physiological properties (Sahne et al., 2017). Accordingly, most of the research concerning turmeric focuses on curcumin. Turmeric contains other compounds, including peptides (turmerin), essential oils (d-aphellandrene, cineol, d-borneol, d-sabinene, and valeric acid), curcuminioids (demethoxycurcumin, cyclocurcumin, and bisdemethoxycurcumin), and volatile components (turmerone, atlantone, and zingiberene) (Mollazadeh et al., 2019).

\subsection{Immune-enhancing properties}

Curcumin has been studied extensively for its immune-modulating properties. Several recent reviews have highlighted curcumin's potential as a therapeutic. A review by Kahkhaie et al. (2019) determined that curcumin suppresses inflammatory cascades, resulting in inhibition of macrophage, dendritic cell, and T cell subset activation, maturation, and cytokine production. Thus, the inflammatory response was lowered through lower immune cell involvement. Another review by Momtazi-Borojeni et al. (2018) looking at systemic lupus erythematosus, determined that curcumin inhibited dendritic cell maturation and function through the reduced expression of major histocompatibility complex II, co-stimulatory molecules, and pro-inflammatory cytokines. Additionally, they determined that curcumin prevented contact between dendritic cells and $\mathrm{T}$ cells in the lymph node, lessening the immune response (MomtaziBorojeni et al., 2018). Furthermore, they determined that curcumin could increase the number and function of Treg cells, ameliorating the Th17/Treg ratio in systemic lupus erythematosus patients.

On the contrary, curcumin has been shown to inhibit Treg cell activities in cancer models (Shafabakhsh et al., 2019). This preclinical work showed that curcumin inhibited Treg cell activities through prevention of cell-to-cell interactions, reduction of suppressive cytokine secretion, and reduction of IL-2 capacity. It is important to note that IL-2 is responsible for limiting T cell responses (Nelson, 2004). Thus, curcumin was effective in augmenting the immune response in cancer models, while decreasing immune response in lupus erythematosus, demonstrating curcumin's role as an immunomodulator.

Curcumin has been described to have additional immunomodulatory mechanisms in cancer development. T cells, B cells, macrophages, natural killer cells, and dendritic cells have all been shown to be impacted by curcumin (Bose et al., 2015). Additionally, anti-tumor responses have been found using curcumin through a variety of mechanisms. These include increased CD4+ and CD8+ $\mathrm{T}$ cells, increased Th1 type cytokines, reduction of Treg cells, and reduction of T cell apoptosis (Bose et al., 2015). Thus, curcumin has been found to increase anti-tumor immunity. Other immunemediated diseases that curcumin has been shown to remedy include rheumatoid arthritis, immune-mediated liver injury, multiple sclerosis, Sjogren's syndrome, type 1 diabetes, chronic serum sickness, allergic inflammatory disease, and graft-versus-host-disease
(Abdollahi et al., 2018). Therefore, curcumin has the potential as an immune modulator for use in a wide variety of diseases.

\subsection{Anti-inflammatory properties}

The anti-inflammatory properties of curcumin have been extensively studied. There is an abundance of many recent reviews which summarize the current research. A review by Mollazadeh et al. (2019) considered the effect of curcumin on the anti-inflammatory cytokine IL-10. They found that curcumin increased the expression and production of IL-10 in many different tissues, taking results from 36 studies. In parallel, pro-inflammatory cytokines (IL-1 $\beta$, IL-4, IL-6, IL-10, IL-12, IL-18, TNF- $\alpha$ ) and chemokines (macrophage inflammatory protein-1 alpha and monocyte chemoattractant protein-1) were found to be decreased by curcumin, as discussed in the literature (Ghosh, Banerjee, and Sil, 2015; Memarzia et al., 2021). Interestingly, Memarzia et al. (2021) highlighted curcumin's role at both increasing and decreasing IL-10 levels. It appears as though IL-10 has contradicting roles as an anti- and pro-inflammatory cytokine, with some clinical trials finding a proinflammatory effect (Mühl, 2013). Additionally, curcumin was found to suppress the inflammatory mediators, 5-lipoxygenase, COX-2, and iNOS (Mirzaei et al., 2017).

Curcumin functions through several anti-inflammatory pathways. These include the Keap1-Nrf2, AKT and ERK, MAPK, STAT, AP-1, and NF- $\kappa$ B pathways (He et al., 2015; Memarzia et al., 2021). Of these, NF-kB has been most discussed. In this connection, interleukins were found to decrease through NF- $\kappa B$ (He et al., 2015) which was in turn inhibited through inhibition of toll-like receptor-4 and MyD88 (Memarzia et al., 2021). Furthermore, as an NF- $\mathrm{kB}$ suppressor, curcumin was found to prevent inflammationinduced apoptosis of chondrocytes in osteoarthritis (Chin, 2016).

In addition to osteoarthritis, curcumin was shown to remedy inflammatory diseases including knee osteoarthritis, irritable bowel syndrome, intracerebral hemorrhage, chronic lung disease, periodontal disease, obesity, obesity-induced inflammation, acute pancreatitis, experimental autoimmune encephalomyelitis, atherosclerosis, heart failure, type 2 diabetes, and dementia (Abdollahi et al., 2018; Shimizu et al., 2019). These findings are primarily based on animal studies. However, several clinical trials support the use of curcumin to treat inflammatory diseases such as rheumatoid arthritis, osteoarthritis, type 2 diabetes, and metabolic diseases (Salehi et al., 2019).

Some clinical trials have shown inconsistent results of curcumin as an anti-inflammatory agent. Saraf-Bank et al. (2019) found that curcumin supplementation had a significant effect on CRP and IL-6 in obesity. Supporting these findings, Jazayeri-Tehrani et al. (2019) found that curcumin supplementation significantly decreased CRP, IL-6, and TNF- $\alpha$ in obesity. However, in a clinical trial of osteoarthritis, curcumin did not significantly change IL-6, TNF- $\alpha$, or IL- $1 \beta$ but patient's symptoms were improved (Gupte et al., 2019). Another clinical trial found that curcumin along with lifestyle modification decreased NF- $\mathrm{BB}$ in non-alcoholic fatty liver disease compared to baseline, however, there was no benefit compared to lifestyle modification alone (Saadati et al., 2019).

Recent reviews and meta-analyses of clinical trials similarly report positive or neutral effects of curcumin on inflammation. Yang et al. (2019) examined 16 clinical trials and found significant improvement in 10 of the studies ( 8 on type 2 diabetes and 2 on ulcerative colitis), while the remaining 6 studies had inconclusive results ( 1 on ulcerative colitis, 1 on lupus nephritis, 2 on rheumatoid arthritis, and 2 on multiple sclerosis). A systematic review that included 11 clinical trials of curcumin supplementation on post- 
exercise inflammation found reduced levels of pro-inflammatory cytokines TNF- $\alpha$, IL-6, and IL-8 with curcumin supplementation (Fernández-Lázaro et al., 2020). Several meta-analyses have also been conducted on clinical trial data. A meta-analysis of 15 clinical trials found that curcumin-containing supplements significantly decreased levels of pro-inflammatory CRP and IL-6, however, there was no significant change in TNF- $\alpha$ levels (Tabrizi et al., 2019). Two other meta-analyses, each including 3 clinical trials, found that curcumin had no significant effects on irritable bowel syndrome ( $\mathrm{Ng}$ et al., 2018) and ulcerative colitis (Grammatikopoulou et al., 2018). There are inconsistent results on the effectiveness of curcumin as an anti-inflammatory agent in clinical trials. A possible limitation of curcumin is its limited bioavailability, but it appears that curcumin is more effective at treating some inflammatory diseases than others. More clinical trials should be conducted using curcumin as it has shown strong potential in treating inflammation with very few side effects.

\subsection{Bioavailability}

Curcumin is reported to have low bioavailability due to its low absorption and rapid systemic elimination. To circumvent low bioavailability, several techniques have been implemented to increase bioavailability. These include nanoemulsion, liposomal encapsulation, phospholipid curcumin complexes, and milk exosomes (Kunnumakkara et al., 2019; Mirzaei et al., 2017). Additionally, formulations such as Teracurmin $\AA$ and Meriva ${ }^{\circledR}$ have been effective at low doses (Kunnumakkara et al., 2019). Another promising option is the use of adjuvants or other natural products, such as piperine, to increase the bioavailability of curcumin (Mirzaei et al., 2017). Thus, effective methods of administration are essential to elicit the beneficial properties of curcumin.

\section{Conclusion}

There is much interest in finding natural products that can act as immune-enhancers and anti-inflammatory agents to promote health. Spices and herbs that are used in traditional medicine are a great starting point to find such products, as they have been used for proposed medicinal properties for centuries. Current research suggests that a variety of spices and herbs may function as immune-enhancers or modulators and anti-inflammatory agents. However, spices and herbs themselves may pose some risks of use themselves which should be considered before administration.

Future work should focus on confirming the applicability of results in humans through clinical trials. Additionally, it may be useful to further study the effects of combining several spices and herbs, as combined consumption is common for culinary spices and herbs. Piperine from black pepper is a great example of a spice that may benefit from combined consumption as it has established its ability as a bioenhancer. Furthermore, the development of more effective techniques to isolate bioactive compounds or to increase bioactive compounds in final products will be useful in creating more potent effects, when desirable.

\section{References}

Abbas, W.T., Abumourad, I.M., Mohamed, L.A., Abbas, H.H., Authman, M. Soliman, W.S., and Elgendy, M.Y. (2019). The Role of the Dietary Supplementation of Fenugreek Seeds in Growth and Immunity in Nile Tilapia with or without Cadmium Contamination. Jordan J. Biol. Sci.
12(5): 649-656.

Abdelnour, S., Alagawany, M., El-Hack, A., Mohamed, E., Sheiha, A.M., Saadeldin, I.M., and Swelum, A.A. (2018). Growth, carcass traits, blood hematology, serum metabolites, immunity, and oxidative indices of growing rabbits fed diets supplemented with red or black pepper oils. Animals (Basel) 8(10): 168.

Abdelrahman, M.T., Maina, E.N., and Elshemy, H.A. (2018). Clove (Syzygium aromaticum) and honey extracts significantly reduce inflammatory cytokines and liver function enzymes in experimental rats fed on carbon tetrachloride (CCl4). J. Radiat. Res. Appl. Sci. 11(4): 416-422.

Abdi, T., Mahmoudabady, M., Marzouni, H.Z., Niazmand, S., and Khazaei, M. (2021). Ginger (Zingiber Officinale Roscoe) Extract Protects the Heart Against Inflammation and Fibrosis in Diabetic Rats. Can. J. Diabetes. 45(3): 220-227.

Abdollahi, E., Momtazi, A.A., Johnston, T.P., and Sahebkar, A. (2018). Therapeutic effects of curcumin in inflammatory and immune-mediated diseases: A nature-made jack-of-all-trades? J. Cell. Physiol. 233(2): 830-848.

Aboutaleb, N., Jamali, H., Abolhasani, M., and Toroudi, H.P. (2019). Lavender oil (Lavandula angustifolia) attenuates renal ischemia/reperfusion injury in rats through suppression of inflammation, oxidative stress and apoptosis. Biomed. Pharmacother. 110: 9-19.

Aderem, A., and Underhill, D.M. (1999). Mechanisms of phagocytosis in macrophages. Annu. Rev. Immunol. 17(1): 593-623.

Al Hroob, A.M., Abukhalil, M.H., Alghonmeen, R.D., and Mahmoud, A.M. (2018). Ginger alleviates hyperglycemia-induced oxidative stress, inflammation and apoptosis and protects rats against diabetic nephropathy. Biomed. Pharmacother. 106: 381-389.

Al Sheyab, F.M., Abuharfeil, N., Salloum, L., Hani, R.B., and Awad, D.S. (2012). The effect of rosemary (Rosmarinus officinalis. L) plant extracts on the immune response and lipid profile in mice. J. Biol. Life Sci. 3(1): 37-58.

Alagawany, M., Abd El-Hack, M.E., Farag, M.R., Shaheen, H.M., AbdelLatif, M.A., Noreldin, A.E., and Khafaga, A.F. (2020). The applications of Origanum vulgare and its derivatives in human, ruminant and fish nutrition-a review. Ann. Anim. Sci. 20(2): 389-407.

Albrecht, C.F. (1996). Hypoxoside: A putative, non-toxic prodrug for the possible treatment of certain malignancies, HIV infections, and inflammatory conditions. Chemistry, Biological and Pharmacological Properties of African Medicinal Plants. Proceedings of the First International IOCD Symposium; Victoria Falls, Zimbabwe. University of Zimbabwe Press, pp. 303-307.

Al-Homidan, I.H., Ebeid, T.A., Al-Muzaini, A., Abou-Emera, O.K., Mostafa, M.M., and Fathi, M.M. (2020). Impact of dietary fenugreek, mung bean, and garden cress on growth performance, carcass traits, blood measurements, and immune response in broiler chickens. Livest. Sci. 242: 104318

Ali, A., Chua, B.L., and Chow, Y.H. (2019). An insight into the extraction and fractionation technologies of the essential oils and bioactive compounds in Rosmarinus officinalis L.: Past, present and future. TrAC Trends in Anal. Chem. 118: 338-351.

Ali, B.H., Blunden, G., Tanira, M.O., and Nemmar, A. (2008). Some phytochemical, pharmacological and toxicological properties of ginger (Zingiber officinale Roscoe): a review of recent research. Food Chem. Toxicol. 46(2): 409-420.

Al-Mufarrej, S.I., Fazea, E.H., Al-Baadani, H.H., and Qaid, M.M. (2019). Effects of clove powder supplementation on performance, blood biochemistry, and immune responses in broiler chickens. S. Afr. J. Anim. Sci. 49(5): 835-844.

Al-Rehaily, A.J., Al-Said, M.S., Al-Yahya, M.A., Mossa, J.S., and Rafatullah, S. (2002). Ethnopharmacological studies on allspice (Pimenta dioica) in laboratory animals. Pharm. Biol. 40(3): 200-205.

Amin, B., Abnous, K., Motamedshariaty, V., and Hosseinzadeh, H. (2014). Attenuation of oxidative stress, inflammation and apoptosis by ethanolic and aqueous extracts of Crocus sativus L. stigma after chronic constriction injury of rats. An. Acad. Bras. Ciênc. 86(4): 1821-1832.

An, S., Liu, G., Guo, X., An, Y., and Wang, R. (2019). Ginger extract enhances antioxidant ability and immunity of layers. Anim. Nutr. 5(4): 407-409.

Anderson, H.L., Brodsky, I.E., and Mangalmurti, N.S. (2018). The evolving erythrocyte: red blood cells as modulators of innate immunity. J. Immunol. 201(5): 1343-1351. 
Andrade, J.M., Faustino, C., Garcia, C., Ladeiras, D., Reis, C.P., and Rijo, P. (2018). Rosmarinus officinalis L.: an update review of its phytochemistry and biological activity. Future Sci. OA 4(4): FSO283.

Aryaeian, N., Shahram, F., Mahmoudi, M., Tavakoli, H., Yousefi, B., Arablou, T., and Karegar, S.J. (2019). The effect of ginger supplementation on some immunity and inflammation intermediate genes expression in patients with active Rheumatoid Arthritis. Gene 698: 179-185.

Asbaghi, O., Sadeghian, M., Sadeghi, O., Rigi, S., Tan, S.C., Shokri, A., and Mousavi, S.M. (2021). Effects of saffron (Crocus sativus L.) supplementation on inflammatory biomarkers: A systematic review and meta-analysis. Phytother. Res. 35(1): 20-32.

Askari, G., Aghajani, M., Salehi, M., Najafgholizadeh, A., Keshavarzpour, Z., Fadel, A., Venkatakrishnan, K., Salei-Sahlabadi, A., Hadi, A., and Pourmasoumi, M. (2020). The effects of ginger supplementation on biomarkers of inflammation and oxidative stress in adults: A systematic review and meta-analysis of randomized controlled trials. J. Herb. Med. 22: 100364

Avola, R., Granata, G., Geraci, C., Napoli, E., Graziano, A.C.E., and Cardile, V. (2020). Oregano (Origanum vulgare L.) essential oil provides antiinflammatory activity and facilitates wound healing in a human keratinocytes cell model. Food Chem. Toxicol. 144: 111586.

Baba, H., Ohtsuka, Y., Haruna, H., Lee, T., Nagata, S., Maeda, M., Yamashiro, Y., and Shimizu, T. (2009). Studies of anti-inflammatory effects of Rooibos tea in rats. Pediatr. Int. 51(5): 700-704.

Banerjee, S., Katiyar, P., Kumar, L., Kumar, V., Saini, S.S., Krishnan, V., Sircar, D., and Roy, P. (2021). Black pepper prevents anemia of inflammation by inhibiting hepcidin over-expression through BMP6-SMAD1/ IL6-STAT3 signaling pathway. Free Radic. Biol. Med. 168: 189-202.

Bao, Y., Gao, Y., Koch, E., Pan, X., Jin, Y., and Cui, X. (2015). Evaluation of pharmacodynamic activities of EPs ${ }^{\circledR} 7630$, a special extract from roots of Pelargonium sidoides, in animals models of cough, secretolytic activity and acute bronchitis. Phytomedicine 22(4): 504-509.

Barceloux, D.G. (2009). Pepper and capsaicin (Capsicum and Piper species). Dis. Mon. 55(6): 380-390.

Barnes, P.J. (2006). How corticosteroids control inflammation: quintiles prize lecture (2005). Br. J. Pharmacol. 148(3): 245-254.

Bathaie, S.Z., and Mousavi, S.Z. (2010). New applications and mechanisms of action of saffron and its important ingredients. Crit. Rev. Food Sci. Nutr. 50(8): 761-786.

Batiha, G.E.S., Alkazmi, L.M., Wasef, L.G., Beshbishy, A.M., Nadwa, E.H., and Rashwan, E.K. (2020). Syzygium aromaticum L.(Myrtaceae): Traditional uses, bioactive chemical constituents, pharmacological and toxicological activities. Biomolecules 10(2): 352

Beltrán, J.M.G., Silvera, D.G., Ruiz, C.E., Campo, V., Chupani, L., Faggio, C. and Esteban, M.Á. (2020). Effects of dietary Origanum vulgare on gilthead seabream (Sparus aurata L.) immune and antioxidant status. Fish Shellfish Immunol. 99: 452-461.

Bereswill, S., Mousavi, S., Weschka, D., Buczkowski, A., Schmidt, S., and Heimesaat, M.M. (2021). Peroral Clove Essential Oil Treatment Ameliorates Acute Campylobacteriosis-Results from a Preclinical Murine Intervention Study. Microorganisms 9(4): 735.

Berger, A. (2000). Th1 and Th2 responses: what are they? BMJ 321(7258): 424.

Bernardo, A.R., da Rocha, J.D.B., de Lima, M.E.F., Ricardo, D.D., da Silva, L.H.P., Peçanha, L.M.T., and Danelli, M.D.G.M. (2015). Modulating effect of the piperine, the main alkaloid from Piper nigrum Linn., on murine B lymphocyte function. Braz. J. Vet. Res. An. Sci. 37(3): 209-216.

Bessler, H., and Djaldetti, M. (2017). Capsaicin modulates the immune cross talk between human mononuclears and cells from two colon carcinoma lines. Nutr. Cancer. 69(1): 14-20.

Bober, Z., Stępień, A., Aebisher, D., Ożog, Ł., and Bartusik-Aebisher, D. (2018). Medicinal benefits from the use of Black pepper, Curcuma and Ginger. Eur. J. Clin. Exp. Med. 16(2): 133-145.

Borges, R.S., Lima, E.S., Keita, H., Ferreira, I.M., Fernandes, C.P., Cruz, R.A.S., Duarte, J.L., Velázquez-Moyado, J., Ortiz, B.L.S., Castro, A.N. and Ferreira, J.V. (2018). Anti-inflammatory and antialgic actions of a nanoemulsion of Rosmarinus officinalis L. essential oil and a molecular docking study of its major chemical constituents. Inflammopharmacology 26(1): 183-195.

Bose, S., Panda, A.K., Mukherjee, S., and Sa, G. (2015). Curcumin and tumor immune-editing: resurrecting the immune system. Cell Div. 10(1): 1-13.

Boskabady, M.H., Gholamnezhad, Z., Khazdair, M.R., and Tavakol-Afshari, J. (2020). Antiinflammatory and immunomodulatory effects of saffron and its derivatives. Saffron. Woodhead Publishing, pp. 405-421.

Bouic, P.J. (2001). The role of phytosterols and phytosterolins in immune modulation: a review of the past 10 years. Curr. Opin. Clin. Nutr. Metab. Care 4(6): 471-475.

Boukes, G.J., and van de Venter, M. (2012). Rooperol as an antioxidant and its role in the innate immune system: an in vitro study. J. Ethnopharmacol. 144(3): 692-699.

Brindisi, M., Bouzidi, C., Frattaruolo, L., Loizzo, M.R., Cappello, M.S., Dugay, A., Deguin, B., Lauria, G., Cappello, A.R., and Tundis, R. (2021). New Insights into the Antioxidant and Anti-Inflammatory Effects of Italian Salvia officinalis Leaf and Flower Extracts in Lipopolysaccharide and Tumor-Mediated Inflammation Models. Antioxidants 10(2): 311.

Bui, T.T., Piao, C.H., Hyeon, E., Fan, Y., Van Nguyen, T., Jung, S.Y., Choi, D.W., Lee, S.Y., Shin, H.S., Song, C.H., and Chai, O.H. (2019). The protective role of Piper nigrum fruit extract in an ovalbumin-induced allergic rhinitis by targeting of NFKBp65 and STAT3 signalings. Biomed. Pharmacother. 109: 1915-1923.

Bui, T.T., Piao, C.H., Song, C.H., Shin, H.S., Shon, D.H., and Chai, O.H. (2017). Piper nigrum extract ameliorated allergic inflammation through inhibiting Th2/Th17 responses and mast cells activation. Cell. Immunol. 322: 64-73.

Bujak, J.K., Kosmala, D., Szopa, I.M., Majchrzak, K., and Bednarczyk, P. (2019). Inflammation, Cancer and Immunity-Implication of TRPV1 Channel. Front. Oncol. 9: 1087.

Business Insider. Real saffron can cost you over $\$ 10,000$ per kilo. Here's what makes it so expensive. www.businessinsider.com/why-realsaffron-is-so-expensive-(2020)-6. Accessed 21 May 2021.

Cappelli, K., Sabino, M., Trabalza-Marinucci, M., Acuti, G., Capomaccio, S., Menghini, L., and Verini-Supplizi, A. (2021). Differential Effects of Dietary Oregano Essential Oil on the Inflammation Related Gene Expression in Peripheral Blood Mononuclear Cells From Outdoor and Indoor Reared Pigs. Front in Vet. Sci. 8: 132

Cardia, G.F.E., Silva-Filho, S.E., Silva, E.L., Uchida, N.S., Cavalcante, H.A.O., Cassarotti, L.L., Salvadego, V.E.C., Spironello, R.A., Bersani-Amado, C.A., and Cuman, R.K.N. (2018). Effect of lavender (Lavandula angustifolia) essential oil on acute inflammatory response. Evid. Based Complementary Altern. Med. 2018: 1413940.

Caterina, M.J., Schumacher, M.A., Tominaga, M., Rosen, T.A., Levine, J.D., and Julius, D. (1997). The capsaicin receptor: a heat-activated ion channel in the pain pathway. Nature 389(6653): 816-824.

Chan, M.M.Y., Ho, C.T., and Huang, H.I. (1995). Effects of three dietary phytochemicals from tea, rosemary and turmeric on inflammationinduced nitrite production. Cancer Lett. 96(1): 23-29.

Chen, M., Xiao, C., Jiang, W., Yang, W., Qin, Q., Tan, Q., Lian, B., Liang, Z., and Wei, C. (2021). Capsaicin Inhibits Proliferation and Induces Apoptosis in Breast Cancer by Down-Regulating FBI-1-Mediated NF-KB Pathway. Drug Des. Devel. Ther. 15: 125.

Chen, X., Zhang, L., Qian, C., Du, Z., Xu, P., and Xiang, Z. (2020). Chemical compositions of essential oil extracted from Lavandula angustifolia and its prevention of TPA-induced inflammation. Microchem. J. 153: 104458.

Chen, Y.H., Zou, X.N., Zheng, T.Z., Zhou, Q., Qiu, H., Chen, Y.L., He, M., Du, J., Lei, H.K., and Zhao, P. (2017). High spicy food intake and risk of cancer: a meta-analysis of case-control studies. Chin. Med. J. 130(18): 2241

Cheng, C., Zou, Y., and Peng, J. (2018). Oregano essential oil attenuates RAW264.7 cells from lipopolysaccharide-induced inflammatory response through regulating NADPH oxidase activation-driven oxidative stress. Molecules 23(8): 1857.

Cheurfa, M., Allem, R., Sadeer, N.B., and Mahomoodally, M.F. (2021). In vivo hypocholesterolemic and anti-inflammatory effect of Aloysia triphylla (L'Hér.) Britton and Trigonella foenum-græcum L. seeds. S. Afr. J. Bot.

Chin, K.Y. (2016). The spice for joint inflammation: anti-inflammatory role of curcumin in treating osteoarthritis. Drug Des. Devel. Ther. 10: 3029.

Chniguir, A., Zioud, F., Marzaioli, V., El-Benna, J., and Bachoual, R. (2019). 
Syzygium aromaticum aqueous extract inhibits human neutrophils myeloperoxidase and protects mice from LPS-induced lung inflammation. Pharm. Biol. 57(1): 55-63.

Cholet, J., Decombat, C., Vareille-Delarbre, M., Gainche, M., Berry, A., Ogéron, C., Ripoche, I., Delort, L., Vermerie, M., Fraisse, D., and Felgines, C. (2019). Comparison of the anti-inflammatory and immunomodulatory mechanisms of two medicinal herbs: Meadowsweet (Filipendula ulmaria) and harpagophytum (Harpagophytum procumbens) Int. J. Plant Anim. Environ. Sci. 9: 145-163.

Chuang, L.T., Tsai, T.H., Lien, T.J., Huang, W.C., Liu, J.J., Chang, H., Chang, M.L., and Tsai, P.J. (2018). Ethanolic extract of origanum vulgare suppresses propionibacterium acnes-induced inflammatory responses in human monocyte and mouse ear edema models. Molecules. 23(8): 1987.

Çifci, A., Tayman, C., Yakut, H.I.., Halil, H., Cakir, E., Cakir, U., and Aydemir, S. (2018). Ginger (Zingiber officinale) prevents severe damage to the lungs due to hyperoxia and inflammation. Turk. J. Med. Sci. 48(4): 892-900.

Clark, R.A., Nielsen, L.D., Welch, M.P., and McPherson, J.M. (1995). Collagen matrices attenuate the collagen-synthetic response of cultured fibroblasts to TGF-beta. J. Cell Sci. 108(3): 1251-1261.

Cortés-Rojas, D.F., de Souza, C.R.F., and Oliveira, W.P. (2014). Clove (Syzygium aromaticum): a precious spice. Asian Pac. J. Trop. Biomed. 4(2): 90-96.

Coussens, L.M., and Werb, Z. (2002). Inflammation and cancer. Nature 420(6917): 860-867.

da Silveira Vasconcelos, M., Mota, E.F., Gomes-Rochette, N.F., Nunes-Pinheiro, D.C.S., Nabavi, S.M., and de Melo, D.F. (2019). Ginger (Zingiber officinale Roscoe). Nonvitamin and Nonmineral Nutritional Supplements. Academic Press, pp. 235-239.

de Almeida Gonçalves, G., de Sá-Nakanishi, A.B., Comar, J.F., Bracht, L., Dias, M.I., Barros, L., Peralta, R.M., Ferreira, I.C., and Bracht, A. (2018). Water soluble compounds of Rosmarinus officinalis L. improve the oxidative and inflammatory states of rats with adjuvantinduced arthritis. Food Funct. 9(4): 2328-2340.

de Araújo Lopes, A., da Fonseca, F.N., Rocha, T.M., de Freitas, L.B., Araújo, E.V.O., Wong, D.V.T., Lima Júnior, R.C.P., and Leal, L.K.A.M. (2018) Eugenol as a promising molecule for the treatment of dermatitis: antioxidant and anti-inflammatory activities and its nanoformulation. Oxid. Med. Cell Longev. 2018: 8194849.

De Santis, F., Poerio, N., Gismondi, A., Nanni, V., Di Marco, G., Nisini, R. Thaller, M.C., Canini, A., and Fraziano, M. (2019). Hydroalcoholic extract from Origanum vulgare induces a combined anti-mycobacterial and anti-inflammatory response in innate immune cells. PLoS ONE 14(3): e0213150.

Deshmane, S.L., Kremlev, S., Amini, S, and Sawaya, B.E. (2009). Monocyte chemoattractant protein-1 (MCP-1): an overview. J. Interferon Cytokine Res. 29(6): 313-326.

Dewitt, D. Bush Medicine: Folk Cures with Chile Peppers. https://www. fieryfoodscentral.com/((2008))/07/02/bush-medicine-folk-cureswith-chile-peppers/. Accessed 6 Apr. 2021.

Díaz-Laviada, I. (2010). Effect of capsaicin on prostate cancer cells. Future Oncol. 6(10): 1545-1550.

Dibazar, S.P., Fateh, S., and Daneshmandi, S. (2014). Clove (Syzygium aromaticum) ingredients affect lymphocyte subtypes expansion and cytokine profile responses: An in vitro evaluation. J. Food Drug Anal. 22(4): 448-454.

Ding, J., Su, J., Zhang, L., and Ma, J. (2015). Crocetin activates Foxp3 through TIPE2 in asthma-associated Treg cells. Cell Physiol. Biochem. 37(6): 2425-2433.

Ding, Y., Yang, Z., Zhang, W., Xu, Y., Wang, Y., Hu, M., Ma, F., Long, H., Tao, N., and Qin, Z. (2018). Eugenol triggers CD11b+ Gr1+ myeloid-derived suppressor cell apoptosis via endogenous apoptosis pathway. RSC Adv. 8(7): 3833-3838.

Eftekhar, N., Moghimi, A., Roshan, N.M., Saadat, S., and Boskabady, M.H. (2019). Immunomodulatory and anti-inflammatory effects of hydroethanolic extract of Ocimum basilicum leaves and its effect on lung pathological changes in an ovalbumin-induced rat model of asthma. BMC Complement. Altern. Med. 19(1): 1-11.

Ege, B., Yumrutas, O., Ege, M., Pehlivan, M., and Bozgeyik, I. (2020). Pharmacological properties and therapeutic potential of saffron (Crocus sativus L.) in osteosarcoma. J. Pharm. Pharmacol. 72(1): 56-67.

El-Ashram, A., Afifi, A., and Sakr, S.F. (2017). Effect of basil oil (Ocimum basilicum) on nonspecific immune response of Nile-tilapia (Oreochromis niloticus). Egypt. J. Aquat. 7(2): 15-31.

Elbagory, A.M., Hussein, A.A., and Meyer, M. (2019). The In Vitro Immunomodulatory Effects Of Gold Nanoparticles Synthesized From Hypoxis hemerocallidea Aqueous Extract And Hypoxoside On Macrophage And Natural Killer Cells. Int. J. Nanomedicine. 14: 9007

El-Ghazaly, M.A., Fadel, N.A., Abdel-Naby, D.H., Abd El-Rehim, H.A., Zaki, H.F., and Kenawy, S.A. (2020). Potential anti-inflammatory action of resveratrol and piperine in adjuvant-induced arthritis: Effect on pro-inflammatory cytokines and oxidative stress biomarkers. Egypt. Rheumatol. 42(1): 71-77.

Elmowalid, G.A., Abd El-Hamid, M.I., Abd El-Wahab, A.M., Atta, M., Abd ElNaser, G., and Attia, A.M. (2019). Garlic and ginger extracts modulated broiler chicks innate immune responses and enhanced multidrug resistant Escherichia coli 078 clearance. Comp. Immunol. Microbiol. Infect. Dis. 66: 101334

El-Taib, M.I., Fakhry, G., Khalifa, Y., and Haredy, H. (2020). Anti-inflammatory activity in vitro and in vivo of ethanolic extracts of Stevia rebaudiana Bertoni and Trigonella foenum-graecum. Sci. J. Agric. Sci. 2(2): 137-143.

Espirito Santo, A.H., Brito, T.S., Brandão, L.L., Tavares, G.C., Leibowitz, M.P., Prado, S.A., Ferraz, V.P., Hoyos, D.C., Turra, E.M., Teixeira, E.A., and Figueiredo, H.C. (2020). Dietary supplementation of dry oregano leaves increases the innate immunity and resistance of Nile tilapia against Streptococcus agalactiae infection. J. World. Aquac. Soc. 51(2): 418-436.

Farahpour, M.R., Pirkhezr, E., Ashrafian, A., and Sonboli, A. (2020). Accelerated healing by topical administration of Salvia officinalis essential oil on Pseudomonas aeruginosa and Staphylococcus aureus infected wound model. Biomed. Pharmacother. 128: 110120.

Faridi, S., Delirezh, N., and Froushani, S.M.A. (2019). Beneficial effects of hydroalcoholic extract of saffron in alleviating experimental autoimmune diabetes in C57bl/6 mice. Iran J. Allergy Asthma Immunol. 18(1): 38-47.

Fattori, V., Hohmann, M.S., Rossaneis, A.C., Pinho-Ribeiro, F.A., and Verri, W.A. (2016). Capsaicin: Current understanding of its mechanisms and therapy of pain and other pre-clinical and clinical uses. Molecules. 21(7): 844 .

Fernández-Albarral, J.A., Ramírez, A.I., de Hoz, R., López-Villarín, N., Salobrar-García, E., López-Cuenca, I., Licastro, E., Inarejos-García, A.M., Almodóvar, P., Pinazo-Durán, M.D., and Ramírez, J.M. (2019). Neuroprotective and anti-inflammatory effects of a hydrophilic saffron extract in a model of glaucoma. Int. J. Mol. Sci. 20(17): 4110.

Fernández-Lázaro, D., Mielgo-Ayuso, J., Seco Calvo, J., Córdova Martínez, A., Caballero García, A., and Fernandez-Lazaro, C.I. (2020). Modulation of exercise-induced muscle damage, inflammation, and oxidative markers by curcumin supplementation in a physically active population: a systematic review. Nutrients 12(2): 501

Feyzi, R., Boskabady, M.H., Seyed Hosseini Tamijani, S.M., Rafatpanah, H., and Rezaei, S.A. (2016). The effect of safranal on Th1/Th2 cytokine balance. Iran. J. Immunol. 13(4): 263-273.

Fiebich, B.L., Muñoz, E., Rose, T., Weiss, G., and McGregor, G.P. (2012). Molecular targets of the antiinflammatory Harpagophytum procumbens (devil's claw): inhibition of TNF $\alpha$ and COX-2 gene expression by preventing activation of AP-1. Phytother. Res. 26(6): 806-811.

Franciosini, M.P., Casagrande-Proietti, P., Forte, C., Beghelli, D., Acuti, G., Zanichelli, D., Dal Bosco, A., Castellini, C., and Trabalza-Marinucci, M. (2016). Effects of oregano (Origanum vulgare L.) and rosemary (Rosmarinus officinalis L.) aqueous extracts on broiler performance, immune function and intestinal microbial population. J. Appl. Anim. Res. 44(1): 474-479.

Freedman, P. (2008). Out of the East: spices and the medieval imagination. Yale University Press.

Galal, A.A.A.E., El-Araby, I.E., Hassanin, O., and El-Said Omar, A. (2016). Positive impact of oregano essential oil on growth performance, humoral immune responses and chicken interferon alpha signalling pathway in broilers. Adv. Anim. Vet. Sci. 4(4): 57-65

Garavand, F., Rahaee, S., Vahedikia, N., and Jafari, S.M. (2019). Different techniques for extraction and micro/nanoencapsulation of saffron 
bioactive ingredients. Trends Food Sci. Technol. 89: 26-44.

Georgescu, S.R., Sârbu, M.I., Matei, C., Ilie, M.A., Caruntu, C., Constantin, C., and Neagu, M. (2017). Capsaicin: friend or foe in skin cancer and other related malignancies? Nutrients 9(12): 1365.

Georgiev, Y.N., Ognyanov, M.H., Kiyohara, H., Batsalova, T.G., Dzhambazov, B.M., Ciz, M., Denev, P.N., Yamada, H., Paulsen, B.S., Vasicek, O., and Lojek, A. (2017a). Acidic polysaccharide complexes from purslane, silver linden and lavender stimulate Peyer's patch immune cells through innate and adaptive mechanisms. Int. J. Biol. Macromol. 105: 730-740.

Georgiev, Y.N., Paulsen, B.S., Kiyohara, H., Ciz, M., Ognyanov, M.H., Vasicek, O., Rise, F., Denev:, N., Yamada, H., Lojek, A., and Kussovski, V. (2017b). The common lavender (Lavandula angustifolia Mill.) pectic polysaccharides modulate phagocytic leukocytes and intestinal Peyer's patch cells. Carbohydr. Polym. 174: 948-959.

Gezici, S. (2018). Promising anticancer activity of lavender (Lavandula angustifolia Mill.) essential oil through induction of both apoptosis and necrosis. Ann. Phytomed. 7(2): 38-45.

Ghorbani, A., and Esmaeilizadeh, M. (2017). Pharmacological properties of Salvia officinalis and its components. J. Tradit. Complement. Med. 7(4): 433-440.

Ghosh, S., Banerjee, S., and Sil, P.C. (2015). The beneficial role of curcumin on inflammation, diabetes and neurodegenerative disease: $A$ recent update. Food Chem. Toxicol. 83: 111-124.

Gorgani, L., Mohammadi, M., Najafpour, G.D., and Nikzad, M. (2017). Piperine-the bioactive compound of black pepper: from isolation to medicinal formulations. Compr. Rev. Food Sci. Food Saf. 16(1): 124-140.

Grammatikopoulou, M.G., Gkiouras, K., Theodoridis, X., Asteriou, E., Forbes, A., and Bogdanos, D.P. (2018). Oral adjuvant curcumin therapy for attaining clinical remission in ulcerative colitis: a systematic review and meta-analysis of randomized controlled trials. Nutrients 10(11): 1737.

Grüter, T., Blusch, A., Motte, J., Sgodzai, M., Bachir, H., Klimas, R., Ambrosius, B., Gold, R., Ellrichmann, G., and Pitarokoili, K. (2020). Immunomodulatory and anti-oxidative effect of the direct TRPV1 receptor agonist capsaicin on Schwann cells. J. Neuroinflammation 17: 1-16.

Guardiola, F.A., Bahi, A., Jiménez-Monreal, A.M., Martínez-Tomé, M., Murcia, M.A., and Esteban, M.A. (2018). Dietary administration effects of fenugreek seeds on skin mucosal antioxidant and immunity status of gilthead seabream (Sparus aurata L.). Fish Shellfish Immunol. 75: 357-364.

Güez, C.M., Souza, R.O.D., Fischer, P., Leão, M.F.D.M., Duarte, J.A., Boligon, A.A., Athayde, M.L., Zuravski, L., Oliveira, L.F.S.D., and Machado, M.M. (2017). Evaluation of basil extract (Ocimum basilicum L.) on oxidative, anti-genotoxic and anti-inflammatory effects in human leukocytes cell cultures exposed to challenging agents. Braz. J. Pharm. Sci. 53(1): .

Güllü, K., Acar, Ü., Kesbiç, O.S., Yılmaz, S., Ağdamar, S., Ergün, S., and Türker, A. (2016). Beneficial effects of Oral Allspice, Pimenta dioica powder supplementation on the hemato-immunological and serum biochemical responses of Oreochromis mossambicus. Aquac. Res. 47(9): 2697-2704.

Guo, Y., Liu, N., Liu, K., and Gao, M. (2019). Capsaicin inhibits the migration and invasion via the AMPK/NF-KB signaling pathway in esophagus sequamous cell carcinoma by decreasing matrix metalloproteinase- 9 expression. Biosci. Rep. 39(8): BSR20190819.

Gupte, P.A., Giramkar, S.A., Harke, S.M., Kulkarni, S.K., Deshmukh, A.P., Hingorani, L.L., Mahajan, M.P., and Bhalerao, S.S. (2019). Evaluation of the efficacy and safety of Capsule Longvida ${ }^{\circledR}$ Optimized Curcumin (solid lipid curcumin particles) in knee osteoarthritis: a pilot clinical study. J. Inflamm. Res. 12: 145.

Gyurkovska, V., Alipieva, K., Maciuk, A., Dimitrova, P., Ivanovska, N., Haas, C., Bley, T., and Georgiev, M. (2011). Anti-inflammatory activity of Devil's claw in vitro systems and their active constituents. Food Chem. 125(1): 171-178.

Hamidi, Z., Aryaeian, N., Abolghasemi, J., Shirani, F., Hadidi, M., Fallah, S., and Moradi, N. (2020). The effect of saffron supplement on clinical outcomes and metabolic profiles in patients with active rheumatoid arthritis: A randomized, double-blind, placebo-controlled clinical trial. Phytother. Res. 34(7): 1650-1658.
Hamza, A.A., Heeba, G.H., Hamza, S., Abdalla, A., and Amin, A. (2021). Standardized extract of ginger ameliorates liver cancer by reducing proliferation and inducing apoptosis through inhibition oxidative stress/inflammation pathway. Biomed. Pharmacother. 134: 111102

Han, X., and Parker, T.L. (2017). Anti-inflammatory activity of clove (Eugenia caryophyllata) essential oil in human dermal fibroblasts. Pharm. Biol. 55(1): 1619-1622.

Han, Y., Li, B., Yin, T.T., Xu, C., Ombati, R., Luo, L., Xia, Y., Xu, L., Zheng, J., Zhang, Y., and Yang, F. (2018). Molecular mechanism of the tree shrew's insensitivity to spiciness. PLoS Biol. 16(7): e2004921.

Harada, K. (1990). Attraction activities of spices for oriental weatherfish and yellowtail. Bull. Jap. Soc. Sci. Fish. 56: 2029-2033.

Haseeb, A., Ansari, M.Y., and Haqqi, T.M. (2017). Harpagoside suppresses IL-6 expression in primary human osteoarthritis chondrocytes. J. Orthop. Res. 35(2): 311-320.

Haught, W.H., Mansour, M., Rothlein, R., Kishimoto, T.K., Mainolfi, E.A., Hendricks, J.B., Hendricks, C., and Mehta, J.L. (1996). Alterations in circulating intercellular adhesion molecule-1 and L-selectin: further evidence for chronic inflammation in ischemic heart disease. Am. Heart J. 132(1): 1-8.

He, Y., Yue, Y., Zheng, X., Zhang, K., Chen, S., and Du, Z. (2015). Curcumin, inflammation, and chronic diseases: how are they linked? Molecules. 20(5): 9183-9213.

He, Z., Lei, L., Kwek, E., Zhao, Y., Liu, J., Hao, W., Zhu, H., Liang, N., Ma, K.Y., Ho, H.M., and He, W.S. (2019). Ginger attenuates trimethylamine$\mathrm{N}$-oxide (TMAO)-exacerbated disturbance in cholesterol metabolism and vascular inflammation. J. Funct. Foods 52: 25-33.

Heitmann, K., Nordeng, H., and Holst, L. (2013). Safety of ginger use in pregnancy: results from a large population-based cohort study. Eur. J. Clin. Pharmacol. 69(2): 269-277.

Herrmann, J., and Thöle, M. (2010). Dry extracts of pelargonium sidoides and pelargonium reniforme. U.S. Patent Application 12/450,823.

Hendricks, R., and Pool, E.J. (2010). The in vitro effects of rooibos and black tea on immune pathways. J. Immunoassay Immunochem. 31(2): 169-180.

Honarvar, N.M., Zarezadeh, M., Khorshidi, M., Arzati, M.M., Yekaninejad, M.S., Abdollahi, M., Effatpanah, M., Hashemi, R., and Saedisomeolia, A. (2019). The effect of an oral ginger supplementation on NF-KB concentration in peripheral blood mononuclear cells and anthropomorphic data of patients with type 2 diabetes: A randomized doubleblind, placebo-controlled clinical trial. Complement. Ther. Med. 42: 7-11.

Hoosen, M. (2019). The Effects of Aspalathus linearis (Rooibos Tea) on Nitric Oxide (NO) and Cytokine Activity. Int. J. Human Health Sci. 3(3): 150-157.

Hoosen, M., and Pool, E.J. (2019). An In Vitro Study to elucidate the Effects of Artemisia afra, Aspalathus linearis (rooibos) and SeptilinTM on Immune Pathways. Int. J. Human Health Sci. 3(3): 134-145.

Hosseini, A., Razavi, B.M., and Hosseinzadeh, H. (2018). Saffron (Crocus sativus) petal as a new pharmacological target: a review. Iran. J. Med. 21(11): 1091

Hosseini, S.A., Zilaee, M., and Shoushtari, M.H. (2018). An evaluation of the effect of saffron supplementation on the antibody titer to heatshock protein (HSP) 70, hsCRP and spirometry test in patients with mild and moderate persistent allergic asthma: A triple-blind, randomized placebo-controlled trial. Respir. Med. 145: 28-34.

Hosseinzadeh, H., and Nassiri-Asl, M. (2013). Avicenna's (Ibn Sina) the canon of medicine and saffron (Crocus sativus): a review. Phytother. Res. 27(4): 475-483.

Hostanska, K., Melzer, J., Rostock, M., Suter, A., and Saller, R. (2014). Alteration of anti-inflammatory activity of $\mathrm{H}$ arpagophytum procumbens (devil's claw) extract after external metabolic activation with S 9 mix. J. Pharm. Pharmacol. 66(11): 1606-1614.

Hsiang, C.Y., Cheng, H.M., Lo, H.Y., Li, C.C., Chou, P.C., Lee, Y.C., and Ho, T.Y. (2015). Ginger and zingerone ameliorate lipopolysaccharide-induced acute systemic inflammation in mice, assessed by nuclear factor- $\mathrm{KB}$ bioluminescent imaging. J. Agric. Food Chem. 63(26): 6051-6058.

Huang, M.T., Ho, C.T., Wang, Z.Y., Ferraro, T., Lou, Y.R., Stauber, K., Ma, W., Georgiadis, C., Laskin, J.D., and Conney, A.H. (1994). Inhibition of skin tumorigenesis by rosemary and its constituents carnosol and ursolic acid. Cancer Res. 54(3): 701-708. 
Hui, Q., Ammeter, E., Liu, S., Yang, R., Lu, P., Lahaye, L., and Yang, C. (2020). Eugenol attenuates inflammatory response and enhances barrier function during lipopolysaccharide-induced inflammation in the porcine intestinal epithelial cells. J. Anim. Sci. 98(8): skaa245.

Humbal, B.R., Sadariya, K.A., Prajapati, J.A., Bhavsar, S.K., and Thaker, A.M. (2019). Evaluation of in-vivo anti-inflammatory activity of Syzygium aromaticum oil in male wistar rats. J. Pharm. Innov. 8(7): 540-543.

Hwang, M.K., Bode, A.M., Byun, S., Song, N.R., Lee, H.J., Lee, K.W., and Dong, Z. (2010). Cocarcinogenic effect of capsaicin involves activation of EGFR signaling but not TRPV1. Cancer Res. 70(17): 6859-6869.

Inaba, K., Murata, K., Naruto, S., and Matsuda, H. (2010). Inhibitory effects of devil's claw (secondary root of Harpagophytum procumbens) extract and harpagoside on cytokine production in mouse macrophages. J. Nat. Med. 64(2): 219-222.

Izgelov, D., Cherniakov, I., Aldouby Bier, G., Domb, A.J., and Hoffman, A. (2018). The effect of piperine pro-nano lipospheres on direct intestinal phase II metabolism: the raloxifene paradigm of enhanced oral bioavailability. Mol. Pharm. 15(4): 1548-1555

Jahejo, A.R., Rajput, N., Wen-xia, T., Naeem, M., Kalhoro, D.H., Kaka, A., Niu, S., and Jia, F.J. (2019). Immunomodulatory and growth promoting effects of basil (Ocimum basilicum) and ascorbic acid in heat stressed broiler chickens. Pak. J. Zool. 51(3): 801.

Jazayeri-Tehrani, S.A., Rezayat, S.M., Mansouri, S., Qorbani, M., Alavian, S.M., Daneshi-Maskooni, M., and Hosseinzadeh-Attar, M.J. (2019) Nano-curcumin improves glucose indices, lipids, inflammation, and Nesfatin in overweight and obese patients with non-alcoholic fatty liver disease (NAFLD): a double-blind randomized placebo-controlled clinical trial. Nutr. Metab. 16(1): 1-13.

Jekabsone, A., Sile, I., Cochis, A., Makrecka-Kuka, M., Laucaityte, G., Makarova, E., Rimondini, L., Bernotiene, R., Raudone, L., Vedlugaite, E. and Baniene, R. (2019). Investigation of antibacterial and antiinflammatory activities of proanthocyanidins from pelargonium sidoides DC root extract. Nutrients 11(11): 2829.

Jiang, X., Williams, K.M., Liauw, W.S., Ammit, A.J., Roufogalis, B.D., Duke, C.C., Day, R.O., and McLachlan, A.J. (2005). Effect of ginkgo and ginger on the pharmacokinetics and pharmacodynamics of warfarin in healthy subjects. Br. J. Clin. Pharmacol. 59(4): 425-432.

Jin, T., Wu, H., Wang, Y., and Peng, H. (2016). Capsaicin induces immunogenic cell death in human osteosarcoma cells. Exp. Ther. Med. 12(2): 765-770.

Jose, S.P., Ratheesh, M., Asha, S., Krishnakumar, I., Sandya, S., and Girish, K.B. (2017). Hepato-protective effect of clove bud polyphenols (Syzygium aromaticum L.)(Clovino ${ }^{\circledR}$ ) by modulating alcohol induced oxidative stress and inflammation. J. Food Res. 7(1): .

Kahkhaie, K.R., Mirhosseini, A., Aliabadi, A., Mohammadi, A., Mousavi, M.J., Haftcheshmeh, S.M., Sathyapalan, T., and Sahebkar, A. (2019). Curcumin: a modulator of inflammatory signaling pathways in the immune system. Inflammopharmacology 27(5): 885-900.

Kamin, W., Maydannik, V.G., Malek, F.A., and Kieser, M. (2010). Efficacy and tolerability of EPs 7630 in patients (aged 6-18 years old) with acute bronchitis: A randomized, double-blind, placebo-controlled clinical dose-finding study. Acta Paediatr. 99(4): 537-543.

Kanani, H.G., Nobahar, Z., Kakoolaki, S., and Jafarian, H. (2014). Effect of ginger-and garlic-supplemented diet on growth performance, some hematological parameters and immune responses in juvenile Huso huso. Fish Physiol. Biochem. 40(2): 481-490.

Kang, C., Wang, B., Kaliannan, K., Wang, X., Lang, H., Hui, S., Huang, L., Zhang, Y., Zhou, M., Chen, M., and Mi, M. (2017). Gut microbiota mediates the protective effects of dietary capsaicin against chronic low-grade inflammation and associated obesity induced by high-fat diet. MBio. 8(3): e00470-17.

Karadağ, A.E., Demirci, B., Çaşkurlu, A., Demirci, F., Okur, M.E., Orak, D., Sipahi, H., and Başer, K.H.C. (2019). In vitro antibacterial, antioxidant, anti-inflammatory and analgesic evaluation of Rosmarinus officinalis L. flower extract fractions. S. Afr. J. Bot. 125: 214-220.

Katerere, D.R., and Eloff, J.N. (2008). Anti-bacterial and anti-oxidant activity of Hypoxis hemerocallidea (Hypoxidaceae): can leaves be substituted for corms as a conservation strategy? S. Afr. J. Bot. 74(4): 613-616.

Kathirvel, P., and Ravi, S. (2012). Chemical composition of the essentia oil from basil (Ocimum basilicum Linn.) and its in vitro cytotoxicity against HeLa and HEp-2 human cancer cell lines and NIH 3 T3 mouse embryonic fibroblasts. Nat. Prod. Res. 26(12): 1112-1118.

Kaur, M., Singh, V., and Shri, R. (2018). Evaluation of mast cell stabilizing activity of Camellia sinensis and Ocimum basilicum and correlation with their antioxidant property. Pharma Innov. J. 7: 69-73.

Kayser, O., and Kolodziej, H. (1997). Antibacterial activity of extracts and constituents of Pelargonium sidoides and Pelargonium reniforme. Planta Med. 63(06): 508-510.

Kayser, O., Kolodziej, H., and Kiderlen, A.F. (2001). Immunomodulatory principles of Pelargonium sidoides. Phytother. Res. 15(2): 122-126.

Khedher, M.R.B., Hammami, M., Arch, J.R., Hislop, D.C., Eze, D., Wargent, E.T., Kępczyńska, M.A., and Zaibi, M.S. (2018). Preventive effects of Salvia officinalis leaf extract on insulin resistance and inflammation in a model of high fat diet-induced obesity in mice that responds to rosiglitazone. Peer J. 6: e4166.

Khodaie, L., and Sadeghpoor, O. (2015). Ginger from ancient times to the new outlook. Jundishapur J. Nat. Pharm. Prod. 10(1): e18402.

Khorasany, A.R., and Hosseinzadeh, H. (2016). Therapeutic effects of saffron (Crocus sativus L.) in digestive disorders: a review. Iran. J. Med. 19(5): 455.

Khound, R., Shen, J., Song, Y., Santra, D., and Su, Q. (2018). Phytoceuticals in fenugreek ameliorate VLDL overproduction and insulin resistance via the insig signaling pathway. Mol. Nutr. Food Res. 62(5): 1700541.

Kim, M.S., and Kim, J.Y. (2018). Ginger attenuates inflammation in a mouse model of dextransulfate sodium-induced colitis. Food Sci. Biotechnol. 27(5): 1493-1501

Kim, S., Lee, M.S., Jung, S., Son, H.Y., Park, S., Kang, B., Kim, S.Y., Kim, I.H., Kim, C.T., and Kim, Y. (2018). Ginger extract ameliorates obesity and inflammation via regulating microRNA-21/132 expression and AMPK activation in white adipose tissue. Nutrients 10(11): 1567.

Kim, S.S., Oh, O.J., Min, H.Y., Park, E.J., Kim, Y., Park, H.J., Han, Y.N., and Lee, S.K. (2003). Eugenol suppresses cyclooxygenase-2 expression in lipopolysaccharide-stimulated mouse macrophage RAW264.7 cells. Life Sci. 73(3): 337-348.

Kolodziej, H., Kayser, O., Radtke, O.A., Kiderlen, A.F., and Koch, E. (2003). Pharmacological profile of extracts of Pelargonium sidoides and their constituents. Phytomedicine 10: 18-24.

Kondamudi, N., Turner, M.W., and McDougal, O.M. (2016). Harpagoside Content in Devil's Claw Extracts. Nat. Prod. Commun. 11(9): 12151216.

Kontogianni, V.G., Tomic, G., Nikolic, I., Nerantzaki, A.A., Sayyad, N., StosicGrujicic, S., Stojanovic, I., Gerothanassis, I.P., and Tzakos, A.G. (2013). Phytochemical profile of Rosmarinus officinalis and Salvia officinalis extracts and correlation to their antioxidant and anti-proliferative activity. Food Chem. 136(1): 120-129.

Kraft, K.H., Brown, C.H., Nabhan, G.P., Luedeling, E., Ruiz, J.D.J.L, d'Eeckenbrugge, G.C., Hijmans, R.J., and Gepts, P. (2014). Multiple lines of evidence for the origin of domesticated chili pepper, Capsicum annuum, in Mexico. Proc. Natl. Acad. Sci. 111(17): 6165-6170.

Krondl, M. (2008). The Taste of Conquest: The Rise and Fall of the Three Great Cities of Spice. Ballantine Books.

Kumar, A., Siddiqi, N.J., Alrashood, S.T., Khan, H.A., Dubey, A., and Sharma, B. (2021). Protective effect of eugenol on hepatic inflammation and oxidative stress induced by cadmium in male rats. Biomed. Pharmacother. 139: 111588

Kunnumakkara, A.B., Harsha, C., Banik, K., Vikkurthi, R., Sailo, B.L., Bordoloi, D., Gupta, S.C., and Aggarwal, B.B. (2019). Is curcumin bioavailability a problem in humans: Lessons from clinical trials. Expert Opin. Drug Metab. Toxicol. 15(9): 705-733.

Laudadio, V., Nasiri-Dehbaneh, M., Bilal, R.M., Qotbi, A., Javandel, F., Ebrahimi, A., Seidavi, A., Slozhenkina, M., Gorlov, I., Dunne:, G., and Tufarelli, V. (2020). Effects of different levels of dietary black cumin (Nigella sativa L.) and fenugreek (Trigonella foenum-graecum L.) and their combination on productive traits, selected blood constituents, microbiota and immunity of broilers. Anim. Biotechnol. 1-14.

Lawal, A.O., and Elekofehinti, O.O. (2019). Real time-quantitative polymerase chain reaction analysis of the anti-inflammatory effect of aqueous rooibos (Aspalathus linearis) extract on diesel exhaust particlesinduced hepatic inflammation. Ife J. Sci. 21(1): 175-186.

Lee, J.G., Kim, D.W., Shin, Y., and Kim, Y.J. (2020). Comparative study of the bioactive compounds, flavours and minerals present in black pepper 
before and after removing the outer skin. LWT 125: 109356

Lewu, F.B., Grierson, D.S., and Afolayan, A.J. (2006). The leaves of Pelargonium sidoides may substitute for its roots in the treatment of bacterial infections. Biol. Conserv. 128(4): 582-584.

Libby, P., Ridker, P.M., and Maseri, A. (2002). Inflammation and atherosclerosis. Circulation. 105(9): 1135-1143.

Lin, R.J., Wu, I.J., Hong, J.Y., Liu, B.H., Liang, R.Y., Yuan, T.M., and Chuang, S.M. (2018). Capsaicin-induced TRIB3 upregulation promotes apoptosis in cancer cells. Cancer Manag. Res. 10: 4237.

Ling, W.H., and Jones, P.J.H. (1995). Dietary phytosterols: a review of metabolism, benefits and side effects. Life Sci. 57(3): 195-206.

Liu, M.Y. (2019). Dietary Fenugreek Attenuates Dextran Sodium SulfateInduced Ulcerative Colitis: Role of 2 Inflammation. Jpn. J. Gastroenterol. Hepatol. 1(1): 1-9.

Liu, N.C., Hsieh, P.F., Hsieh, M.K., Zeng, Z.M., Cheng, H.L., Liao, J.W., and Chueh, P.J. (2012). Capsaicin-mediated tNOX (ENOX2) up-regulation enhances Cell Prolif and migration in vitro and in vivo. J. Agric. Food Chem. 60(10): 2758-2765.

Liu, T., Zhang, L., Joo, D., and Sun, S.C. (2017). NF-KB signaling in inflammation. Signal Transduct. Target. Ther. 2(1): 1-9.

Locatelli, M., Ferrante, C., Carradori, S., Secci, D., Leporini, L., Chiavaroli, A., Leone, S., Recinella, L., Orlando, G., Martinotti, S., and Brunetti, L. (2017). Optimization of aqueous extraction and biological activity of Harpagophytum procumbens root on ex vivo rat colon inflammatory model. Phytother. Res. 31(6): 937-944.

Ma, L., Mu, Y., Zhang, Z., and Sun, Q. (2018). Eugenol promotes functional recovery and alleviates inflammation, oxidative stress, and neural apoptosis in a rat model of spinal cord injury. Restor. Neurol. Neurosci. 36(5): 659-668.

Mabrok, M.A.E., and Wahdan, A. (2018). The immune modulatory effect of oregano (Origanum vulgare L.) essential oil on Tilapia zillii following intraperitoneal infection with Vibrio anguillarum. Aquacult. Int. 26(4): 1147-1160.

Mahassni, S.H., and Bukhari, O.A. (2019). Beneficial effects of an aqueous ginger extract on the immune system cells and antibodies, hematology, and thyroid hormones in male smokers and non-smokers. J. Nutr. Intermed. Metab. 15: 10-17.

Mahrous, H.S., El-Far, A.H., Sadek, K.M., and Abdel-Latif, M.A. (2017). Effects of Different Levels of Clove Bud (Syzygium Aromaticum) Dietary Supplementation on Immunity, Antioxidant Status, and Performance in Broiler Chickens. Alex. J. Vet. Sci. 54(2): .

Mammen, R.R., Natinga Mulakal, J., Mohanan, R., Maliakel, B., and Illathu Madhavamenon, K. (2018). Clove bud polyphenols alleviate alterations in inflammation and oxidative stress markers associated with binge drinking: A randomized double-blinded placebo-controlled crossover study. J. Med. Food 21(11): 1188-1196.

Manasa, D., Srinivas, P., and Sowbhagya, H.B. (2013). Enzyme-assisted extraction of bioactive compounds from ginger (Zingiber officinale Roscoe). Food Chem. 139(1-4): 509-514.

Mao, K., Lei, D., Zhang, H., and You, C. (2017). Anticonvulsant effect of piperine ameliorates memory impairment, inflammation and oxidative stress in a rat model of pilocarpine-induced epilepsy. Exp. Ther. Med. 13(2): 695-700.

Mao, Q.Q., Xu, X.Y., Cao, S.Y., Gan, R.Y., Corke, H., and Li, H.B. (2019). Bioactive compounds and bioactivities of ginger (Zingiber officinale Roscoe). Foods 8(6): 185.

Marmouzi, I., Alami, R., El Jemli, M., Kharbach, M., Mamouch, F., Attar, A., Faridi, B., Cherrah, Y., and Faouzi, M.E.A. (2019). Modulatory effect of Syzygium aromaticum and Pelargonium graveolens on oxidative and sodium nitroprusside stress and inflammation. Orient. Pharm. Exp. Med. 19(2): 201-210.

Mativandlela, S.P.N., Lall, N., and Meyer, J.J.M. (2006). Antibacterial, antifungal and antitubercular activity of (the roots of) Pelargonium reniforme (CURT) and Pelargonium sidoides (DC)(Geraniaceae) root extracts. S. Afr. J. Bot. 72(2): 232-237.

Matyanga, C.M., Morse, G.D., Gundidza, M., and Nhachi, C.F. (2020). African potato (Hypoxis hemerocallidea): a systematic review of its chemistry, pharmacology and ethno medicinal properties. BMC Complement. Med. Ther. 20(1): 1-12.

McGee, H. (2007). On food and cooking: the science and lore of the kitchen. Simon and Schuster.
McKay, D.L., and Blumberg, J.B. (2007). A review of the bioactivity of South African herbal teas: rooibos (Aspalathus linearis) and honeybush (Cyclopia intermedia). Phytother. Res. 21(1): 1-16.

Mehri, S., Razavi, B.M., and Hosseinzadeh, H. (2020). Safety and toxicity of saffron. Saffron. Woodhead Publishing, pp. 517-530.

Melnyk, J.P., Wang, S., and Marcone, M.F. (2010). Chemical and biological properties of the world's most expensive spice: Saffron. Food Res. Int. 43(8): 1981-1989.

Memarzia, A., Khazdair, M.R., Behrouz, S., Gholamnezhad, Z., Jafarnezhad, M., Saadat, S., and Boskabady, M.H. (2021). Experimental and clinical reports on anti-inflammatory, antioxidant, and immunomodulatory effects of Curcuma longa and curcumin, an updated and comprehensive review. BioFactors 47(3): 311-350.

Menon, V., Elgharib, M., El-awady, R., and Saleh, E. (2021). Ginger: From serving table to salient therapy. Food Biosci. 41: 100934

Michaelis, M., Doerr, H.W., and Cinatl Jr, J. (2011). Investigation of the influence of EPs ${ }^{\circledR} 7630$, a herbal drug preparation from Pelargonium sidoides, on replication of a broad panel of respiratory viruses. Phytomedicine 18(5): 384-386.

Mills, E., Foster, B.C., van Heeswijk, R., Phillips, E., Wilson, K., Leonard, B., Kosuge, K., and Kanfer, I. (2005). Impact of African herbal medicines on antiretroviral metabolism. AIDS 19(1): 95-97.

Min, B.G., Park, S.M., Choi, Y.W., Ku, S.K., Cho, I.J., Kim, Y.W., Byun, S.H., Park, C.A., Park, S.J., Na, M., and Kim, S.C. (2020). Effects of Pelargonium sidoides and Coptis Rhizoma 2: 1 Mixed Formula (PS + CR) on Ovalbumin-Induced Asthma in Mice. Evid. Based Complement Alternat. Med. 2020: 9135637.

Mirzaei, H., Shakeri, A., Rashidi, B., Jalili, A., Banikazemi, Z., and Sahebkar, A. (2017). Phytosomal curcumin: A review of pharmacokinetic, experimental and clinical studies. Biomed. Pharmacother. 85: 102-112.

Mobasseri, M., Ostadrahimi, A., Tajaddini, A., Asghari, S., Barati, M., Akbarzadeh, M., Nikpayam, O., Houshyar, J., Roshanravan, N., and Alamdari, N.M. (2020). Effects of saffron supplementation on glycemia and inflammation in patients with type 2 diabetes mellitus: A randomized double-blind, placebo-controlled clinical trial study. Diabetes Metab. Syndr. 14(4): 527-534.

Moens, U., Kostenko, S., and Sveinbjørnsson, B. (2013). The role of mitogen-activated protein kinase-activated protein kinases (MAPKAPKs) in inflammation. Genes 4(2): 101-133.

Moghaddasi, M.S., and Kashani, H.H. (2012). Ginger (Zingiber officinale): A review. J. Med. Plant Res. 6(26): 4255-4258.

Mohammadi, G., Rashidian, G., Hoseinifar, S.H., Naserabad, S.S., and Van Doan, H. (2020). Ginger (Zingiber officinale) extract affects growth performance, body composition, haematology, serum and mucosal immune parameters in common carp (Cyprinus carpio). Fish Shellfish Immunol. 99: 267-273.

Mohammed, Z.I., Kadhim, K.S., and Taher, M.G. (2017). Effects of feeding different levels of ocimum basilicum seeds on per-formance and immune traits of broiler. J. Kerbala Agri. Sci. 4(5): 249-258.

Mollazadeh, H., Cicero, A.F., Blesso, C.N., Pirro, M., Majeed, M., and Sahebkar, A. (2019). Immune modulation by curcumin: The role of interleukin-10. Crit. Rev. Food Sci. Nutr. 59(1): 89-101.

Momtazi-Borojeni, A.A., Haftcheshmeh, S.M., Esmaeili, S.A., Johnston, T.P., Abdollahi, E., and Sahebkar, A. (2018). Curcumin: A natural modulator of immune cells in systemic lupus erythematosus. Autoimmun. Rev. 17(2): 125-135.

Montoya-Ballesteros, L.C., González-León, A., García-Alvarado, M.A., and Rodríguez-Jimenes, G.C. (2014). Bioactive compounds during drying of chili peppers. Dry. Technol. 32(12): 1486-1499.

Mori, H.M., Kawanami, H., Kawahata, H., and Aoki, M. (2016). Wound healing potential of lavender oil by acceleration of granulation and wound contraction through induction of TGF- $\beta$ in a rat model. BMC Complement. Altern. Med. 16(1): 1-11.

Motte, J., Ambrosius, B., Grüter, T., Bachir, H., Sgodzai, M., Pedreiturria, X., Pitarokoili, K., and Gold, R. (2018). Capsaicin-enriched diet ameliorates autoimmune neuritis in rats. J. Neuroinflammation 15(1): 1-13.

Moustafa, E.M., Dawood, M.A., Assar, D.H., Omar, A.A., Elbialy, Z.I., Farrag, F.A., Shukry, M., and Zayed, M.M. (2020). Modulatory effects of fenugreek seeds powder on the histopathology, oxidative status, and immune related gene expression in Nile tilapia (Oreochromis niloticus) infected with Aeromonas hydrophila. Aquaculture 515: 734589. 
Mozaffari-Khosravi, H., Naderi, Z., Dehghan, A., Nadjarzadeh, A., and Fallah Huseini, H. (2016). Effect of ginger supplementation on proinflammatory cytokines in older patients with osteoarthritis: outcomes of a randomized controlled clinical trial. J. Nutr. Gerontol. Geriatr. 35(3): 209-218.

Mueller, M., Hobiger, S., and Jungbauer, A. (2010). Anti-inflammatory activity of extracts from fruits, herbs and spices. Food Chem. 122(4): 987-996.

Mühl, H. (2013). Pro-inflammatory signaling by IL-10 and IL-22: bad habit stirred up by interferons? Front. Immunol. 4: 18.

Murdoch, J.R., and Lloyd, C.M. (2010). Chronic inflammation and asthma. Mutat. Res-Fund. Mol. M. 690(1-2): 24-39.

Nagamma, T., Konuri, A., Bhat, K.M., Maheshwari, R., Udupa, P., and Nayak, Y. (2021). Modulation of inflammatory markers by petroleum ether fraction of Trigonella foenum-graecum L. seed extract in ovariectomized rats. J. Food Biochem. 45(4): e13690.

Naiel, M.A., Ismael, N.E., Negm, S.S., Ayyat, M.S., and Al-Sagheer, A.A (2020). Rosemary leaf powder-supplemented diet enhances performance, antioxidant properties, immune status, and resistance against bacterial diseases in Nile Tilapia (Oreochromis niloticus). Aquaculture 526: 735370.

Nathan, C. (2006). Neutrophils and immunity: challenges and opportunities. Nat. Rev. Immunol. 6(3): 173-182.

Nawale, S., Priya, K.P., Pranusha, P., and Raju, M.G. (2018). Data of antihyperlipidaemic activity for methanolic extract of Tagetes patula Linn. flower head along with piperine, as bioavailability enhancer. Data Brief 21: 587.

Nayak, Y., and Abhilash, D. (2008). Protection of cyclophosphamide induced myelosuppression by alcoholic extract of Pimenta dioica leaves in mice. Pharmacologyonline 3: 719-723.

Nayak, Y., Abhilash, D., Vijaynarayana, K., and Fernandes, J. (2008). Antioxidant and hepatoprotective activity of Pimenta dioica leaves extract. Cell Tissue Res. 8(3): 1571.

Nel, E., Binns, T., and Bek, D. (2007). 'Alternative foods' and communitybased development: Rooibos tea production in South Africa's West Coast Mountains. Appl. Geogr. 27(2): 112-129.

Nelson, B.H. (2004). IL-2, regulatory T cells, and tolerance. J. Immunol. 172(7): 3983-3988.

Neveu, V., Perez-Jiménez, J., Vos, F., Crespy, V., du Chaffaut, L., Mennen, L., Knox, C., Eisner, R., Cruz, J., Wishart, D., and Scalbert, A. (2010). Phenol-Explorer: an online comprehensive database on polyphenol contents in foods. Database 2010: bap024.

Ng, Q.X., Soh, A.Y.S., Loke, W., Venkatanarayanan, N., Lim, D.Y., and Yeo, W.S. (2018). A meta-analysis of the clinical use of curcumin for irritable bowel syndrome (IBS). J. Clin. Med. 7(10): 298

Nikkhah Bodagh, M., Maleki, I., and Hekmatdoost, A. (2019). Ginger in gastrointestinal disorders: A systematic review of clinical trials. Food Sci. Nutr. 7(1): 96-108.

Nöldner, M., and Schötz, K. (2007). Inhibition of lipopolysaccharid-induced sickness behavior by a dry extract from the roots of Pelargonium sidoides (EPs ${ }^{\circledR} 7630$ ) in mice. Phytomedicine 14: 27-31.

Norman, D.M., Mason, J.R., and Clark, L. (1992). Capsaicin effects on consumption of food by cedar waxwings and house finches. Wilson Bull. 104(3): 549-551.

Omari, S.A., Adams, M.J., Kunde, D.A., and Geraghty, D.P. (2016). Capsaicin-induced death of human haematological malignant cell lines is independent of TRPV1 activation. Pharmacol. 98(1-2): 79-86.

Oniga, I., Pușcaș, C., Silaghi-Dumitrescu, R., Olah, N.K., Sevastre, B., Marica, R., Marcus, I., Sevastre-Berghian, A.C., Benedec, D., Pop, C.E., and Hanganu, D. (2018). Origanum vulgare ssp. vulgare: Chemical composition and biological studies. Molecules. 23(8): 2077

Osei Akoto, C., Acheampong, A., Boakye, Y.D., Naazo, A.A., and Adomah D.H. (2020). Anti-inflammatory, antioxidant, and anthelmintic activities of Ocimum basilicum (Sweet Basil) fruits. J. Chem. 2020: 2153534.

Park, S.M., Min, B.G., Jung, J.Y., Jegal, K.H., Lee, C.W., Kim, K.Y., Kim, Y.W. Choi, Y.W., Cho, I.J., Ku, S.K., and Kim, S.C. (2018). Combination of Pelargonium sidoides and Coptis chinensis root inhibits nuclear factor kappa B-mediated inflammatory response in vitro and in vivo. BMC Complement. Altern. Med. 18(1): 20.

Pei, H., Xue, L., Tang, M., Tang, H., Kuang, S., Wang, L., Ma, X., Cai, X., Li,
Y., Zhao, M., and Peng, A. (2020). Alkaloids from black pepper (piper nigrum L.) exhibit anti-inflammatory activity in murine macrophages by inhibiting activation of NF-kB pathway. J. Agric. Food Chem. 68(8): 2406-2417.

Peng, C.H., Su, J.D., Chyau, C.C., Sung, T.Y., Ho, S.S., Peng, C.C., and Peng, R.Y. (2007). Supercritical fluid extracts of rosemary leaves exhibit potent anti-inflammation and anti-tumor effects. Biosci. Biotechnol. Biochem. 71(9): 2223-2232.

Perić, A., Vezmar Kovačević, S., Barać, A., Gaćeša, D., Perić, A.V., and Vojvodić, D. (2020). Effects of Pelargonium sidoides extract on chemokine levels in nasal secretions of patients with non-purulent acute rhinosinusitis. J. Drug Assess. 9(1): 145-150.

Persson, I.A.L., Josefsson, M., Persson, K., and Andersson, R.G. (2006). Tea flavanols inhibit angiotensin-converting enzyme activity and increase nitric oxide production in human endothelial cells. J. Pharm. Pharmacol. 58(8): 1139-1144.

Petruzzello, M. Fenugreek. Encyclopædia Britannica. www.britannica. com/plant/fenugreek. Accessed: 13 Jun. 2021.

Phippen, W.B., and Simon, J.E. (1998). Anthocyanins in basil (Ocimum basilicum L.). J. Agric. Food Chem. 46(5): 1734-1738.

Piao, C.H., Bui, T.T., Song, C.H., Shin, H.S., Shon, D.H., and Chai, O.H. (2017). Trigonella foenum-graecum alleviates airway inflammation of allergic asthma in ovalbumin-induced mouse model. Biochem. Biophys. Res. Commun. 482(4): 1284-1288.

Pournamdari, M., Mandegary, A., Sharififar, F., Zarei, G., Zareshahi, R., Asadi, A., and Mehdipour, M. (2018). Anti-inflammatory subfractions separated from acidified chloroform fraction of fenugreek seeds (Trigonella foenum-graecum L.). J. Diet. Suppl. 15(1): 98-107.

Poursamimi, J., Shariati-Sarabi, Z., Tavakkol-Afshari, J., Mohajeri, S.A., Ghoryani, M., and Mohammadi, M. (2020). Immunoregulatory Effects of Krocina ${ }^{\mathrm{TM}}$, a Herbal Medicine Made of Crocin, on Osteoarthritis Patients: A Successful Clinical Trial in Iran. Iran J. Allergy Asthma Immunol. 19(3): 253-263.

Prasad, S., and Aggarwal, B.B. (2011). Turmeric, the golden spice. Herbal Medicine: Biomolecular and Clinical Aspects. 2nd edition.

Prashar, A., Locke, I.C., and Evans, C.S. (2004). Cytotoxicity of lavender oil and its major components to human skin cells. Cell Prolif. 37(3): 221-229.

Purushothaman, B., PrasannaSrinivasan, R., Suganthi, P., Ranganathan, B., Gimbun, J., and Shanmugam, K. (2018). A comprehensive review on Ocimum basilicum. J. Nat. Remedies. 18(3): 71-85.

Qorbanpour, M., Fahim, T., Javandel, F., Nosrati, M., Paz, E., Seidavi, A., Ragni, M., Laudadio, V., and Tufarelli, V. (2018). Effect of dietary ginger (Zingiber officinale Roscoe) and multi-strain probiotic on growth and carcass traits, blood biochemistry, immune responses and intestinal microflora in broiler chickens. Animals (Basel) 8(7): 117.

Radulescu, C., Stihi, C., Ilie, M., Lazurcă, D., Gruia, R., Olaru, O.T., Bute, O.C., Dulama, I.D., Stirbescu, R.M., Teodorescu, S., and Florescu, M. (2017). Characterization of Phenolics in Lavandula angustifolia. Anal. Lett. 50(17): 2839-2850.

Radulović, N.S., Blagojević, P.D., and Miltojević, A.B. (2013). $\alpha$-Linalool-a marker compound of forged/synthetic sweet basil (Ocimum basilicum L.) essential oils. J. Sci. Food Agric. 93(13): 3292-3303.

Rahbardar, M.G., Amin, B., Mehri, S., Mirnajafi-Zadeh, S.J., and Hosseinzadeh, H. (2017). Anti-inflammatory effects of ethanolic extract of Rosmarinus officinalis $\mathrm{L}$. and rosmarinic acid in a rat model of neuropathic pain. Biomed. Pharmacother. 86: 441-449.

Rahimi, A., Razmkhah, K., Mehrnia, M., Mohamadnia, A., Sahebjamee, H., Salehi, S., Asl, E.A., Tahmasebi, H., Shandiz, S.A.S., Davouodbeglou, F., and Ghasemi, S. (2016). Molecular docking and binding study of harpagoside and harpagide as novel anti-inflammatory and antianalgesic compound from Harpagophytum procumbens based on their interactions with COX-2 enzyme. Asian Pac. J. Trop. Dis. 6(3): 227-231.

Rai, V.K., Sinha, P., Yadav, K.S., Shukla, A., Saxena, A., Bawankule, D.U., Tandon, S., Khan, F., Chanotiya, C.S., and Yadav, N.P. (2020). Anti-psoriatic effect of Lavandula angustifolia essential oil and its major components linalool and linalyl acetate. J. Ethnopharmacol. 261: 113127.

Raja, M.R.C., Kar, A., Srinivasan, S., Chellappan, D., Debnath, J., and Mahapatra, S.K. (2020). Oral administration of eugenol oleate cures experimental visceral leishmaniasis through cytokines abundance. 
Cytokine 145: 155301.

Rashidian, G., Boldaji, J.T., Rainis, S., Prokić, M.D., and Faggio, C. (2021). Oregano (Origanum vulgare) Extract Enhances Zebrafish (Danio rerio) Growth Performance, Serum and Mucus Innate Immune Responses and Resistance against Aeromonas hydrophila Challenge. Animals (Basel) 11(2): 299.

Rasouli, B., Movahhedkhah, S., Seidavi, A., Haq, Q.M.I., Kadim, I., Laudadio, V., Mazzei, D., and Tufarelli, V. (2020). Effect of sage (Salvia officinalis L.) aqueous leaf extract on performance, blood constituents, immunity response and ileal microflora of broiler chickens. Agrofor. Syst. 94(4): 1179-1187.

Ren, C., and Liang, Z. (2018). Piperine alleviates lipopolysaccharideinduced inflammatory injury by down-regulating microRNA-127 in murine chondrogenic ATDC5 cells. Biomed. Pharmacother. 103: 947-954.

Reynoso-Moreno, I., Najar-Guerrero, I., Escareño, N., Flores-Soto, M.E., Gertsch, J., and Viveros-Paredes, J.M. (2017). An endocannabinoid uptake inhibitor from black pepper exerts pronounced anti-inflammatory effects in mice. J. Agric. Food Chem. 65(43): 9435-9442.

Ribeiro-Santos, R., Carvalho-Costa, D., Cavaleiro, C., Costa, H.S., Albuquerque, T.G., Castilho, M.C., Ramos, F., Melo, N.R., and Sanches-Silva, A. (2015). A novel insight on an ancient aromatic plant: The rosemary (Rosmarinus officinalis L.). Trends Food Sci. Technol. 45(2): 355-368.

Rivera-Gomis, J., Peres Rubio, C., Conesa, C.M., Salaverri, J.O., Cerón, J.J., Tortosa, D.E., and Pablo, M.J.C. (2020). Effects of Dietary Supplementation of Garlic and Oregano Essential Oil on Biomarkers of Oxidative Status, Stress and Inflammation in Postweaning Piglets. Animals (Basel) 10(11): 2093.

Rodrigues, L.B., Martins, A.O.B.P.B., Cesário, F.R.A.S., e Castro, F.F., de Albuquerque, T.R., Fernandes, M.N.M., da Silva, B.A.F., Júnior, L.J.Q., da Costa, J.G.M., Coutinho, H.D.M., and Barbosa, R. (2016). Anti-inflammatory and antiedematogenic activity of the Ocimum basilicum essential oil and its main compound estragole: in vivo mouse models. Chem. Biol. Interact. 257: 14-25.

Rodrigues, L.B., Martins, A.O.B.P.B., Ribeiro-Filho, J., Cesário, F.R.A.S., e Castro, F.F., de Albuquerque, T.R., Fernandes, M.N.M., da Silva, B.A.F., Júnior, L.J.Q., de Sousa Araújo, A.A., and dos Passos Menezes, P. (2017). Anti-inflammatory activity of the essential oil obtained from Ocimum basilicum complexed with $\beta$-cyclodextrin $(\beta-C D)$ in mice. Food Chem. Toxicol. 109: 836-846.

Rostami, H., Seidavi, A., Dadashbeiki, M., Asadpour, Y., Simões, J., Shah, A.A., Laudadio, V., Losacco, C., Perillo, A., and Tufarelli, V. (2018). Supplementing dietary rosemary (Rosmarinus officinalis L.) powder and vitamin $E$ in broiler chickens: evaluation of humoral immune response, lymphoid organs, and blood proteins. Environ. Sci. Pollut. Res. 25(9): 8836-8842.

Rozin, P., and Schiller, D. (1980). The nature and acquisition of a preference for chili pepper by humans. Motiv. Emot. 4(1): 77-101.

Russo, C., Edwards, K.D., Margetts, G., Kleidonas, S., Zaibi, N.S., Clapham, J.C., and Zaibi, M.S. (2021). Effects of Salvia officinalis L. and Chamaemelum nobile (L.) extracts on inflammatory responses in two models of human cells: Primary subcutaneous adipocytes and neuroblastoma cell line (SK-N-SH). J. Ethnopharmacol. 268: 113614.

Saadati, S., Sadeghi, A., Mansour, A., Yari, Z., Poustchi, H., Hedayati, M., Hatami, B., and Hekmatdoost, A. (2019). Curcumin and inflammation in non-alcoholic fatty liver disease: a randomized, placebo controlled clinical trial. BMC Gastroenterol. 19(1): 1-6.

Saeed, T.A., Osman, O.A., Amin, A.E., and El Badwi, S.M. (2017). Safety assessment and potential anti-inflammatory effect of ethanolic extract of Syzygium aromaticum in albino rats. Adv. Biosci. Biotechnol. 8(11): 411-420.

Saeidnia, S., Manayi, A., Gohari, A.R., and Abdollahi, M. (2014). The story of beta-sitosterol-areview. Eur. J. Med. Plants. 4(5): 590-609.

Sahne, F., Mohammadi, M., Najafpour, G.D., and Moghadamnia, A.A. (2017). Enzyme-assisted ionic liquid extraction of bioactive compound from turmeric (Curcuma longa L.): Isolation, purification and analysis of curcumin. Ind. Crops Prod. 95: 686-694.

Sahu, A., and Lambris, J.D. (2001). Structure and biology of complement protein $\mathrm{C} 3$, a connecting link between innate and acquired immunity. Immunol. Rev. 180(1): 35-48.

Salehi, B., Stojanović-Radić, Z., Matejić, J., Sharifi-Rad, M., Kumar, N.V.A.,
Martins, N., and Sharifi-Rad, J. (2019). The therapeutic potential of curcumin: A review of clinical trials. Eur. J. Med. Chem. 163: 527-545.

Samani, S.K., Ghorbani, M.R., Fayazi, J., and Salari, S. (2020). The effect of different levels of Fenugreek (Trigonella foenum-graecum L.) powder and extract on performance, egg quality, blood parameters and immune responses of laying hens in second production cycle. Vet. Res. Forum. 11(1): 53-57.

Sandeep, T., Roopakala, M.S., Silvia, C.R.W.D., Chandrashekara, S., and Rao, M. (2010). Evaluationof serum immunoglobulin E levels in bronchial asthma. Lung India 27(3): 138 .

Saraf-Bank, S., Ahmadi, A., Paknahad, Z., Maracy, M., and Nourian, M. (2019). Effects of curcumin supplementation on markers of inflammation and oxidative stress among healthy overweight and obese girl adolescents: A randomized placebo-controlled clinical trial. Phytother. Res. 33(8): 2015-2022.

Saraphanchotiwitthaya, A., Khorana, N., and Sripalakit, P. (2019). Comparative anti-inflammatory activity of eugenol and eugenyl acetate on the murine immune response in vitro. Songklanakarin J. Sci. Technol. 41(3):

Sarip, M.S.M., Morad, N.A., Ali, N.A.M., Yusof, Y.A.M., and Yunus, M.A.C. (2014). The kinetics of extraction of the medicinal ginger bioactive compounds using hot compressed water. Sep. Purif. Technol. 124: 141-147.

Schnitzler, P., Schneider, S., Stintzing, F.C., Carle, R., and Reichling, J. (2008). Efficacy of an aqueous Pelargonium sidoides extract against herpesvirus. Phytomedicine 15(12): 1108-1116.

Schopohl, P., Grüneberg, P., and Melzig, M.F. (2016). The influence of harpagoside and harpagide on TNF $\alpha$-secretion and cell adhesion molecule mRNA-expression in IFN $\gamma /$ LPS-stimulated THP-1 cells. Fitoterapia 110: 157-165.

Seckin, C., Alpun Kalayci, G., Turan, N., Yilmaz, A., Cizmecigil, U.Y., Aydin, O., Richt, J.A., and Yilmaz, H. (2018). Immunomodulatory effects of Echinacea and Pelargonium on the innate and adoptive immunity in calves. Food Agr. Immunol. 29(1): 744-761.

Shafabakhsh, R., Pourhanifeh, M.H., Mirzaei, H.R., Sahebkar, A., Asemi, Z., and Mirzaei, H. (2019). Targeting regulatory T cells by curcumin: A potential for cancer immunotherapy. Pharmacol. Res. 147: 104353.

Shahidi, F., and Ambigaipalan, P. (2015). Phenolics and polyphenolics in foods, beverages and spices: Antioxidant activity and health effectsA review. J. Funct. Foods. 18: 820-897.

Shang, K., Amna, T. Amina, M., Al-Musayeib, N.M., Al-Deyab, S.S., and Hwang, I. (2017). Influence of capsaicin on inflammatory cytokines induced by lipopolysaccharide in myoblast cells under in vitro environment. Pharmacogn. Rev. 13(Suppl 1): S26-S32.

Sharifi-Rigi, A., Heidarian, E., and Amini, S.A. (2019). Protective and antiinflammatory effects of hydroalcoholic leaf extract of Origanum vulgare on oxidative stress, TNF- $\alpha$ gene expression and liver histological changes in paraquat-induced hepatotoxicity in rats. Arch. Physiol. Biochem. 125(1): 56-63.

Sharifi-Rigi, A., Heidarian, E., and Amini, S.A. (2019). Protective and antiinflammatory effects of hydroalcoholic leaf extract of Origanum vulgare on oxidative stress, TNF- $\alpha$ gene expression and liver histological changes in paraquat-induced hepatotoxicity in rats. Arch. Physiol. Biochem. 125(1): 56-63.

Shelef, L.A. (1984). Antimicrobial effects of spices. J. Food Saf. 6(1): 29-44.

Sherman, P.W., and Flaxman, S.M. (2001). Protecting ourselves from food: Spices and morning sickness may shield us from toxins and microorganisms in the diet. Am. Sci. 89(2): 142-151.

Shimizu, K., Funamoto, M., Sunagawa, Y., Shimizu, S., Katanasaka, Y., Miyazaki, Y., Wada, H., Hasegawa, K., and Morimoto, T. (2019). Antiinflammatory action of curcumin and its use in the treatment of lifestyle-related diseases. Eur. Cardiol. 14(2): 117.

Shokrollahi, B., Amini, F., Fakour, S., and Andi, M.A. (2015). Effect of rosemary (Rosmarinus officinalis) extract on weight, hematology and cell-mediated immune response of newborn goat kids. J. Agr. Rural. Dev. Trop. 116(1): 91-97.

Shourbela, R.M., El-Hawarry, W.N., Elfadadny, M.R., and Dawood, M.A. (2021). Oregano essential oil enhanced the growth performance, immunity, and antioxidative status of Nile tilapia (Oreochromis niloticus) reared under intensive systems. Aquaculture 542: 736868

Simon, J.E. (1998). "Basil". Center for New Crops \& Plant Products, De- 
partment of Horticulture, Purdue University, West Lafayette, IN. Retrieved 2 April 2021.

Sindhu, G., Shyni, G.L., Pushpan, C.K., Nambisan, B., and Helen, A. (2018). Evaluation of anti-arthritic potential of Trigonella foenum graecum L.(Fenugreek) mucilage against rheumatoid arthritis. Prostaglandins Other Lipid Mediat. 138: 48-53.

Singh, P., Bajpai, V., Gond, V., Kumar, A., Tadigoppula, N., and Kumar, B. (2020). Determination of bioactive compounds of fenugreek (Trigonella foenum-graecum) seeds using LC-MS techniques. Legume Genomics. Humana, New York, NY, pp. 377-393.

Singletary, K. (2010). Oregano: Overview of the literature on health benefits. Nutr. Today. 45(3): 129-138.

Smit, S.E., Manirafasha, C., Marais, E., Johnson, R., and Huisamen, B. (2020). Cardioprotective Function of Green Rooibos (Aspalathus linearis) Extract Supplementation in Ex Vivo Ischemic Prediabetic Rat Hearts. Planta Med.

Souri, F., Rakhshan, K., Erfani, S., Azizi, Y., Maleki, S.N., and Aboutaleb, N. (2019). Natural lavender oil (Lavandula angustifolia) exerts cardioprotective effects against myocardial infarction by targeting inflammation and oxidative stress. Inflammopharmacology 27(4): 799-807.

Soutar, D.A., Doucette, C.D., Liwski, R.S., and Hoskin, D.W. (2017). Piperine, a pungent alkaloid from black pepper, inhibits B lymphocyte activation and effector functions. Phytother. Res. 31(3): 466-474.

Sukumaran, V., Park, S.C., and Giri, S.S. (2016). Role of dietary ginger Zingiber officinale in improving growth performances and immune functions of Labeo rohita fingerlings. Fish Shellfish Immunol. 57: 362-370.

Sumner, J. (2000). The natural history of medicinal plants. Timber press.

Tabrizi, R., Vakili, S., Akbari, M., Mirhosseini, N., Lankarani, K.B., Rahimi, M., Mobini, M., Jafarnejad, S., Vahedpoor, Z., and Asemi, Z. (2019). The effects of curcumin-containing supplements on biomarkers of inflammation and oxidative stress: A systematic review and meta-analysis of randomized controlled trials. Phytother. Res. 33(2): 253-262.

Talpur, A.D., Ikhwanuddin, M., and Bolong, A.M.A. (2013). Nutritional effects of ginger (Zingiber officinale Roscoe) on immune response of Asian sea bass, Lates calcarifer (Bloch) and disease resistance against Vibrio harveyi. Aquaculture 400: 46-52.

Tapsell, L.C., Hemphill, I., Cobiac, L., Sullivan, D.R., Fenech, M., Patch, C.S., Roodenrys, S., Keogh, J.B., Clifton:, M., Williams:, G., and Fazio, V.A (2006). Health benefits of herbs and spices: the past, the present, the future. Med. J. Aust. 185(S4): S1-S24.

Tavakoly, R., Maracy, M.R., Karimifar, M., and Entezari, M.H. (2018). Does fenugreek (Trigonella foenum-graecum) seed improve inflammation, and oxidative stress in patients with type 2 diabetes mellitus? A parallel group randomized clinical trial. Eur. J. Integr. Med. 18: 13-17.

Timmer, A., Guenther, J., Motschall, E., Ruecker, G., Antes, G., and Kern, W.V. (2013). Pelargonium sidoides extract for treating acute respiratory tract infections. Cochrane Database of Syst. Rev. (10): CD006323.

Tiwari, A., Mahadik, K.R., and Gabhe, S.Y. (2020). Piperine: A comprehensive review of methods of isolation, purification, and biological properties. Med. Drug Discov. 7: 100027.

Tsai, T.H., Huang, W.C., Lien, T.J., Huang, Y.H., Chang, H., Yu, C.H., and Tsai, P.J. (2017). Clove extract and eugenol suppress inflammatory responses elicited by Propionibacterium acnes in vitro and in vivo. Food Agr. Immunol. 28(5): 916-931.

Vasanthkumar, T., Hanumanthappa, M., and Prabhakar, B.T. (2018). Protective effect of dietary curcumin and capsaicin on LPS-induced inflammation in mice. Pharmacogn. J. 10(4): 725-729.

Viljoen, E., Visser, J., Koen, N., and Musekiwa, A. (2014). A systematic review and meta-analysis of the effect and safety of ginger in the treatment of pregnancy-associated nausea and vomiting. Nutr. J. 13(1): $1-14$.

Viswanadha, V.P., Dhivya, V., Beeraka, N.M., Huang, C.Y., Gavryushova, L.V. Minyaeva, N.N., Chubarev, V.N., Mikhaleva, L.M., Tarasov, V.V., and Aliev, G. (2020). The protective effect of piperine against isoproterenol-induced inflammation in experimental models of myocardial toxicity. Eur. J. of Pharmacol. 885: 173524.

Viveros-Paredes, J.M., Puebla-Pérez, A.M., Gutiérrez-Coronado, O., Macías-Lamas, A.M., Hernández-Flores, G., Ortiz-Lazareno, P.C., Bravo-Cuéllar, A., and Villaseñor-García, M.M. (2021). Capsaicin attenuates immunosuppression induced by chronic stress in BALB/C mice. Int. Immunopharmacol. 93: 107341
Wael, S., Watuguly, T.W., Arini, I., Smit, A., Matdoan, N., Prihati, D.R., Sari, A.B., Wahyudi, D., Nuringtyas, T.R., Wijayanti, N., and Astuti, P. (2018). Potential of Syzygium aromaticum (Clove) Leaf Extract on Immune Proliferation Response in Balb/c Mice Infected with Salmonella typhimurium. Clin. Med. Case Rep. 7(12): 613.

Wang-Sheng, C., Jie, A., Jian-Jun, L., Lan, H., Zeng-Bao, X., and Chang-Qing, L. (2017). Piperine attenuates lipopolysaccharide (LPS)-induced inflammatory responses in BV2 microglia. Int. Immunopharmacol. 42: 44-48.

Wani, S.A., and Kumar, P. (2018). Fenugreek: A review on its nutraceutical properties and utilization in various food products. J. Saudi Soc. Agric. Sci. 17(2): 97-106.

Weissmann, G., Korchak, H., Ludewig, R., Edelson, H., Haines, K., Levin, R.I., Herman, R., Rider, L., Kimmel, S, and Abramson, S. (1987). Nonsteroidal anti-inflammatory drugs: how do they work? Eur. J. Rheumatol. Inflamm. 8(1): 6-17.

Wiegertjes, G.F., Stet, R.M., Parmentier, H.K., and van Muiswinkel, W.B. (1996). Immunogenetics of disease resistance in fish: a comparative approach. Dev. Comp. Immunol. 20(6): 365-381.

Williams, C.A. (2013). Specialized dietary supplements. In: Geor, R.J., Coenen, M., and Harris, P. (Ed.). Equine applied and clinical nutrition E-book: Health, welfare and performance. Elsevier Health Sciences, pp. 351-366.

Wing, K., and Sakaguchi, S. (2010). Regulatory T cells exert checks and balances on self tolerance and autoimmunity. Nat. Immunol. 11(1): $7-13$

Witte, K., Koch, E., Volk, H.D., Wolk, K., and Sabat, R. (2015). The pelargonium sidoides extract EPs 7630 drives the innate immune defense by activating selected MAP Kinase pathways in human Monocytes. PLoS ONE 10(9): e0138075.

Woronuk, G., Demissie, Z., Rheault, M., and Mahmoud, S. (2011). Biosynthesis and therapeutic properties of Lavandula essential oil constituents. Planta Med. 77(01): 7-15.

Xiong, Y., Wang, J., Yu, H., Zhang, X., and Miao, C. (2015). Anti-asthma potential of crocin and its effect on MAPK signaling pathway in a murine model of allergic airway disease. Immunopharmacol. Immunotoxicol. 37(3): 236-243.

Xu, G.L., Li, G., Ma, H.P., Zhong, H., Liu, F., and Ao, G.Z. (2009). Preventive effect of crocin in inflamed animals and in LPS-challenged RAW 264.7 cells. J. Agric. Food Chem. 57(18): 8325-8330.

Xu, S., Zhang, L., Cheng, X., Yu, H., Bao, J., and Lu, R. (2018). Capsaicin inhibits the metastasis of human papillary thyroid carcinoma BCPAP cells through the modulation of the TRPV1 channel. Food Funct. 9(1): 344-354.

Xu, Y., Gu, Q., and Qu, C. (2017). Capsaicin pretreatment reversed pulmonary arterial hypertension by alleviating inflammation via p38MAPK pathway. Exp. Lung Res. 43(1): 8-18.

Yang, M., Akbar, U., and Mohan, C. (2019). Curcumin in autoimmune and rheumatic diseases. Nutrients 11(5): 1004.

Yılmaz, S., and Ergün, S. (2014). Dietary supplementation with allspice Pimenta dioica reduces the occurrence of streptococcal disease during first feeding of Mozambique Tilapia fry. J. Aquat. Anim. Health 26(3): 144-148

Yousef, M., Crozier, R.W., Hicks, N.J., Watson, C.J., Boyd, T., Tsiani, E., and MacNeil, A.J. (2020). Attenuation of allergen-mediated mast cell activation by rosemary extract (Rosmarinus officinalis L.). J. Leukoc. Biol. 107(5): 843-857.

Yousefi, M., Hoseini, S.M., Vatnikov, Y.A., Kulikov, E.V., and Drukovsky, S.G. (2019). Rosemary leaf powder improved growth performance, immune and antioxidant parameters, and crowding stress responses in common carp (Cyprinus carpio) fingerlings. Aquaculture 505: $473-480$

Yousefi, M., Shabunin, S.V., Vatnikov, Y.A., Kulikov, E.V., Adineh, H., Hamidi, M.K., and Hoseini, S.M. (2020). Effects of lavender (Lavandula angustifolia) extract inclusion in diet on growth performance, innate immunity, immune-related gene expression, and stress response of common carp, Cyprinus carpio. Aquaculture 515: 734588.

Yu, H., Liang, H., Ren, M., Ji, K., Yang, Q., Ge, X., Xi, B., and Pan, L. (2019). Effects of dietary fenugreek seed extracts on growth performance, plasma biochemical parameters, lipid metabolism, Nrf2 antioxidant capacity and immune response of juvenile blunt snout bream (Mega- 
lobrama amblycephala). Fish Shellfish Immunol. 94: 211-219.

Yuan, Y., Zhou, J., Hu, R., Zou, L., Ji, L., and Jiang, G. (2021). Piperine protects against pancreatic $\beta$-cell dysfunction by alleviating macrophage inflammation in obese mice. Life Sci. 274: 119312.

Zafar, F., Jahan, N., and Bhatti, H.N. (2019). Increased oral bioavailability of piperine from an optimized Piper nigrum nanosuspension. Planta Med. 85(03): 249-257.

Zhang, H., Bai, Y., Gao, M., Zhang, J., Dong, G., Yan, F., Ma, Q., Fu, X., Zhang, Q., Li, C., and Shi, H. (2019). Hepatoprotective effect of capsaicin against concanavalin A-induced hepatic injury via inhibiting oxidative stress and inflammation. Am. J. Transl. Res. 11(5): 3029

Zhang, L., and Lokeshwar, B.L. (2012). Medicinal properties of the Jamaican pepper plant Pimenta dioica and Allspice. Curr. Drug Targets. 13(14): 1900-1906

Zhang, L., Shamaladevi, N., Jayaprakasha, G.K., Patil, B.S., and Lokeshwar, B.L. (2015). Polyphenol-rich extract of Pimenta dioica berries (Allspice) kills breast cancer cells by autophagy and delays growth of triple negative breast cancer in athymic mice. Oncotarget 6(18): 16379.
Zhang, R., Wang, X.W., Liu, L.L., Cao, Y.C., and Zhu, H. (2020). Dietary oregano essential oil improved the immune response, activity of digestive enzymes, and intestinal microbiota of the koi carp, Cyprinus carpio. Aquaculture 518: 734781.

Zhao-Hui, J.I.N., Wen, Q.I.U., Hui, L.I.U., Jiang, X.H., and Ling, W.A.N.G. (2018). Enhancement of oral bioavailability and immune response of Ginsenoside Rh2 by co-administration with piperine. Chin. J. Nat. Med. 16(2): 143-149.

Zhou, C., Qin, Y., Chen, R., Gao, F., Zhang, J., and Lu, F. (2020). Fenugreek attenuates obesity-induced inflammation and improves insulin resistance through downregulation of iRhom2/TACE. Life Sci. 258: 118222.

Zimudzi, C. (2014). African Potato (Hypoxis Spp): Diversity and comparison of the phytochemical profiles and cytotoxicity evaluation of four Zimbabwean Species. J. Appl. Pharm. Sci. 4(4): 079-083.

Zulfiqar, F., Khan, S.I., Ali, Z., Wang, Y.H., Ross, S.A., Viljoen, A.M., and Khan, I.A. (2020). Norlignan glucosides from Hypoxis hemerocallidea and their potential in vitro anti-inflammatory activity via inhibition of iNOS and NF-KB. Phytochemistry 172: 112273. 